\title{
General approach to characterizing reservoir fluids for EoS models using a large PVT database
}

Varzandeh, Farhad; Stenby, Erling Halfdan; Yan, Wei

Published in:

Fluid Phase Equilibria

Link to article, DOI:

10.1016/j.fluid.2016.10.018

Publication date:

2017

Document Version

Peer reviewed version

Link back to DTU Orbit

Citation (APA):

Varzandeh, F., Stenby, E. H., \& Yan, W. (2017). General approach to characterizing reservoir fluids for EoS models using a large PVT database. Fluid Phase Equilibria, 433, 97-111.

https://doi.org/10.1016/j.fluid.2016.10.018

\section{General rights}

Copyright and moral rights for the publications made accessible in the public portal are retained by the authors and/or other copyright owners and it is a condition of accessing publications that users recognise and abide by the legal requirements associated with these rights.

- Users may download and print one copy of any publication from the public portal for the purpose of private study or research.

- You may not further distribute the material or use it for any profit-making activity or commercial gain

- You may freely distribute the URL identifying the publication in the public portal 


\section{General Approach to Characterizing Reservoir Fluids for EoS Models Using a Large PVT Database}

Farhad Varzandeh, Center for Energy Resources Engineering (CERE), Department of Chemistry, Technical University of Denmark, DK-2800 Lyngby, Denmark, email: farvar@kemi.dtu.dk, Tel: +45 45252034

Erling H. Stenby, Center for Energy Resources Engineering (CERE), Department of Chemistry, Technical University of Denmark, DK-2800 Lyngby, Denmark, email: ehst@kemi.dtu.dk, Tel: +45 4525 2012, Fax: +45 45883136

Wei Yan, corresponding author, Center for Energy Resources Engineering (CERE), Department of Chemistry, Technical University of Denmark, DK-2800 Lyngby, Denmark, email: weya @kemi.dtu.dk, Tel: +45 4525 2914, Fax: +45 45882258 


\section{Abstract}

Fluid characterization is needed when applying any EoS model to reservoir fluids. It is important especially for non-cubic models such as PC-SAFT where fluid characterization is less mature. Furthermore, there is a great interest to apply non-cubic models to high pressure high temperature reservoir fluids as they are believed to give better description of density and compressibility over a wide temperature and pressure range. We proposed a general approach to characterizing reservoir fluids and applied it to PC-SAFT. The approach consists in first, developing the correlations based on the DIPPR database, and then adjusting the correlations based on a large PVT database. The adjustment was made to minimize the deviation in key PVT properties like saturation pressures, densities at reservoir temperature and stock tank oil densities, while keeping the n-alkane limit of the correlations unchanged. The general approach can also be applied to other EoS models for improving their fluid characterization and we showed this for SRK and PR. In addition, we developed a PNA based characterization method for PC-SAFT based on the same general principles. We made a comprehensive comparison in PVT calculation involving 17 EoS-characterization combinations and 260 reservoir fluids. The new characterization methods generally improved the PVT calculation results.

\section{Keywords}

Equation of state; Reservoir fluids; $\mathrm{C}_{7+}$ characterization; PC-SAFT; PVT database. 


\section{Introduction}

Accurate description of PVT, including phase equilibrium and physical properties, is always needed for development of natural gas and petroleum reservoir fluids. It is especially a crucial problem for reservoirs at high pressure and high temperature (HPHT) conditions, where the importance for density and compressibility in production forecast is more pronounced. Since traditional cubic EoS models have intrinsic problems to provide satisfactory density and compressibility description at high pressures, it is attractive to use non-cubic EoS models such as PC-SAFT, Perturbed-Chain Statistical Association Fluid Theory [1] and Soave-BWR, i.e., Soave's modification of Benedict-Webb-Rubin EoS [2], which are better in accurate density description over a wide temperature and pressure range. PC-SAFT has received more attention due to its rigorous theoretical basis. It has shown promising performance in comparison to cubic EoSs for calculation of complex phase behavior, high pressure density, and second-order derivative properties, such as compressibility and speed of sound [3]-[7].

To apply any cubic or non-cubic EoS model to PVT calculation of a reservoir fluid, we need to represent the reservoir fluid with an appropriate number of pseudo-components and assign appropriate model parameters to these components. Reservoir fluid characterization for cubic EoSs like SRK [8] and PR [9] is relatively mature. For example, the method of Pedersen et al. [10], [11] and that of Whitson et al. [12], [13] are amongst the widely used characterization methods in the upstream oil industry. The model parameters needed for SRK and PR, including $T_{c}, P_{c}$, and $\omega$, can be generated by these methods. For non-cubic models like PC-SAFT, their respective model parameters should be generated for the pseudo components in the $\mathrm{C}_{7+}$ fractions but characterization for non-cubics is less mature.

Reservoir fluid characterization for PC-SAFT has been investigated mainly in connection with the recent research on asphaltene precipitation modeling with PC-SAFT [5], [14][22]. It is surely important that a specific EoS, such as PC-SAFT, can model phase behavior as complex as asphaltene precipitation with a proper characterization method. 
However, the main objective of a characterization method for any EoS should be a reasonable modeling of basic PVT properties. Once the basic PVT properties are satisfactorily described, specific adjustments of the characterization method can be introduced to model particular phase equilibrium phenomena like asphaltene precipitation. Among several recent PC-SAFT characterization methods for basic PVT modeling [23]-[27], some follow Pedersen's or Whitson's method and only use a different set of correlations [23]-[25], [27], whereas the others use a completely different procedure in addition to a new set of correlations [26]. The correlations developed for PC-SAFT model parameters are usually expressed as a function of molecular weight $M W$ and/or boiling point $T_{b}$ and specific gravity $S G$ for each SCN (Single Carbon Number) fraction [24]-[27], and some are developed for the PNA content in each fraction [5], [23], [28]. Leekumjorn and Krejbjerg [29] commented that reliable and generally applicable petroleum fluid characterization procedures are still to be developed for the PC-SAFT EoS.

In our previous study [24], a reservoir fluid characterization method for PC-SAFT was proposed by combining Pedersen's method with a new set of correlations for the PCSAFT model parameters $m, m \varepsilon / k$ and $m \sigma^{3}$. The correlations were developed based on the properties of 29 normal alkanes and 318 other hydrocarbons from the DIPPR database [30]. In this study, we further improved the characterization method by adjusting the correlations with a large PVT database. We have further improved the correlations and more importantly, we would like to establish a general approach to characterizing reservoir fluids for any EoS. The approach consists in developing correlations of model parameters first with a database for well-defined components and then adjusting the correlations with a large PVT database. Apart from applying the approach to PC-SAFT, we have also shown that the approach can be applied to classical cubic models like SRK and PR. In addition, we discussed how to develop a PNA based characterization for PCSAFT and also utilize a large PVT database to further improve the characterization. Development of all these new characterization methods is presented in Section 3. Section 4 presents a comprehensive comparison between PC-SAFT, SRK and PR with the new characterization methods and these models with existing characterization methods, i.e., 
traditional characterization methods for SRK and PR and some recent characterization methods [24], [25], [27] for PC-SAFT. In addition, Soave-BWR was used in the comparison.

\section{Equations of state}

Our study involves two cubic EoSs (SRK and PR) and two non-cubic ones (PC-SAFT and Soave-BWR). The two non-cubic models are briefly described below. PC-SAFT is used here to show how characterization methods can be developed for non-cubic models while Soave-BWR is only used for the purpose of comparison.

\subsection{PC-SAFT EOS}

The PC-SAFT EoS was proposed by Gross and Sadowski [3] to model asymmetric and highly non-ideal systems and it can be expressed in terms of the reduced Helmholtz energy $\tilde{a}$ :

$$
\tilde{a} \equiv \frac{\dot{A}}{N k T}=\tilde{a}^{i d}+\tilde{a}^{h c}+\tilde{a}^{d i s p}+\tilde{a}^{a s s o c}
$$

where $\tilde{a}^{i d}$ is the ideal gas contribution, $\tilde{a}^{h c}$ is the contribution of the hard-sphere chain

reference system, $\tilde{a}^{\text {disp }}$ is the dispersion contribution arising from the square well attractive potential and $\tilde{a}^{a s s o c}$ is the association contribution based on Wertheim's theory [31]. For reservoir fluid systems consisting only of non-associating components, the $\tilde{a}^{a s s o c}$ term in Eq. (1) disappears. The remaining three terms have rather complicated forms as compared with SRK or PR. However, there are only three model parameters for a non-associating component, the chain length $m$, the segment diameter $\sigma$ and the segment energy $\varepsilon$.

von Solms et al. [6] simplified the original PC-SAFT EoS by assuming that all the segments in the mixture have the same mean diameter $d$, which gives a mixture volume fraction identical to that of the actual mixture. This variation of PC-SAFT, called the simplified PC-SAFT EoS, is identical to the original PC-SAFT EoS for pure components. For mixtures, the simplified version and the original version are very similar [6]. The 
main motivation to use the simplified version is that it reduces the computation times for non-associating systems and significantly for associating systems. Therefore, it is more suitable to use the simplified version if the model is considered to be used for reservoir simulation in the future. The simplified version of PC-SAFT is used in this study.

\subsection{Soave-BWR EoS}

The Benedict-Webb-Rubin (BWR) equation of state [32] belongs to the so-called virial type equations of state. Despite its empirical nature, this model provides a highly accurate density description than many other types of EoS models. A recent modification of the BWR EoS is given by Soave in 1999:

$$
z=\frac{P}{R T \rho}=1+B \rho+D \rho^{4}+E \rho^{2}\left(1+F \rho^{2}\right) \exp \left(-F \rho^{2}\right)
$$

where $\rho$ is the density, and $B, D, E$, and $F$ are the five model parameters. The SoaveBWR EoS used in this study refers to this version of BWR EoS. This EoS has three parameters for each component, $T_{c}, P_{c}$, and $\omega$. Further details about Soave-BWR EoS can be found elsewhere [2], [24].

\section{Characterization}

\subsection{Considerations in a general characterization approach}

Reservoir fluid characterization is to represent the petroleum reservoir fluid with an appropriate number of pseudo-components and to find the equations of state parameters needed for each of them. This procedure normally involves the following steps: (1) estimating the relation between molar composition distribution and carbon number or molecular weight or determining the characteristic parameters of a continuous molar composition distribution function; (2) estimating the required properties or parameters of the chosen equation of state for each pseudo-component (carbon number fraction). For example, $T_{c}, P_{c}$, and $\omega$ are needed for SRK and PR and $m, \sigma$, and $\varepsilon$ for PC-SAFT. In addition, a binary interaction parameter $\left(k_{i j}\right)$ is needed for each pair of components; (3) lumping the fractions into a reasonable number of pseudo-components as it is time 
consuming to work with all the SCN fractions. Both the method of Pedersen et al. [10], [11] and that of Whitson et al. [13] have the above three steps although they differ in the sequence of these steps and the details involved in each step.

From a pragamatic viewpoint, it is convient to modify only the correlations of model parameters in step (2) when developing a characterization method for an EoS. Since the two other steps are kept unchanged, implementation into the existing codes is straightforward. This also facillitates evaluation of the new method since the existing PVT software needs little change, and a quicker acceptance of the new correlations can be expected if the evaluation results are positive. Modifications of the other two steps may also lead to a further improvement of the characterization results. But such modifications should in principle be effective to cubic models as well and it is better to study the necessity of such modifications in a more general context, not just limited to non-cubic models. For example, one can naturally ask whether those changes are needed for cubic models and whether the widely used procedures such as Pedersen's method and Whitson's method should be updated in the existing software. Those questions are interesting butnot our focus here. Our major interest is non-cubic models where there is no "standard" characterization commonly accepted in the industry. We stick to the principle that the development should be mainly on the correlations for model parameters.

We here propose a general approach to developing the new correlations as illustrated by steps A and B in Fig. 1. In the first step (A), a set of correlations for the model parameters is developed based on a large database for pure components, e.g., the DIPPR database [30]. We prefer correlations developed in a two-step perturbation way because the properties of n-alkanes are expressed with high accuracy and the correction for the aromaticity is given in a separate set of equations. In the second step (B), the correlations accounting for the aromaticity will be adjusted using a large PVT database but the paraffinic limit should be kept unchanged. The general approach is applied to PC-SAFT in Section 3.2 and to SRK and PR in Section 3.3. In Section 3.4 where characterization 
using explicit PNA information is tried, we also use the general principles discussed above in the development.

\subsection{General characterization approach for PC-SAFT}

We use Pedersen's characterization method as the framework and only modify the correlations in step (2) as discussed in Section 3.1. We first develop the correlations using the DIPPR database and then adjust them using a large PVT database. The adjustment is made to minimize the deviation in key PVT properties like saturation pressures, densities at reservoir temperature and Stock Tank Oil (STO) densities from single-stage separation.

The first step was completed in our earlier study [24]. A set of correlations for the PCSAFT model parameters $m, \sigma$, and $\varepsilon$ were developed using a two-step perturbation method similar to that used by Twu [33] in the development of correlations of critical properties. In the first step, the properties of the n-alkanes at the $T_{b}$ of the SCN component were calculated. The molecular weight of the n-alkanes at this $T_{b}, M W_{p}$, was estimated using Twu's correlations [33]. The PC-SAFT model parameters for n-alkanes, $m_{p}, \sigma_{p}$, and $\varepsilon_{p}$, were then calculated by the following linear correlations:

$$
\begin{aligned}
& m_{p}=0.02644 M W_{p}+0.83500 \\
& m_{p} \varepsilon_{p} / k=6.90845 M W_{p}+139.30870 \\
& m_{p} \sigma_{p}^{3}=1.71638 M W_{p}+19.19189
\end{aligned}
$$

In these correlations $m_{p}$ is dimensionless, ${ }^{\varepsilon_{p}} / k$ is in Kelvin, and $\sigma_{p}$ has the unit of $\AA$. In the second step, the properties of the SCN component were estimated by using the difference in specific gravity $\triangle S G=S G-S G_{p}$ as the perturbation parameter, where $S G_{p}$ is the specific gravity of the n-alkane calculated by Soave's correlation [34] as a function of $T_{b}$ (in Kelvin):

$$
S G_{p}=\left(1.8 T_{b}\right)^{1 / 3}\left(11.7372+3.336 \times 10^{-3} T_{b}-976.3 T_{b}^{-1}+3.257 \times 10^{5} T_{b}^{-2}\right)^{-1}
$$

The final correlations suggested for $m, \varepsilon$ and $\sigma$ by Yan et al. [24] are as follows:

$$
\begin{aligned}
& \sigma=\sigma_{p} \\
& \varepsilon=\varepsilon_{p}(1.1303391 \Delta S G+1)
\end{aligned}
$$




$$
m=m_{p}\left(1.0460471 \Delta S G^{2}-1.6209973 \Delta S G+1\right)
$$

Eqs. (7-9), developed based on the DIPPR database, provide the optimal parameters that can calculate saturation pressure and density for the relevant hydrocarbon components in the DIPPR database. Despite a large number of components are involved, the heavy aromatic and naphthenic components are not well-represented. In the database, the heaviest n-alkane is $\mathrm{n}-\mathrm{C}_{36}$ with $T_{b}$ equal to $770.15 \mathrm{~K}$ and the heaviest aromatic component is Tetraphenylethylene $\left(\mathrm{C}_{25} \mathrm{H}_{20}\right)$ with $T_{b}$ equal to $760 \mathrm{~K}$. Only around $19 \%$ of the components in the database have $T_{b}$ higher than $600 \mathrm{~K}$ and it decreases to around $5 \%$ for the components with $T_{b}$ higher than $700 \mathrm{~K}$. This shows that the majority of the components (around 81\%) in the database are light and have $T_{b}$ lower than $600 \mathrm{~K}$. Furthermore, the naphthenic and aromatic components in the database do not necessarily represent the most probable population in the common reservoir fluids. Therefore, the developed correlations optimal for the database may not be optimal for common reservoir fluids. To address this problem, we suggest further tuning the correlations based on a large PVT database so that the resulting correlations can be representative for common reservoir fluid samples. The tuning is performed only for the Eqs. (7-9) in order to keep the correct n-alkane limit (Eqs. (3-5)). Development of the correlations for model parameters based on a PVT database was used before, e.g., by Pedersen et al. [10]. In their study, the correlations were developed without consideration for the n-alkane limit. As a result, the critical properties and acentric factors generated for n-alkanes by the correlations can be very different from the experimental values. We stress here the importance of keeping the n-alkane limit (Eqs. (3-5)) since the parameters for paraffinic fluids will not be distorted. Besides, the tuning is only made for the coefficients in Eqs. (7) to (9) in order to keep the same functional forms for hydrocarbons other than nalkanes.

Apparently, a larger database will give more representative results. We have included 260 reservoir fluids in our database (see Section 4.1). Three properties are used in the tuning of the coefficients: saturation pressure, density at reservoir temperature, and Stock Tank Oil (STO) density. The density at reservoir temperature includes liquid density of oils in both single-phase and two-phase regions, and density of gas condensates above dew point 
pressure. Selection of these properties is based on two considerations: first, these three properties are usually measured with the lowest uncertainty; second, each property has its particular importance. Saturation pressure is a crucial property for reservoir development since a second phase appears below the saturation pressure, and it is perhaps the most influential property in tuning of a PVT model in phase equilibrium calculation. Density at reservoir temperature is directly related to all the volume related engineering calculations in the reservoir. STO density reflects the volume calculation results at surface conditions and indirectly influences the calculation of formation volume factors and solution gas oil ratios. There is no apparent way to modify Eq. (7) and we only considered tuning of Eqs. (8) and (9). In the tuning, we tried to use as few coefficients as possible and change them as little as possible. Two schemes were tested. In the first scheme, the only coefficient in the $\varepsilon$ correlation (Eq. (8)) was regressed to minimize the deviation in saturation pressure, density and STO density. In the second scheme, all the three coefficients in the correlations for $m$ and $\varepsilon$ (Eqs. (8) and (9)) were tuned simultaneously. The tuning showed that the saturation pressure was the most influential data for the final values of the regressed coefficients whereas the influence of density at reservoir temperature and STO density was moderate. The final correlations for the two schemes are as follows:

1. Regressing $\varepsilon$ coefficient in Eq. (8): $\varepsilon=\varepsilon_{p}(0.9533431 \Delta S G+1)$

2. Regressing $m$ and $\varepsilon$ coefficients in Eqs. (8) and (9) at the same time:

$$
\begin{aligned}
& \varepsilon=\varepsilon_{p}(0.9550243 \Delta S G+1) \\
& m=m_{p}\left(2.4516079 \Delta S G^{2}-1.6710480 \Delta S G+1\right)
\end{aligned}
$$

It should be noted that the above correlations are not proposed to be the ultimate correlations for the PC-SAFT characterization. Instead, they are used as an illustration how the correlations can be developed for an EoS. With a different PVT database, a different set of correlations can be developed by minimizing the deviations of the properties of interest for that database.

The characterization method developed using the general approach can be later applied to PVT calculation ( $A \rightarrow B \rightarrow C \rightarrow D$ in Fig. 1). The correlations developed in step B represent 
the average performance for the fluids in the database. For any other fluid sample not in the database, the calculation ( specific fluid, final tuning in step D can be made. This procedure is compared in Fig. 1 with another procedure $\left(A \rightarrow B^{\prime} \rightarrow C^{\prime}\right)$ for improving the characterization results for $a$ specific fluid sample. In step B', the model parameters can be tuned using boiling points and/or specific gravities of SCN fractions for a specific fluid, such as discussed in Yan et al. [24] and Liang et al. [23]. The boiling points and specific gravities are not final PVT data and the calculation based on the tuned model parameters is still predictive. However, since the tuning is directly used for the model parameters, the obtained parameters can only be used for this specific fluid. For the final PVT model, further tuning of model parameters in step C' can be made.

\subsection{Application of the general approach to SRK and PR}

For cubic EoSs, we still use Pedersen's method as the framework for our development. But instead of using Pedersen's correlations [5], we would like to use a set of correlations similar to Twu's correlations for $T_{c}$ and $P_{c}$ [33] where their n-alkane limits are explicitly given. The Lee-Kesler correlations [35], [36] for $\omega$ is usually used together with Twu's correlations. This combination gives good estimate of critical properties of hydrocarbons in $\mathrm{C}_{7+}$ and has been recommended by Whitson [37].

Twu's correlations estimate the critical properties in two steps. In the first step, the properties of the n-alkanes $\left(T_{c p}, P_{c p}\right)$ at the $T_{\mathrm{b}}$ of the SCN component are calculated using

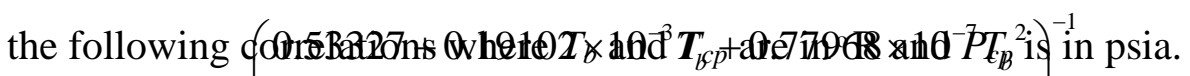

$$
\begin{aligned}
& T_{c p}=T_{b}\left(-0.28438 \times 10^{-10} T_{b}^{3}+\frac{0.95947 \times 10^{28}}{T_{b}^{13}}\right) \\
& \left\{\begin{array}{l}
\alpha=1-T_{b} / T_{c p} \\
P_{c p}=\left(3.83354+1.19629 \alpha^{0.5}+34.8888 \alpha+36.1952 \alpha^{2}+104.193 \alpha^{4}\right)^{2}
\end{array}\right. \\
& V_{c p}=\left(1-\left(0.419869-0.505839 \alpha-1.56436 \alpha^{3}-9481.7 \alpha^{14}\right)\right)^{-8}
\end{aligned}
$$


In the second perturbation step, the properties of the SCN component are estimated by using $\triangle S G$ as the perturbation parameter. The calculated $T_{c}$ and $P_{c}$ are in ${ }^{\circ} \mathrm{R}$ and psia respectively.

$$
\left\{\begin{array}{l}
S G_{0}=0.843593-0.128624 \alpha-3.36159 \alpha^{3}-13749.5 \alpha^{12} \\
\Delta S G_{T}=\exp \left(5\left(S G_{0}-S G\right)\right)-1 \\
f_{T}=\Delta S G_{T}\left(-0.362456 / T_{b}^{0.5}+\left(0.0398285-0.948125 / T_{b}^{0.5}\right) \Delta S G_{T}\right) \\
T_{c}=T_{c p}\left(\left(1+2 f_{T}\right) /\left(1-2 f_{T}\right)\right)^{2} \\
--- \\
\Delta S G_{V}=\exp \left(4\left(S G_{0}{ }^{2}-S G^{2}\right)\right)-1 \\
f_{V}=\Delta S G_{V}\left(0.466590 / T_{b}^{0.5}+\left(-0.182421+3.01721 / T_{b}^{0.5}\right) \Delta S G_{V}\right) \\
V_{c}=V_{c p}\left(\left(1+2 f_{v}\right) /\left(1-2 f_{v}\right)\right)^{2} \\
--- \\
\Delta S G_{P}=\exp \left(0.5\left(S G_{0}-S G\right)\right)-1 \\
f_{P}=\Delta S G_{P}\left(\begin{array}{l}
\left(2.53262-46.1955 / T_{b}^{0.5}-0.00127885 T_{b}\right)+ \\
\left(-11.4277+252.14 / T_{b}^{0.5}+0.00230535 T_{b}\right) \Delta S G_{p}
\end{array}\right) \\
P_{c}=P_{c p}\left(T_{c} / T_{c p}\right)\left(V_{c p} / V_{c}\right)\left(\left(1+2 f_{P}\right) /\left(1-2 f_{P}\right)\right)^{2}
\end{array}\right.
$$

Since the correlations in the second step (Eq. (16)) are complex and difficult to update during the tuning process with a PVT database, we tried to replace them with simpler correlations. Fig. 2 illustrates how $T_{c} / T_{c p}$ and $P_{c} / P_{c p}$ change with $\Delta S G$ for 318 hydrocarbons in the DIPPR database. Fitting a second order polynomial through the data points for $T_{c} / T_{c p}$ and a linear function for $P_{c} / P_{c p}$ give the following correlations for $T_{c}$ and $P_{c}$ where $T_{c}$ is in Kelvin and $P_{c}$ is in bar:

$$
\begin{aligned}
& P_{c}=P_{c p}(3.56179 \Delta S G+1) \\
& T_{c}=T_{c p}\left(-0.39220 \Delta S G^{2}+0.50239 \Delta S G+1\right)
\end{aligned}
$$

In these correlations $T_{c p}$ and $P_{c p}$ are the critical temperature and pressure of n-alkanes calculated by Eqs. $(13,14)$ and are converted to Kelvin and bar respectively. The difference in the specific gravity $\triangle S G=S G-S G_{p}$ is calculated using $S G_{p}$ from Eq. (6). It 
should be noted that Eq. (18) has a maximum around $\Delta S G=0.62$, and we keep $T_{c} / T_{c p}$ constant after its maximum value.

Fig. 3 compares original Twu's method (Eqs. (13-16)) with our simplified version (Eqs. (13-15), (17-18)) in calculation of critical properties of 318 pure components in DIPPR. As can be seen in Fig. 3, the simplified Twu's method gives very close results to that of original Twu's method. The percent average absolute deviations AAD\% of the original Twu's method in $T_{c}$ and $P_{c}$ are $1.1 \%$ and $7.8 \%$, respectively, while those of the simplified version are $1.0 \%$ and $7.5 \%$, respectively. It shows that the simplified version of Twu's method (Eqs. (13-15), (17-18)) can be used instead of the original Twu's method for calculation of critical properties.

The new correlations for $T_{c}$ and $P_{c}$ can be used together with the Lee-Kesler correlations for $\omega$. For the tuning of Eqs. (17-18) based on the PVT database, two schemes were tested for SRK and PR, similar to that used for PC-SAFT. In the first scheme, the only coefficient in the $P_{c}$ correlation (Eq. (17)) was regressed to minimize the deviation in saturation pressure, density and STO density. In the second scheme, all the three coefficients in the correlations for $P_{c}$ and $T_{c}$ (Eqs. (17) and (18)) were tuned simultaneously. The final correlations for the two schemes are summarized below for SRK and PR:

1. Regressing $P_{c}$ coefficient in Eq. (17) for SRK:

$$
P_{c}=P_{c p}(4.9242447 \Delta S G+1)
$$

2. Regressing $P_{c}$ and $T_{c}$ coefficients in Eqs. (17) and (18) at the same time for SRK:

$$
\begin{aligned}
& P_{c}=P_{c p}(5.4974598 \Delta S G+1) \\
& T_{c}=T_{c p}\left(-0.7220183 \Delta S G^{2}+0.6604209 \Delta S G+1\right)
\end{aligned}
$$

3. Regressing $P_{c}$ coefficient in Eq. (17) for PR:

$$
P_{c}=P_{c p}(5.4536065 \Delta S G+1)
$$

4. Regressing $P_{c}$ and $T_{c}$ coefficients in Eqs. (17) and (18) at the same time for PR:

$$
\begin{aligned}
& P_{c}=P_{c p}(5.5119793 \Delta S G+1) \\
& T_{c}=T_{c p}\left(-0.7316782 \Delta S G^{2}+0.6181465 \Delta S G+1\right)
\end{aligned}
$$


Again, the above correlations are examples showing how the general approach can be applied to SRK and PR.

\subsection{A PNA based characterization method for PC-SAFT}

The aromaticity of a SCN component is sometimes represented by use of the content of paraffinic (P), naphthenic $(\mathrm{N})$ and aromatic (A) components in it. In both Pedersen's method and Whitson's method, PNA distribution is not used explicitly in the characterization. The aromatic content in each SCN component is reflected by the difference in $S G$. It can be advantageous sometimes to account for aromatic content explicitly. For example, when precipitation of asphaltene happens, it is reasonable to assume that the interaction between paraffinic compounds and asphaltenes and that between aromatic compounds and asphaltenes are different. Explicit expression of PNA components might also be useful in composition gradient modeling in petroleum reservoirs since it provides more flexibility.

In principle, if we can find representative chemical compounds to represent $\mathrm{P}, \mathrm{N}$ and $\mathrm{A}$, and somehow estimate the PNA distribution for each SCN fraction, then we can estimate the model parameters for $\mathrm{P}, \mathrm{N}$ and $\mathrm{A}$ in each $\mathrm{SCN}$ fraction separately. In practice, however, there are several challenges. The first challenge is that PNA distribution is usually unavailable. For heavy molecules, it is not easy to classify them into P, N or A, e.g. if they have aromatic rings, naphthenic rings and long paraffinic chains at the same time. There are some correlations for PNA estimation [38], [39] but their accuracy is difficult to evaluate for a wide range of SCN components. We present below a simple trial characterization method which bypasses the first problem: Assuming that there are only $\mathrm{P}$ and $\mathrm{A}$ classes in each $\mathrm{SCN}$ fraction and their specific gravities are known, we can use volume additivity to get the composition of $\mathrm{P}$ and A directly from the $S G$ for the SCN fraction:

$$
\frac{1}{S G_{S C N}}=\sum \frac{w_{i}}{S G_{i}}=\frac{w_{p}}{S G_{p}}+\frac{w_{A_{1}}}{S G_{A_{1}}}+\frac{w_{A_{2}}}{S G_{A_{2}}}
$$

In this equation $w_{p}, w_{A 1}, w_{A 2}$ are the weight fraction of paraffinic, aromatic group 1 and aromatic group 2, respectively, $S G_{p}, S G_{A 1}$, and $S G_{A 2}$ are the specific gravity of each 
group, and $S G_{S C N}$ is the specific gravity of each $\mathrm{SCN}$ fraction. We assume here two possible aromatic groups: aromatics with one benzene ring $A_{1}$, which are essentially linear alkylbenzenes and the aromatics with two benzene rings $\mathrm{A}_{2}$, which are mainly naphthalene derivatives with alkane chains. The heaviest aromatic component in $\mathrm{A}_{1}$ group is n-octadecylbenzene $\left(\mathrm{C}_{24} \mathrm{H}_{42}\right)$ with $T_{b}$ equal to $673.15 \mathrm{~K}$ and the heaviest component in group $\mathrm{A}_{2}$ is 1-n-decylnaphthalene $\left(\mathrm{C}_{20} \mathrm{H}_{28}\right)$ with $T_{b}$ equal to $652.15 \mathrm{~K}$. The $\mathrm{A}_{1}$ group appears after $353.2 \mathrm{~K}$ and the $\mathrm{A}_{2}$ group appears after $491.1 \mathrm{~K}$. There are other possible aromatic compounds but it is difficult to classify them into classes with information as systematic and complete as for the $\mathrm{A}_{1}$ and $\mathrm{A}_{2}$ groups selected above. In addition, we assume that $w_{A l}$ is equal to $w_{A 2}$ if all three groups exist in the SCN fraction. Hence, knowing the value of $S G_{S C N}$, we can solve Eq. (25) to find the weight percent of each group.

The model parameters, $M W$ and $S G$ for $\mathrm{P}, \mathrm{A}_{1}$ and $\mathrm{A}_{2}$ are readily available and their correlations can be easily developed. It seems that the characterization is straightforward but there is a second challenge. Fig. 4 shows the distribution of $S G$ with $T_{b}$ for n-alkanes and 318 other hydrocarbons. As can be seen, $S G$ for the $\mathrm{P}$ group increases with $T_{b}$ while $S G$ for the $\mathrm{A}_{1}$ and $\mathrm{A}_{2}$ groups decreases with increasing $T_{b}$. But we know that the density of SCN fractions increases with the $T_{b}$ (see Fig. 4). The general perception is that the $S G$ for aromatics should also increase with $T_{b}$. The opposite trends for $\mathrm{A}_{1}$ and $\mathrm{A}_{2}$ groups are because with increasing $T_{b}$, the complexity of the aromatics is expected to increase, not just the length of the alkane chain. This is not reflected in the selected aromatic groups. In fact, it would be difficult to select a homologous aromatic family that shows an increase in $S G$ with $T_{b}$. It should also be noted that the groups $\mathrm{A}_{1}$ and $\mathrm{A}_{2}$ are the aromatics groups that we have the most data for. For other groups of aromatics, it can be difficult to find a common trend in their model parameters. The difficulty of finding representative aromatic compounds is another challenge with PNA based characterization methods. Since $S G$ for $\mathrm{A}_{1}$ and $\mathrm{A}_{2}$ can be far away from the $S G$ for the actual aromatic group, it happens often that the density of a SCN fraction cannot be met by combining $\mathrm{P}, \mathrm{A}_{1}$ and $\mathrm{A}_{2}$ groups. In such case, we have to assume the fraction is completely made up of $\mathrm{A}_{2}$. 
Fig. 5 illustrates the problem for the above test PNA characterization method. Compared with a previous characterization method for PC-SAFT [24], the test PNA method gives a smaller phase envelope for Fluid 7 (31.28\% methane and $\left.36.78 \% \mathrm{C}_{7+}\right)$ from Jaubert et al. [40]. It is caused by inadequate characterization of heavy fractions because for SCN components with large carbon numbers, their specific gravities can be larger than that of the $\mathrm{A}_{2}$ group and we had to approximate these $\mathrm{SCN}$ components with $\mathrm{A}_{2}$. Even with this approximation, the obtained fraction will have properties lighter than it should have. This behavior was observed for most of the systems tested.

In order to select the representative aromatic group that shows an increase in $S G$ with $T_{b}$, we selected some aromatic compounds that capture the upper limit of SG in the aromatic compounds in the DIPPR database. The selection is somewhat arbitrary but we tried to consider the presence of single-ring, double-ring and multiple ring aromatics in the representative aromatic group. The black dashed line in Fig. 4 passes through the representative components from different aromatic groups. The components and their properties are presented in Table 1. The lightest aromatic component in the A group is Benzene $\left(\mathrm{C}_{6} \mathrm{H}_{6}\right)$ with $T_{b}$ equal to $353.24 \mathrm{~K}$ which corresponds to $\mathrm{C}_{7}$ fraction, and the heaviest aromatic component is Tetraphenylethylene $\left(\mathrm{C}_{26} \mathrm{H}_{20}\right)$ with $T_{b}$ equal to $760.0 \mathrm{~K}$ corresponding to $\mathrm{C}_{35} \mathrm{SCN}$ fraction. The aromatic group appears after $353.24 \mathrm{~K}$.

The values of $m, m \varepsilon / k, m \sigma^{3}$ can be estimated as a function of $T_{b}$ for the representative aromatic group using the following correlations. $T_{b}$ in the following equations is in Kelvin:

$$
\begin{aligned}
& m_{A}=5.98957 \times 10^{-6} \times T_{b}^{2}+2.44045 \times 10^{-3} \times T_{b}+0.807171 \\
& (m \varepsilon / k)_{A}=2.85713 \times 10^{-3} \times T_{b}^{2}+0.661777 \times T_{b}+107.971 \\
& \left(m \sigma^{3}\right)_{A}=4.92174 \times 10^{-4} \times T_{b}^{2}+0.0938404 \times T_{b}+30.1198
\end{aligned}
$$

Using the above correlations in a wide range of $T_{b}$ (from $300 \mathrm{~K}$ to $1000 \mathrm{~K}$ ), the molar density of the aromatic group $\rho_{A}$ can be found using PC-SAFT. The correlation for $\rho_{A}$ as a function of $T_{b}$ can therefore be written as:

$$
\rho_{A}=2.03166 \times 10^{-5} \times T_{b}^{2}-3.93733 \times 10^{-2} \times T_{b}+21.9838
$$


Assuming that there are only $\mathrm{P}$ and A classes in each $\mathrm{SCN}$ fraction, we can calculate the composition of $\mathrm{P}_{M}$ and A by solving the following equation:

$$
\frac{M W_{S C N}}{S G_{S C N}}=\frac{x_{p} M W_{p}}{S G_{p}}+\frac{x_{A}}{\rho_{A}}
$$

where $x_{p}$ and $x_{A}$ are the mole fractions of paraffinic and representative aromatic group, respectively. $M W_{p}$ and $M W_{A}$ are the molecular weights and $S G_{p}$ is the specific gravity of the paraffinic group, while $M W_{S C N}$ and $S G_{S C N}$ are the molecular weight and specific gravity of each SCN fraction, the values of which are known from the first step of Pedersen's characterization. The specific gravity of the paraffinic group can be calculated by Eq. (6) while $M W_{p}$ is calculated by a few iterations using the following correlation as a $\underset{\text { starting value }[33]}{ } \quad M W_{p}^{0}=\frac{T_{b}}{10.44-0.0052 T_{b}}$

In this correlation $T_{b}$ is in ${ }^{\circ} \mathrm{R}$. As all the necessary parameters in Eq. (30) are known, this equation can be solved to find the composition of $\mathrm{P}$ and A groups ( $\left.x_{p}=1-x_{A}\right)$.

Given the composition of each group, $M W_{A}$ can then be found using the following equation:

$$
M W_{S C N}=x_{p} M W_{p}+x_{A} M W_{A}
$$

which can later be used in calculation of the specific gravity of the aromatic group, $S G_{A}$. In our calculations, instead of applying this methodology to each SCN group and lumping them together to find the final pseudo-components parameters, we used the weighted average $T_{b}$ (Eq. (33)) for each pseudo-component and found $m, m \varepsilon / k, m \sigma^{3}$ for the pseudocomponents directly using $T_{b \text {, pseudo }}$ instead of $T_{b}$ in the Eqs. (26-29). In other words, we found the PC-SAFT parameters after lumping the SCN fractions into fewer pseudocomponents.
$T_{b, \text { pseudo }}=\frac{\sum_{i} z_{i} M W_{i} T_{b, i}}{\sum_{i} z_{i} M W_{i}}$

In addition, we further regressed the coefficients in Eq. (27) using the PVT database to minimize the deviation in saturation pressure, density and STO density. To reduce the number of tuned coefficients from three to two, we included $T_{b}$ of benzene in Eq. (27) 
and fixed the last coefficient to make sure the new correlation would reproduce the correct value of $m \varepsilon / k$ for benzene, which is the lightest aromatic compound in our representative aromatic group. As a result, we only tuned the first two coefficients in Eq. (27). The final set of correlations for $m, m \varepsilon / k, m \sigma^{3}$ is given by

$$
\begin{aligned}
& m_{A}=5.98957 \times 10^{-6} \times T_{b}^{2}+2.44045 \times 10^{-3} \times T_{b}+0.807171 \\
& (m \varepsilon / k)_{A}=1.7044 \times 10^{-3} \times\left(T_{b}-T_{b, \text { benzene }}\right)^{2}+3.3024 \times\left(T_{b}-T_{b, \text { benzene }}\right)+711.6350 \\
& \left(m \sigma^{3}\right)_{A}=4.92174 \times 10^{-4} \times T_{b}^{2}+0.0938404 \times T_{b}+30.1198
\end{aligned}
$$

The calculation results using the new PNA approach with only two representative groups (P and $\mathrm{A}$ ) together with other EoSs are presented in Table 2.

\section{Results and Discussions}

\subsection{Petroleum fluid database}

In order to investigate and compare the overall performance of different EoSs and different characterization methods in PVT modeling, a petroleum fluids database covering wide composition, temperature and pressure ranges is needed. In this work, 260 petroleum fluids have been collected from different sources in the literature [40], [41], as well as from an internal PVT database [42]. An overview of these fluids including their methane and $\mathrm{C}_{7+}$ contents is given in Table $\mathrm{A} 1$ in the supplementary information. There are different types of petroleum fluids, from gas condensate to quite heavy oil. The database covers a wide range of methane content from $2.26 \%$ to $74.71 \%$ while the $\mathrm{C}_{7+}$ content changes from $6.39 \%$ to $83.21 \%$. The range for the $S G$ of $\mathrm{C}_{7+}$ is from 0.7597 to 0.9747, and maximum reservoir temperature and saturation pressure are $469.15 \mathrm{~K}$ and 427.96 bar, respectively. There are some fluids for which only the saturation pressure data is available [41]. However, various experimental data from different measurements, such as constant mass expansion (CME), differential liberation (DL), and/or separator test, are available for most of the fluids in this database. It should be noted that systems

showing deviations larger than $20 \%$ in saturation pressure, density and/or STO density using all the EoSs tested were excluded from the final database. The large deviations 
could be due to poor quality of the data or the uniqueness of the system (being too heavy or too asymmetric) which may be better treated separately.

\subsection{Deviations in saturation pressure, density and STO density}

The percent average absolute deviations AAD\% of saturation pressure, density, and STO density for the 260 petroleum fluids are listed in Table A2 in the supplementary information where we have compared the performance of PC-SAFT EoS with Yan et al.'s characterization method [24] with SRK, PR, and Soave-BWR EoSs. Compared to the previous study [24], STO density is included in the evaluations. The critical properties for SRK, PR and Soave-BWR were calculated by the original Twu's method [33] and the acentric factor was calculated from the Lee-Kesler correlation [35], [36].

Assareh et al. [27] developed a set of correlations based on $M W$ and $S G$ for PC-SAFT parameters using a database of 840 pure components from three families (n-alkanes, cycloalkanes and alkylbenzenes). The pure component parameters were generated by the correlations of Tihic et al. [43] and Panuganti et al. [18] in the $M W$ range of 70-350. Their correlations are linear functions of $M W$ and quadratic functions of specific gravity and were used in this study to compare with our proposed characterization method.

In order to compare the performance of the new general characterization method and several recent methods suggested for PC-SAFT [24], [25], [27], the global deviations in saturation pressure, density and STO density for all 260 fluids were evaluated (Table 2). The results from SRK, PR and Soave-BWR are also presented as references. Since volume translation is commonly used to improve the density calculation by cubic EoSs, we also included SRK and PR with volume translation in the comparison. Furthermore, Table 2 summarizes the performance of the new general characterization method for SRK and PR with/without volume translation and the new PNA approach for PC-SAFT. The binary interaction parameters for all the cases are taken from Yan et al. [24] except for the characterization method suggested by Liang et al. [25] for which the $k_{i j}$ values are taken from Liang et al. [23]. The detailed AAD\% of saturation pressure, density and STO 
density using the new general characterization for PC-SAFT together with SRK and PR with volume translation are listed in Table A3 in the supplementary information.

Comparison between cubic EoSs without volume translation and non-cubic EoSs shows that all previous versions of PC-SAFT [24], [25], [27] have better performance than SRK, PR, and Soave-BWR in density and stock tank oil density while the cubic ones give slightly lower deviation in saturation pressure. Using volume translation for cubics improves the density and STO density predictions. The change in deviation of density calculation is more significant for SRK than for PR.

Among the existing characterization methods for PC-SAFT tested here, Yan et al.'s [24] method gives the smallest $\mathrm{AAD} \%$ and maximum deviation in saturation pressure while Assareh et al. [27] method has better performance in density and STO density calculations.

The application of the new general characterization method to SRK and PR (Eqs. 19-24) yields lower deviation in all three properties than SRK and PR with the classical characterization. Actually, the new characterization method for cubics gives the lowest deviation in saturation pressure among all the combinations of EoSs and characterization methods studied in Table 2. However, the deviation in density and STO density for SRK and PR with the new general characterization method is still higher than SRK and PR with the classical characterization and volume translation. Applying volume translation to SRK and PR with the new characterization method further reduces deviations in density and STO density.

Applying the new PNA characterization approach to PC-SAFT gives lower deviation in density and STO density than the previous characterization methods for this EoS. However, the deviation in saturation pressure is poorer than the other models.

Applying the new characterization method developed in this study to Yan et al.'s [24] correlations, yields lower deviations in all three properties. Regressing the coefficient in 
the equation for $\varepsilon$ (Eq. (11)) mainly influences the saturation pressure deviation while the deviations in density and STO density reduce slightly. Regressing all three coefficients at the same time (Eqs. (11) and (12)) gives even lower deviations in density and STO density but the deviation in saturation pressure slightly increases. In both regression cases, the deviation in saturation pressure is the lowest among the deviations calculated by the previous characterization methods for PC-SAFT and is very close to that of cubic EoSs. For the case where all the three coefficients are regressed, both the average and maximum deviation in density and STO density are very close to that of SRK and PR with volume translation.

In terms of maximum deviation, PC-SAFT with the new characterization method has a slightly higher maximum deviation for saturation pressure than the cubic models. However, it gives the lowest deviation in saturation pressure, density and STO density calculation among other characterization methods for PC-SAFT.

In summary, application of the proposed general characterization method in this study to PC-SAFT makes this model superior to the previous PC-SAFT characterization methods and gives the smallest $\mathrm{AAD} \%$ and maximum deviation for all three properties. Furthermore, application of the new characterization method to the cubic EoSs yields better performance in saturation pressure calculation in comparison to the original SRK and PR. Using volume translation together with the new characterization approach for SRK and PR gives comparable results for density and STO density to that of SRK and PR with volume translation.

\subsection{Simulation of $D L$ and CME tests}

The accuracy of our method is tested against the other three characterization methods for PC-SAFT in calculation of oil density, gas compressibility factor, oil formation volume factor, solution gas-oil ratio and compressibility of an oil sample from the book of Pedersen and Christensen [44]. The composition and experimental data for the Constant Mass Expansion (CME) and Differential Liberation (DL) tests can be found in tables 3.7, 
3.6 and 3.12 of Pedersen and Christensen's book [44]. This fluid was not used in our regression and the presented results are pure predictions.

Table 3 summarizes the AAD\% in calculation of different properties for this oil mixture. It can be seen that our proposed characterization approach gives the lowest deviation in saturation pressure and density while Soave-BWR gives the lowest deviation in STO density. Yan et al.'s [24] method has better performance in calculation of STO density among other PC-SAFT characterization methods.

For the gas compressibility factor, PR with volume translation gives the lowest deviation. Among non-cubic models, Soave-BWR has better performance and PC-SAFT gives the highest deviation for this property.

PC-SAFT with Assareh et al.'s characterization method [27] seems to give the lowest deviation in calculation of Oil Formation Volume Factor $\left(B_{o}\right)$ and solution gas-oil ratio $\left(R_{s}\right)$, while Liang et al.'s method [25] gives the lowest deviation in calculation of compressibility. Our new characterization method for PC-SAFT gives slightly higher deviation in compressibility compared to Liang et al.'s method. For relative volume, the non-cubic models including Soave-BWR seem to have better performance in comparison to the cubic models.

Figures 6-10 show the simulated DL results for the oil mixture from Pedersen and Christensen's book [44] using SRK and PR with and without volume translation, as well as Soave-BWR, and PC-SAFT with different characterization methods. It can be seen from Fig. 6 that SRK and PR under predict the density over the whole pressure range while PC-SAFT with the new characterization method gives the lowest deviation and almost a good match of the experimental data at all pressures. Using volume translation, improves the density prediction of cubic models, however, the final results are not as good as the PC-SAFT prediction. 
Fig. 7 illustrates the density prediction results using different characterization methods for PC-SAFT where our developed method gives the lowest deviation especially at higher pressures.

Fig. 8 presents the results for the gas compressibility factor. In general, it seems all the models have some deficiencies in calculation of $Z$ factor especially at higher pressures. PR with volume translation gives the closest predictions to the experimental data. All the characterization methods for PC-SAFT give more or less similar predictions, while Assareh et al.'s method [27] is slightly better than the rest of PC-SAFT characterization methods.

The simulated Oil Formation Volume Factors $\left(B_{o}\right)$ are compared with the experimental data in Fig. 9. The results show that our characterization method for PC-SAFT gives better prediction of $B_{o}$ than cubics and Soave-BWR in the whole pressure range. SRK and PR without volume translation under predict $B_{o}$ especially at higher pressures, while using volume translation yields over prediction of the experimental data. This trend is also observed in Fig. 10 where $R_{s}$ is plotted against pressure. For most of the reservoir fluids in the database it was noticed that using volume translation for cubics might improve the prediction of $B_{o}$ and $R_{s}$ for pressures below the saturation pressure, however, it makes the predictions worse for higher pressures or vice versa. In general, it would be difficult to get accurate prediction of $B_{o}$ and $R_{s}$ in the whole pressure range using cubic EoSs either with or without volume translation.

Oil compressibility is one of the important properties in HPHT reservoirs as expansion of the reservoir fluid is the main production mechanism from these types of reservoirs. Therefore, accurate prediction of this property is of great importance. Fig. 11 shows the compressibility calculation above saturation pressure for the oil mixture from [44]. Our proposed characterization method for PC-SAFT gives the lowest deviation in compressibility compared to the cubic EoSs and Soave-BWR, and predicts this property almost accurately in the whole pressure range. The cubic models over predict the compressibility even after using volume translation while Soave-BWR seems to give the 
correct slope for the experimental data. Although, the deviation is larger at lower pressures, the cubics seem to give better prediction of compressibility at higher pressures. As another example and for slightly heavier reservoir fluid, the compressibility calculation results for reservoir fluid 73 from the database are presented in Fig. 12. The results show almost similar trend as in Fig. 11.

Yan et al. [24] investigated the sensitivity of PC-SAFT to binary interaction parameters $\left(k_{i j}\right)$ in calculation of saturation pressure and vapor phase composition for 35 reservoir fluids. They showed that although PC-SAFT gives small absolute average $k_{i j}$ values, it is more sensitive to the change in $k_{i j}$. Sensitivity to $k_{i j}$ is a possible reason for the large deviations of PC-SAFT when applied to PVT calculation. The current method does not include $k_{i j}$ in the tuning process. Including $k_{i j}$ in the future tuning as an additional parameter could improve the PVT calculation results. Knowing the $k_{i j}$ for the binary mixtures of $\mathrm{C}_{1} / \mathrm{N}_{2} / \mathrm{CO}_{2}$ and $\mathrm{C}_{7+}$ is difficult and cannot be completely reflected by the binary VLE systems that we know so far. Use of a large PVT database can make up for this defect.

\section{Conclusions}

We presented a general approach to characterizing reservoir fluids based on a large PVT database and applied it to non-cubic PC-SAFT as well as cubic SRK and PR. In this approach, the correlations for the EoS model parameters were developed first based on a large pure component database such as DIPPR, and the coefficients in the obtained correlations were further adjusted using a large PVT database. We suggest keeping the $\mathrm{n}$ alkane limit during the adjustment step, which can be readily realized for correlations developed in a two-step perturbation manner. Our final correlations were obtained using a PVT database of 260 reservoir fluids. The developed correlations are not meant to be an ultimate version. They can be constantly improved with a larger PVT database, or even customized to a certain type of reservoir fluid. Repeating the whole procedure for a set of improved correlations is rather straightforward. The obtained correlations can be easily implemented in PVT software. 
PC-SAFT with the new general characterization method gives the lowest AAD\% and maximum deviation in calculation of saturation pressure, density and STO density, and is superior to the previous characterization methods for PC-SAFT. Furthermore, application of the new characterization method to SRK and PR improves the saturation pressure calculation in comparison to the original characterization method for SRK and PR. Using volume translation together with the new characterization approach for SRK and PR gives comparable results for density and STO density to that of original characterization for SRK and PR with volume translation. The characterization method based on PNA content for PC-SAFT gives accurate results for reservoir fluid density and STO density whereas the deviation in saturation pressure is not as low as other characterization methods for PC-SAFT.

For the PVT database used in this study, cubic EoSs seem to have better performance than PC-SAFT in calculation of saturation pressure; PC-SAFT and cubics with volume translation show comparable results in calculation of density and STO density. For calculation of the derivative properties such as compressibility, PC-SAFT has shown to be superior to cubics for the two reservoir fluids tested. Most of the reservoir fluids in the current PVT database are black oil. For lighter reservoir fluids with higher composition of methane or certain type of reservoir fluids such as volatile oil, PC-SAFT might have better performance than cubics in saturation pressure, density and STO density calculations.

\section{Acknowledgement}

This study was carried out under the NextOil project funded by the Innovation Fund Denmark, Maersk Oil and DONG Energy. 


\section{References}

[1] J. Gross and G. Sadowski, "Perturbed-Chain SAFT: An Equation of State Based on a Perturbation Theory for Chain Molecules," Ind. Eng. Chem. Res., vol. 40, no. 4, pp. 1244-1260, Feb. 2001.

[2] G. S. Soave, "An effective modification of the Benedict-Webb-Rubin equation of state," Fluid Phase Equilib., vol. 164, no. 2, pp. 157-172, Oct. 1999.

[3] J. Gross and G. Sadowski, "Perturbed-Chain SAFT: An Equation of State Based on a Perturbation Theory for Chain Molecules," Ind. Eng. Chem. Res., vol. 40, no. 4, pp. 1244-1260, Feb. 2001.

[4] G. M. Kontogeorgis and G. K. Folas, Thermodynamic models for industrial applications - from classical and advanced mixing rules to association theories. New York: John Wiley and Sons, Inc., 2010.

[5] K. S. Pedersen and C. H. Sørensen, "PC-SAFT Equation of State Applied to Petroleum Reservoir Fluids," in SPE Annual Technical Conference and Exhibition, 2007, vol. 1, no. 4, pp. 1-10.

[6] N. Von Solms, I. A. Kouskoumvekaki, M. L. Michelsen, and G. M. Kontogeorgis, "Capabilities, limitations and challenges of a simplified PC-SAFT equation of state," Fluid Phase Equilib., vol. 241, no. 1-2, pp. 344-353, Mar. 2006.

[7] A. J. De Villiers, "Evaluation and improvement of the sPC-SAFT equation of state for complex mixtures.," Stellenbosch University, 2011.

[8] G. Soave, "Equilibrium constants from a modified Redlich-Kwong equation of state," Chem. Eng. Sci., vol. 27, no. 6, pp. 1197-1203, 1972.

[9] D. Y. Peng and D. B. Robinson, "A New Two-Constant Equation of State," Ind. Eng. Chem. Fundam., vol. 15, no. 1, pp. 59-64, Feb. 1976.

[10] K. S. Pedersen, A. Fredenslund, and P. Thomassen, Propertises of Oils and Natural gases. Houston: Gulf Publishing Inc., 1989.

[11] K. S. Pedersen, P. Thomassen, and A. Fredenslund, Characterization of Gas Condensate Mixtures, vol. 1. New York: Taylor \& Francis, 1989.

[12] C. H. Whitson, "Characterizing Hydrocarbon Plus Fractions," Soc. Pet. Eng. J., vol. 23, no. 4, pp. 683-694, 1983.

[13] C. H. Whitson, T. F. Andersen, and I. Søreide, "C7+ characterization of related equilibrium fluids using the gamma distribution.," Adv. Thermodyn., vol. 1, pp. 35-36, 1989.

[14] P. D. Ting, P. C. Joyce, P. K. Jog, W. G. Chapman, and M. C. Thies, "Phase equilibrium modeling of mixtures of long-chain and short-chain alkanes using Peng-Robinson and SAFT," Fluid Phase Equilib., vol. 206, no. 1-2, pp. 267-286, Apr. 2003.

[15] D. L. Gonzalez, P. D. Ting, G. J. Hirasaki, and W. G. Chapman, "Prediction of asphaltene instability under gas injection with the PC-SAFT equation of state," Energy and Fuels, vol. 19, no. 4, pp. 1230-1234, Jul. 2005.

[16] D. L. Gonzalez, G. J. Hirasaki, J. Creek, and W. G. Chapman, "Modeling of asphaltene precipitation due to changes in composition using the perturbed chain statistical associating fluid theory equation of state," Energy and Fuels, vol. 21, no. 3, pp. 1231-1242, May 2007.

[17] D. L. Gonzalez, F. M. . Vargas, G. J. Hirasaki, and W. G. Chapman, "Modeling 
Study of CO2-Induced Asphaltene Precipitation," Energy and Fuels, vol. 22, no. 6, pp. 757-762, 2008.

[18] S. R. Panuganti, F. M. Vargas, D. L. Gonzalez, A. S. Kurup, and W. G. Chapman, "PC-SAFT characterization of crude oils and modeling of asphaltene phase behavior," Fuel, vol. 93, pp. 658-669, Mar. 2012.

[19] S. R. Panuganti, M. Tavakkoli, F. M. Vargas, D. L. Gonzalez, and W. G. Chapman, "SAFT model for upstream asphaltene applications," Fluid Phase Equilib., vol. 359, pp. 2-16, Dec. 2013.

[20] S. Punnapala and F. M. Vargas, "Revisiting the PC-SAFT characterization procedure for an improved asphaltene precipitation prediction," Fuel, vol. 108, pp. 417-429, Jun. 2013.

[21] F. M. Vargas, D. L. Gonzalez, J. L. Creek, J. Wang, J. Buckley, G. J. Hirasaki, and W. G. Chapman, "Development of a General Method for Modeling Asphaltene Stability," Energy and Fuels, vol. 23, no. 3, pp. 1147-1154, 2009.

[22] F. M. Vargas, D. L. Gonzalez, G. J. Hirasaki, and W. G. Chapman, "Modeling asphaltene phase behavior in crude oil systems using the perturbed chain form of the statistical associating fluid theory (PC-SAFT) equation of state," Energy and Fuels, vol. 23, no. 3, pp. 1140-1146, 2009.

[23] X. Liang, W. Yan, K. Thomsen, and G. M. Kontogeorgis, "On petroleum fluid characterization with the PC-SAFT equation of state," Fluid Phase Equilib., vol. 375, pp. 254-268, Aug. 2014.

[24] W. Yan, F. Varzandeh, and E. H. Stenby, "PVT modeling of reservoir fluids using PC-SAFT EoS and Soave-BWR EoS," Fluid Phase Equilib., vol. 386, pp. 96-124, Jan. 2015.

[25] X. Liang, W. Yan, K. Thomsen, and G. M. Kontogeorgis, "Modeling the liquidliquid equilibrium of petroleum fluid and polar compounds containing systems with the PC-SAFT equation of state," Fluid Phase Equilib., vol. 406, pp. 147-155, 2015.

[26] P. Hosseinifar, M. Assareh, and C. Ghotbi, "Developing a new model for the determination of petroleum fraction PC-SAFT parameters to model reservoir fluids," Fluid Phase Equilib., vol. 412, pp. 145-157, 2016.

[27] M. Assareh, C. Ghotbi, M. Tavakkoli, and G. Bashiri, "PC-SAFT modeling of petroleum reservoir fluid phase behavior using new correlations for petroleum cuts and plus fractions," Fluid Phase Equilib., vol. 408, pp. 273-283, 2016.

[28] K. S. Pedersen, S. Leekumjorn, K. Krejbjerg, and J. Azeem, "Modeling of EOR PVT data using PC-SAFT equation," Abu Dhabi Int. Pet. Conf. Exhib. 11-14 Novemb. , Abu Dhabi, UAE, p. 11, 2012.

[29] S. Leekumjorn and K. Krejbjerg, "Phase behavior of reservoir fluids: Comparisons of PC-SAFT and cubic EOS simulations," Fluid Phase Equilib., vol. 359, pp. 1723, Dec. 2013.

[30] T. E. Daubert and R. P. Danner, Physical and Thermodynamic Properties of Pure Compounds: Data Compilation Title. Hemisphere, New York, 1998.

[31] J. Gross and G. Sadowski, "Modeling Polymer Systems Using the Perturbed-Chain Statistical Associating Fluid Theory Equation of State," Ind. Eng. Chem. Res., vol. 41, no. 5, pp. 1084-1093, 2002.

[32] M. Benedict, G. B. Webb, and L. C. Rubin, "An Empirical Equation for 
Thermodynamic Properties of Light Hydrocarbons and Their Mixtures I. Methane, Ethane, Propane and n-Butane," J. Chem. Phys., vol. 8, no. 4, pp. 334-345, 1940.

[33] C. H. Twu, "An internally consistent correlation for predicting the critical properties and molecular weights of petroleum and coal-tar liquids," Fluid Phase Equilib., vol. 16, no. 2, pp. 137-150, 1984.

[34] G. S. Soave, "Estimation of the critical constants of heavy hydrocarbons for their treatment by the Soave-Redlich-Kwong equation of state," Fluid Phase Equilib., vol. 143, no. 1-2, pp. 29-39, 1998.

[35] B. I. Lee and M. G. Kesler, "A Generalized Thermodynamic Correlation Based on Three-Parameter Corresponding," AIChE J., vol. 21, no. 3, pp. 510-527, 1975.

[36] M. G. Kesler and B. I. Lee, "Improve Prediction of Enthalpy of Fractions.," Hydrocarb. Process., vol. 55, no. 3, pp. 153-158, 1976.

[37] C. H. Whitson and M. R. Brule, Phase Behavior, vol. 20. 2000.

[38] K. Van Nes and H. A. Van Westen, Aspects of the constitution of mineral oils. Houston-Amsterdam: Elsevier Pub. Co., 1951.

[39] M. R. Riazi and T. E. Daubert, "Prediction of Molecular-Type Analysis of Petroleum Fractions and Coal Liquids," Ind. Eng. Chem. Process, vol. 25, pp. 1009-1015, 1986.

[40] J. N. Jaubert, L. Avaullee, and J. F. Souvay, "A crude oil data bank containing more than 5000 PVT and gas injection data," J. Pet. Sci. Eng., vol. 34, no. 1-4, pp. 65-107, Jun. 2002.

[41] A. M. Elsharkawy, "An empirical model for estimating the saturation pressures of crude oils," J. Pet. Sci. Eng., vol. 38, no. 1-2, pp. 55-77, May 2003.

[42] "Internal PVT Database at Center for Energy Resources Engineering, Technical University of Denmark,” 2014.

[43] A. Tihic, G. M. Kontogeorgis, N. von Solms, and M. L. Michelsen, "Applications of the simplified perturbed-chain SAFT equation of state using an extended parameter table," Fluid Phase Equilib., vol. 248, no. 1, pp. 29-43, Oct. 2006.

[44] K. S. Pedersen and P. Christensen, Phase Behavior of Petroleum Reservoir Fluids, Second Ed. Boca Raton, London, New York: CRC Press, Taylor \& Francis Group, 2007. 


\section{Figure captions}

Fig. 1. The recommended characterization procedure (steps A and B) and its application to PVT calculation

Fig. 2. $T_{c}$ and $P_{c}$ correlations as a function of $\Delta S G$ for the pure components in DIPPR database

Fig. 3. Comparison between original and simplified Twu's method in calculation of critical temperature and pressure vs. experimental data from DIPPR

Fig. 4. $S G$ vs. $T_{b}$ for n-alkanes and other hydrocarbons in DIPPR database. The black dashed line passes through the representative aromatic group listed in Table 1.

Fig. 5. Phase envelope diagram for Fluid 7 from [40] using PC-SAFT and the "trial" PNA Approach

Fig. 6. Density vs. pressure for the oil mixture from [44] - comparison between cubics with and without volume translation and non-cubic models including PC-SAFT with different characterization methods

Fig. 7. Density vs. pressure for the oil mixture from [44] - comparison between different characterization methods for PC-SAFT

Fig. 8. Gas compressibility factor vs. pressure for the oil mixture from [44]

Fig. 9. Oil formation volume factor vs. pressure for the oil mixture from [44]

Fig. 10. Solution gas-oil ratio vs. pressure for the oil mixture from [44]

Fig. 11. Oil compressibility vs. pressure for the oil mixture from [44]

Fig. 12. Oil compressibility vs. pressure for fluid 73 from the database 


\section{Tables}

Table 1. Representative aromatic components and their parameters for the new PNA approach

\begin{tabular}{llcccccccc}
\hline Component & Family & $\begin{array}{c}M W \\
\mathrm{~g} / \mathrm{mol})\end{array}$ & $T_{b}(\mathrm{~K})$ & $S G$ & $m(-)$ & $\sigma(\AA)$ & $\varepsilon / k(\mathrm{~K})$ & $m . \varepsilon / k(\mathrm{~K})$ & $m . \sigma^{3}\left(\AA^{3}\right)$ \\
\hline Benzene & n-Alkylbenzenes & 78.112 & 353.24 & 0.883 & 2.487 & 3.626 & 286.104 & 711.635 & 118.603 \\
Toluene & n-Alkylbenzenes & 92.138 & 383.78 & 0.873 & 2.780 & 3.727 & 288.065 & 800.738 & 143.859 \\
1,2,3-trimethylindene & Cyclobenzenes & 158.240 & 509.00 & 1.019 & 3.893 & 3.870 & 311.764 & 1213.750 & 225.719 \\
1-phenylindene & Cyclobenzenes & 192.256 & 610.00 & 1.092 & 4.756 & 3.798 & 340.167 & 1617.830 & 260.654 \\
Indane & Cyclobenzenes & 118.176 & 451.12 & 0.969 & 3.079 & 3.839 & 318.609 & 980.873 & 174.230 \\
Ethynylbenzene & Monoaromatics & 102.133 & 416.00 & 0.934 & 2.683 & 3.869 & 318.811 & 855.488 & 155.378 \\
Naphthalene & Naphthalenes & 128.171 & 491.143 & 1.028 & 3.013 & 3.910 & 353.084 & 1063.758 & 180.100 \\
Tetraphenylmethane & Polyaromatics & 320.426 & 743.00 & 1.350 & 5.835 & 3.995 & 369.840 & 2158.003 & 372.009 \\
Tetraphenylethylene & Polyaromatics & 332.437 & 760.00 & 1.347 & 6.127 & 3.985 & 369.619 & 2264.786 & 387.795 \\
\hline
\end{tabular}


Table 2. Summary of AAD\% and maximum deviations in the calculated saturation pressures, reservoir fluid densities and STO densities using SRK, PR, Soave-BWR and PC-SAFT with different characterization methods

\begin{tabular}{|c|c|c|c|c|c|c|}
\hline \multirow{2}{*}{ EoS } & \multicolumn{2}{|c|}{ Saturation Pressure } & \multicolumn{2}{|c|}{ Density } & \multicolumn{2}{|c|}{ STO Density } \\
\hline & $\mathrm{AAD} \%$ & Max. Dev. & $\mathrm{AAD} \%$ & Max. Dev. & $\mathrm{AAD} \%$ & Max. Dev. \\
\hline SRK & 6.35 & 21.84 & 12.62 & 25.60 & 16.49 & 27.11 \\
\hline PR & 6.26 & 22.36 & 3.95 & 16.94 & 6.76 & 18.61 \\
\hline SRK-VT & 6.35 & 21.84 & 1.63 & 7.70 & 0.66 & 2.67 \\
\hline PR-VT & 6.26 & 22.36 & 1.55 & 7.42 & 0.80 & 2.83 \\
\hline Soave-BWR & 6.72 & 31.27 & 4.46 & 26.20 & 6.45 & 23.52 \\
\hline PC-SAFT Yan et al. (2015) & 7.36 & 28.73 & 2.82 & 9.39 & 2.03 & 7.41 \\
\hline PC-SAFT Liang et al. (2015) & 7.84 & 42.84 & 2.71 & 9.11 & 2.67 & 15.57 \\
\hline PC-SAFT Assareh et al. (2016) & 7.45 & 37.54 & 2.00 & 8.25 & 1.87 & 4.16 \\
\hline SRK This work - Eq. (19) & 5.83 & 27.27 & 12.18 & 26.43 & 16.37 & 27.96 \\
\hline SRK This work - Eqs. (20-21) & 5.76 & 27.65 & 10.92 & 25.08 & 14.88 & 26.56 \\
\hline SRK This work - Eqs. (20-21) - With VT & 5.76 & 27.65 & 1.67 & 6.08 & 0.79 & 2.68 \\
\hline PR This work - Eq. (22) & 6.01 & 29.53 & 3.92 & 15.68 & 4.77 & 20.88 \\
\hline PR This work - Eqs. (23-24) & 5.75 & 27.33 & 3.92 & 16.02 & 5.01 & 20.65 \\
\hline PR This work - Eqs. (23-24) - With VT & 5.75 & 27.33 & 1.66 & 6.67 & 0.91 & 2.92 \\
\hline PC-SAFT New PNA Method - Eqs. (34-36) & 9.40 & 26.76 & 1.64 & 7.33 & 0.77 & 3.07 \\
\hline PC-SAFT This work - Eq. (11) & 6.50 & 23.99 & 2.36 & 7.92 & 1.75 & 6.79 \\
\hline PC-SAFT This work - Eqs. (11), (12) & 6.51 & 24.08 & 1.73 & 7.73 & 0.86 & 2.98 \\
\hline
\end{tabular}


Table 3. AAD\% in calculated saturation pressure, density, STO density and other properties of the oil from [44] using SRK, PR, Soave-BWR and PC-SAFT EoS with different characterization methods

\begin{tabular}{lcccccccc}
\hline EoS & $\begin{array}{c}\text { Saturation } \\
\text { Pressure }\end{array}$ & Density & $\begin{array}{c}\text { STO } \\
\text { Density }\end{array}$ & $\begin{array}{c}\text { Gas Z } \\
\text { Factor }\end{array}$ & $B_{o}$ & $R_{s}$ & Compressibility & $\begin{array}{c}\text { Relative } \\
\text { Volume }\end{array}$ \\
\hline SRK & 8.07 & 16.50 & 21.40 & 2.63 & 3.15 & 14.49 & 25.56 & 2.73 \\
PR & 9.51 & 6.85 & 12.04 & 1.52 & 2.70 & 4.67 & 21.02 & 2.10 \\
SRK-VT & 8.07 & 1.18 & 1.51 & 1.93 & 3.45 & 8.14 & 9.33 & 1.95 \\
PR-VT & 9.51 & 1.37 & 1.74 & 0.50 & 3.70 & 8.73 & 15.44 & 2.01 \\
Soave-BWR & 3.23 & 3.47 & 0.33 & 1.36 & 7.70 & 7.43 & 9.14 & 1.41 \\
PC-SAFT Yan et al. (2015) & 2.01 & 0.67 & 0.93 & 2.62 & 1.49 & 5.20 & 4.28 & 1.27 \\
PC-SAFT Liang et al. (2015) & 3.53 & 0.62 & 2.41 & 2.68 & 2.70 & 6.48 & 2.65 & 1.35 \\
PC-SAFT Assareh et al. (2016) & 2.94 & 1.18 & 3.12 & 2.43 & 0.75 & 3.05 & 3.69 & 1.18 \\
PC-SAFT This work - Eqs. (11), (12) & 1.69 & 0.35 & 1.85 & 2.57 & 2.12 & 6.60 & 3.21 & 1.13 \\
\hline
\end{tabular}




\section{Figures}

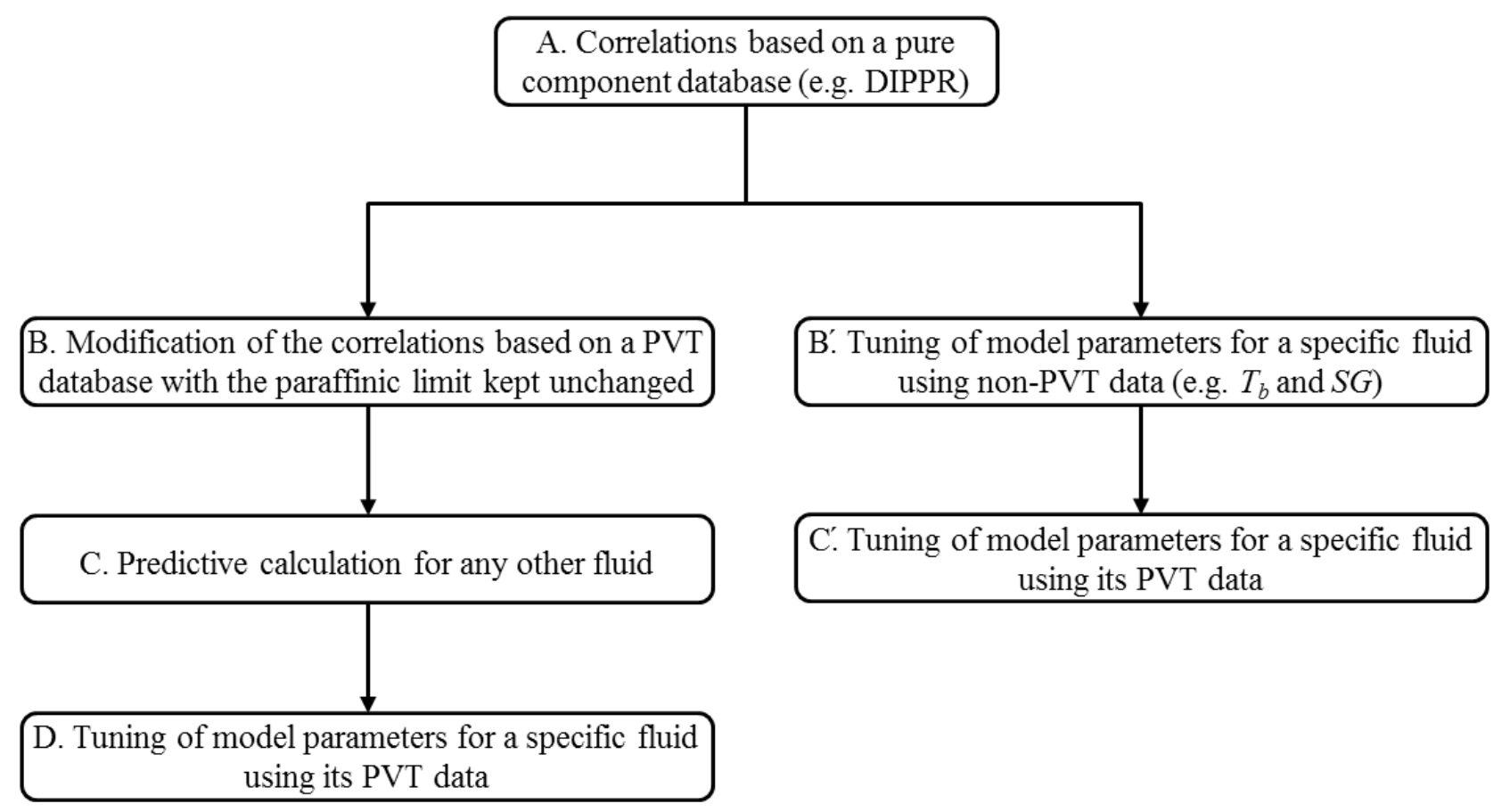

Fig. 1. The recommended characterization procedure (steps A and B) and its application to PVT calculation 


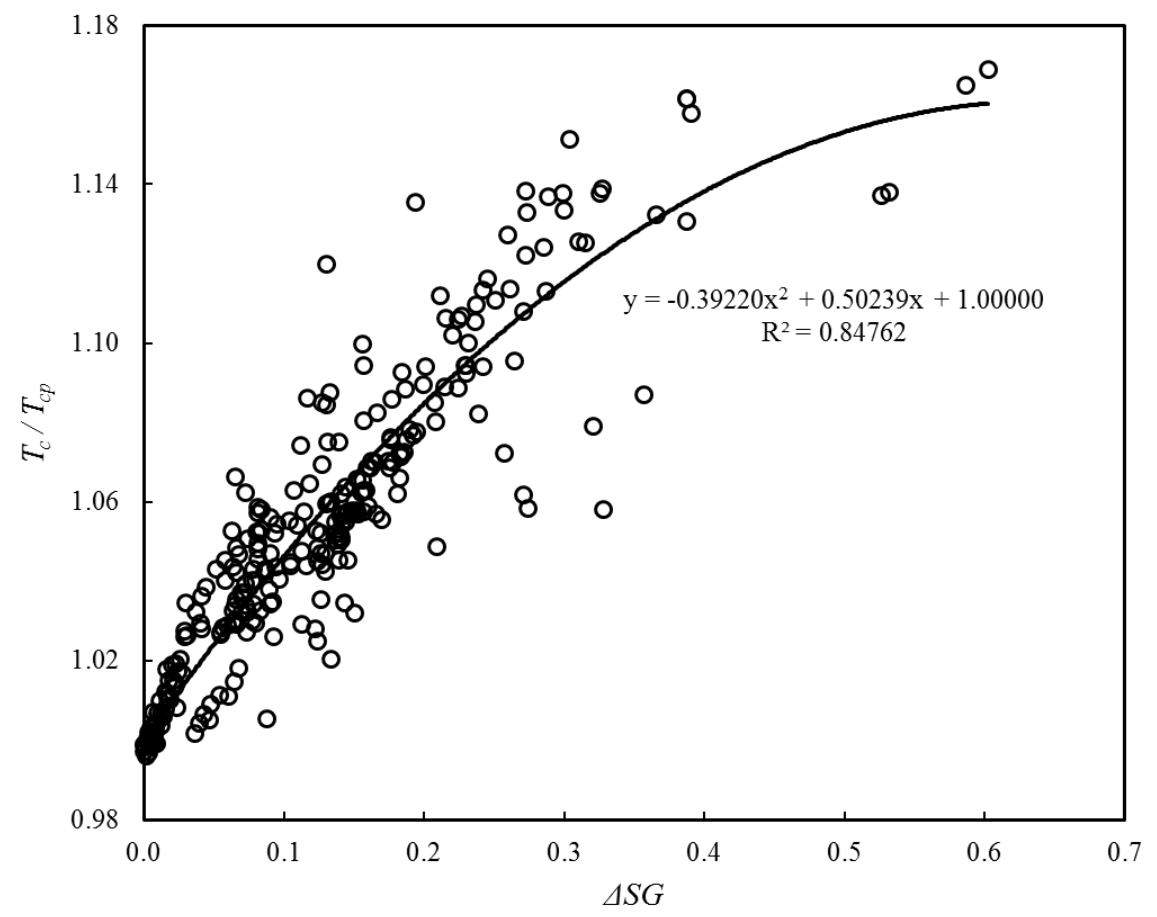

a) 


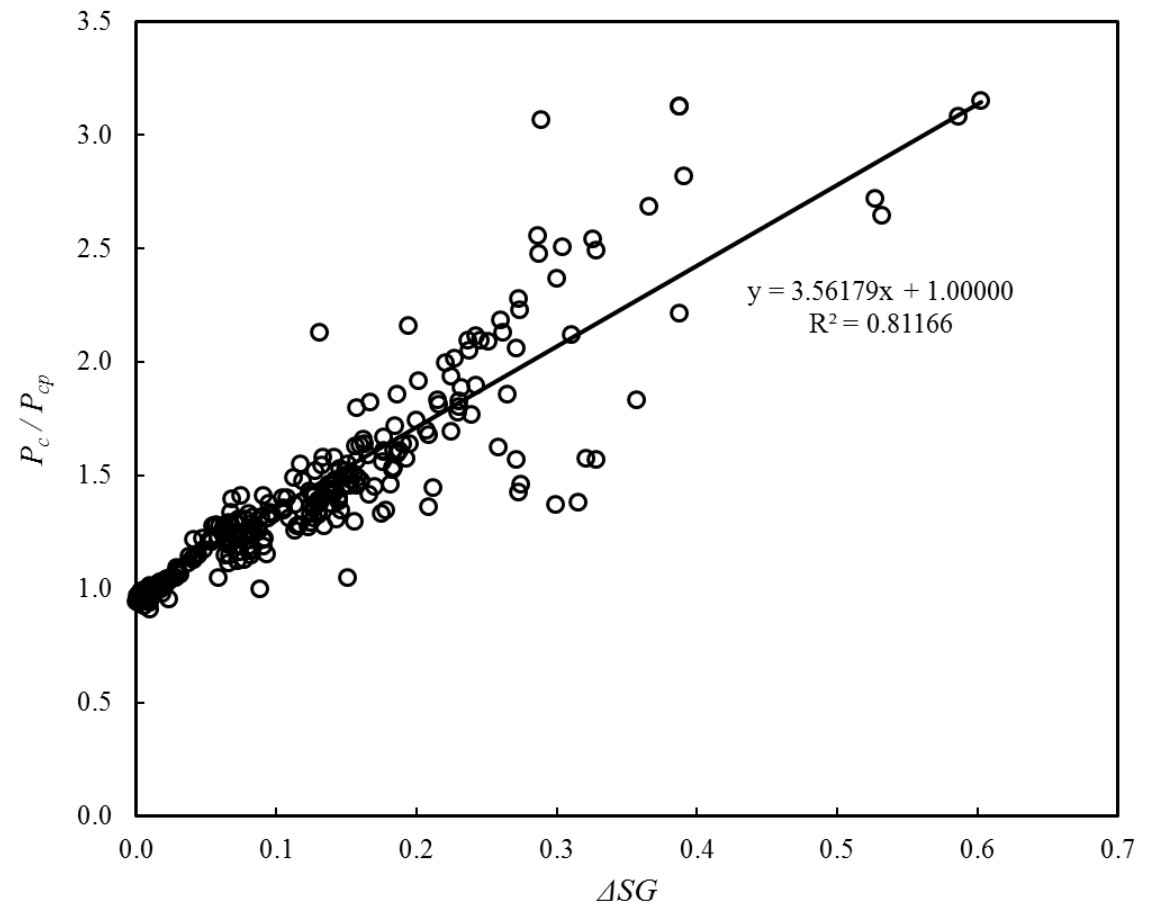

b)

Fig. 2. $T_{c}$ and $P_{c}$ correlations as a function of $\triangle S G$ for the pure components in DIPPR database 


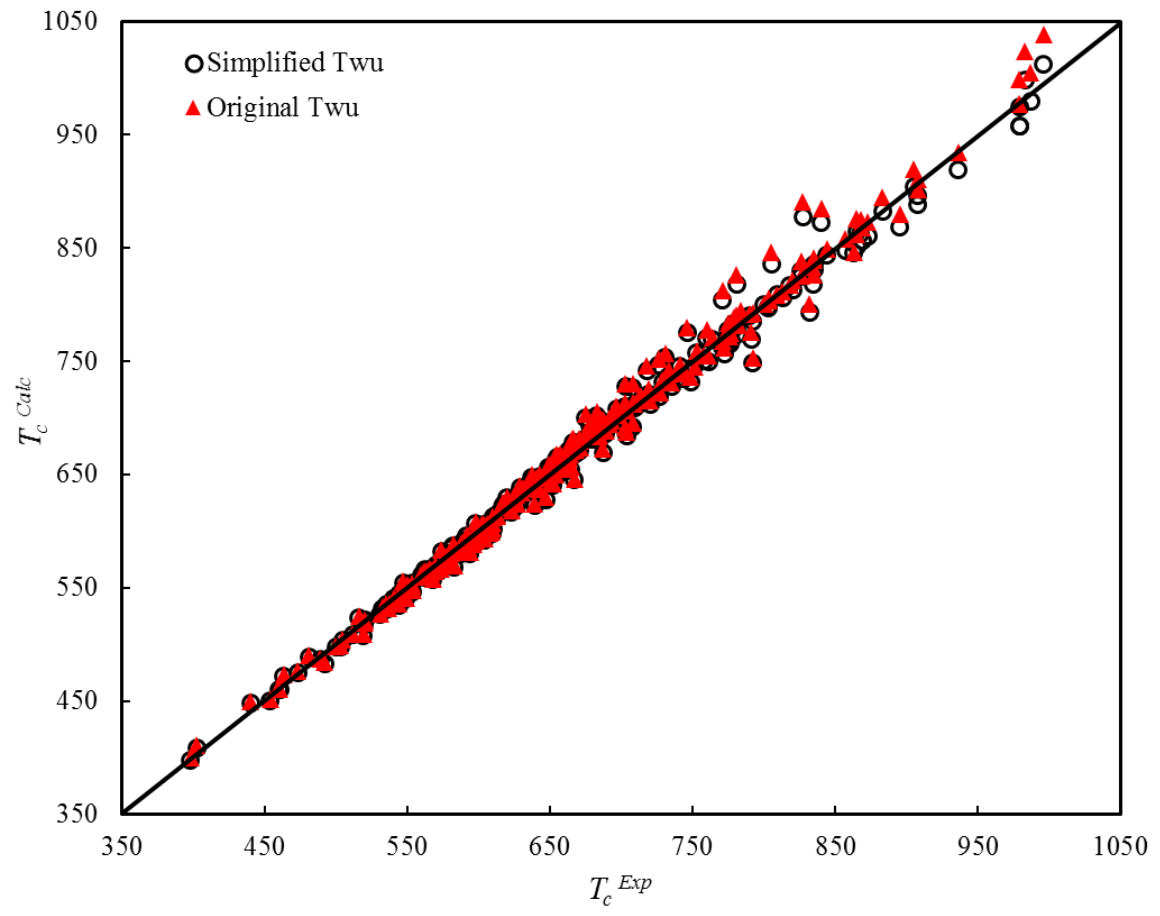

a) 


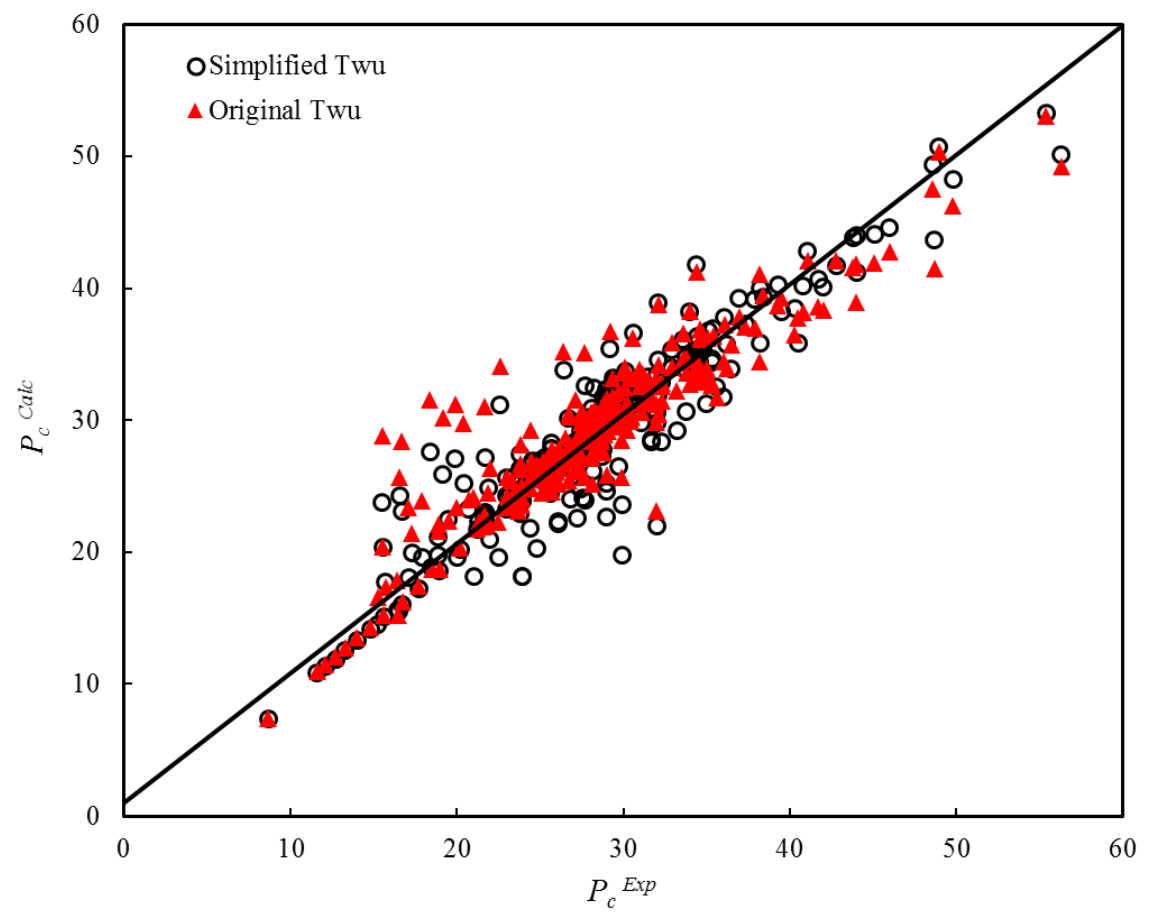

b)

Fig. 3. Comparison between original and simplified Twu's method in calculation of critical temperature and pressure vs. experimental data from DIPPR 


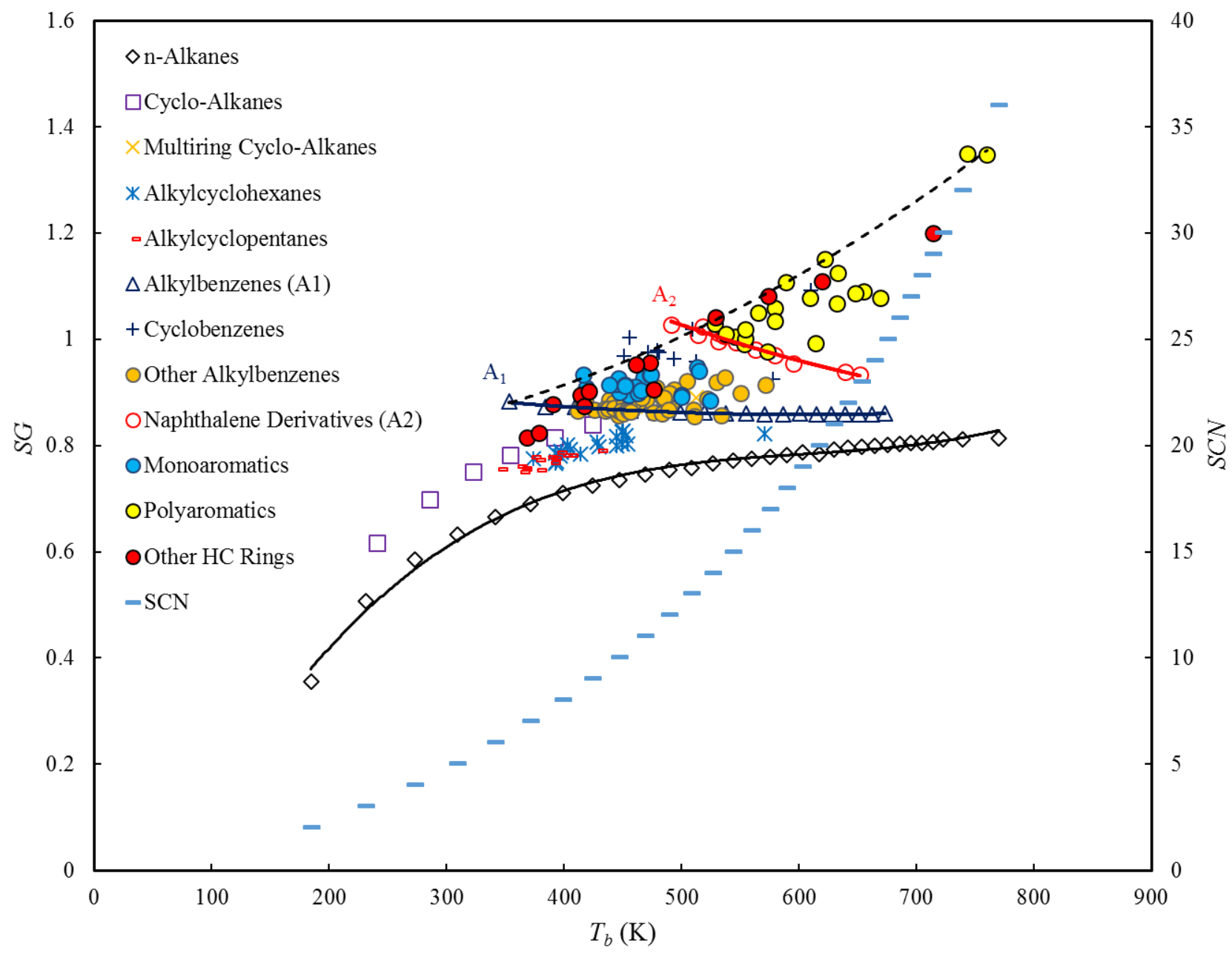

Fig. $4 . S G$ vs. $T_{b}$ for n-alkanes and other hydrocarbons in DIPPR database. The black dashed line passes through the representative aromatic group listed in Table 1. 


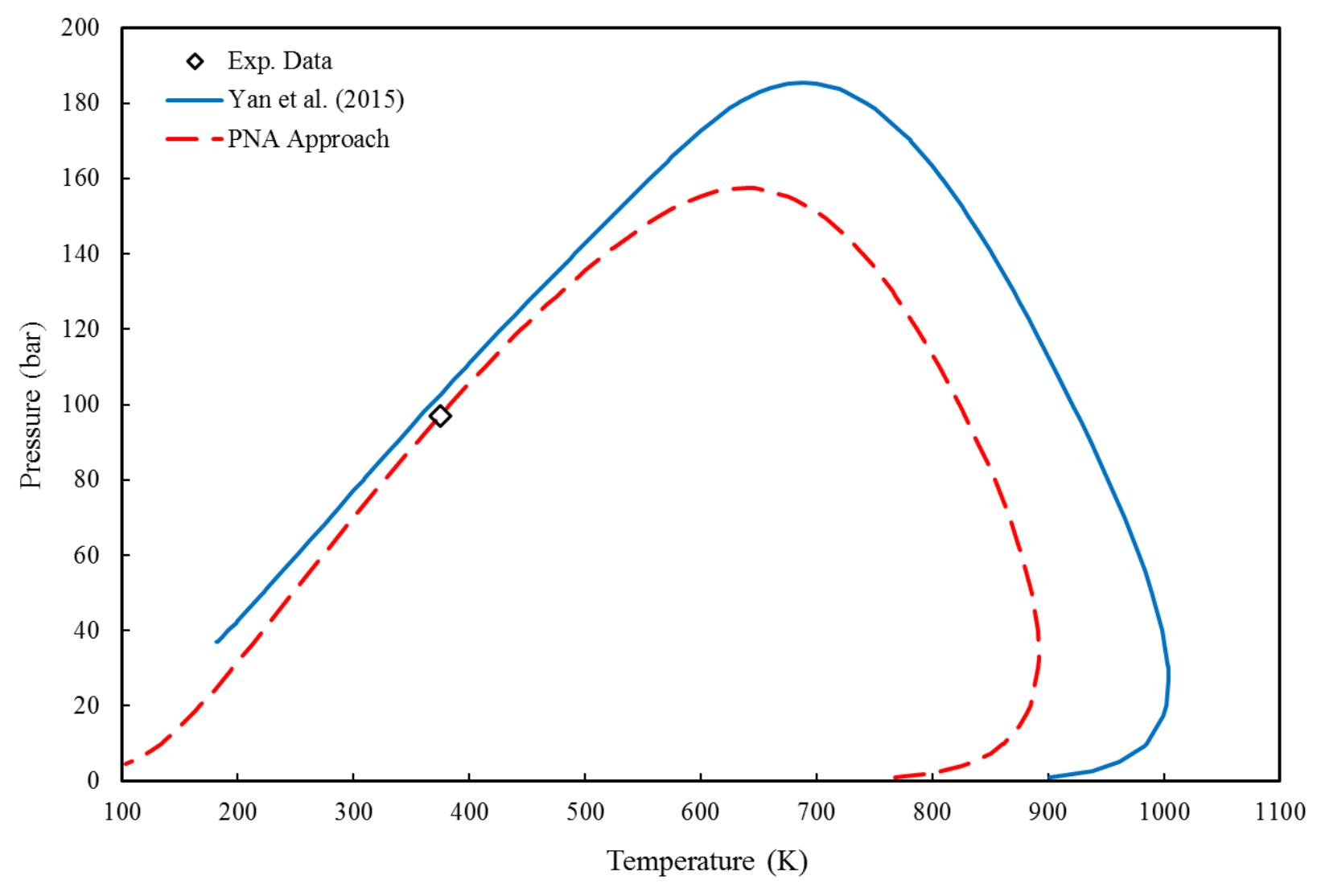

Fig. 5. Phase envelope diagram for Fluid 7 from [40] using PC-SAFT and the "trial" PNA Approach 


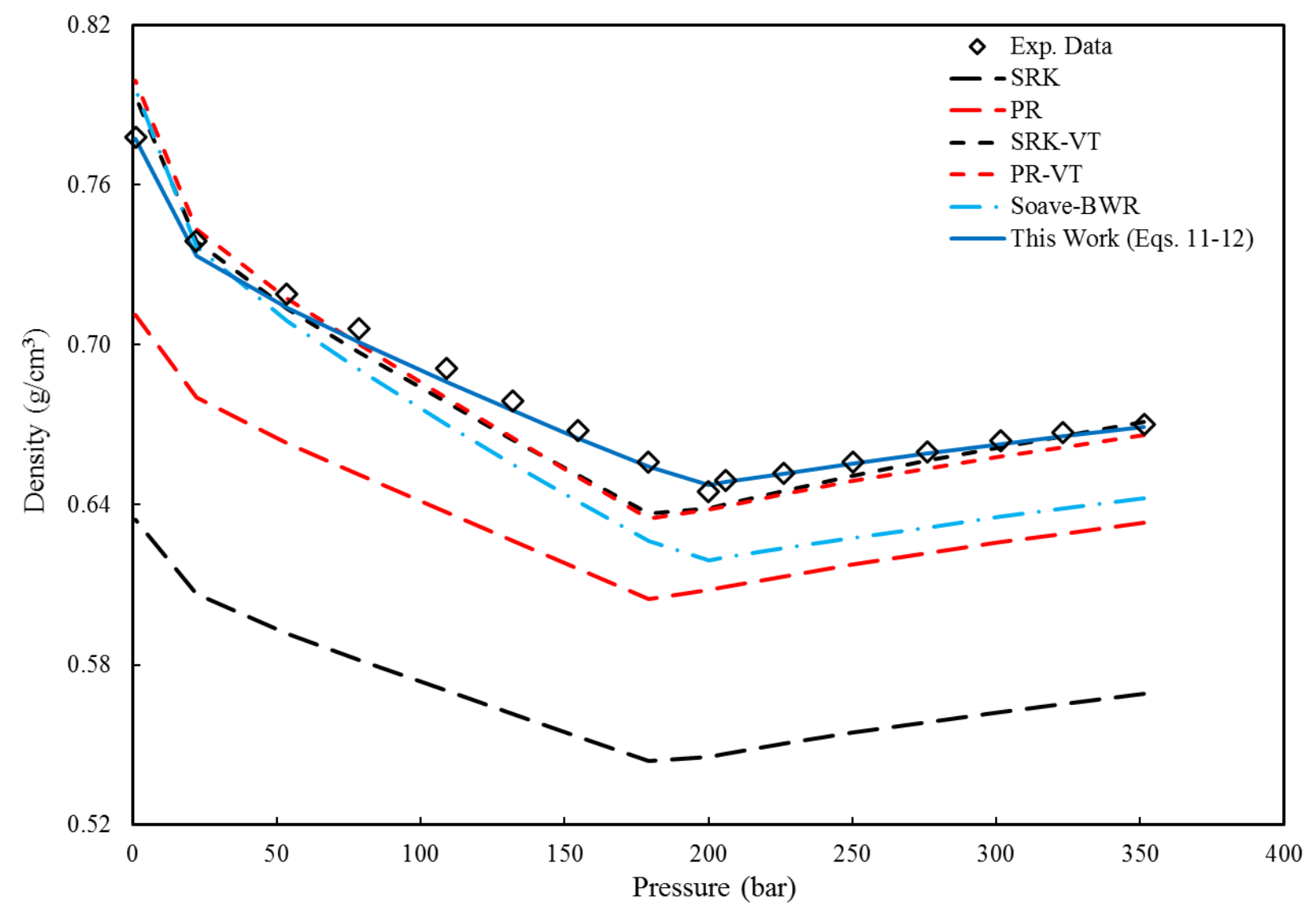

Fig. 6. Density vs. pressure for the oil mixture from [44] - comparison between cubics with and without volume translation and non-cubic models including PC-SAFT with different characterization methods 


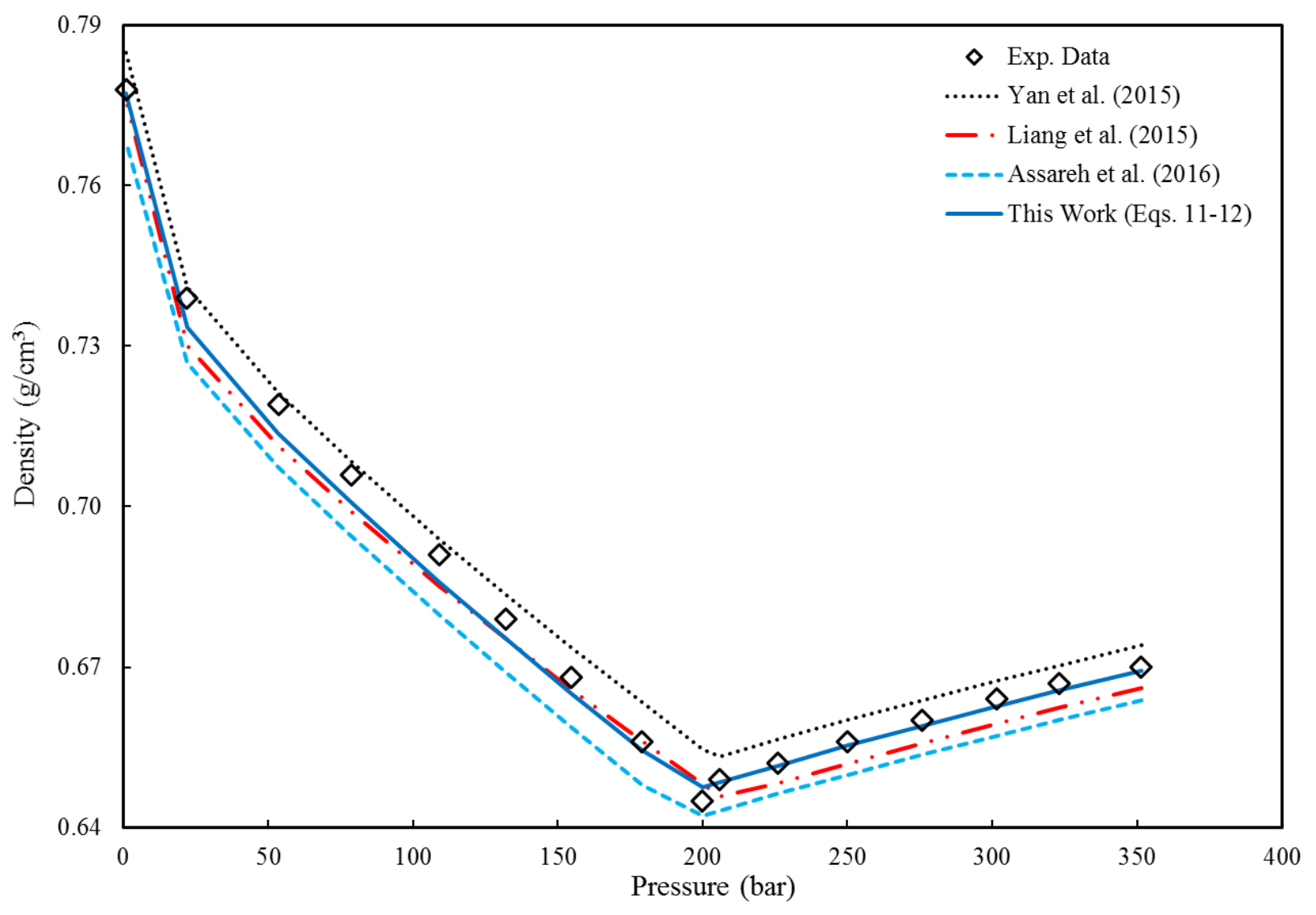

Fig. 7. Density vs. pressure for the oil mixture from [44] - comparison between different characterization methods for PC-SAFT 


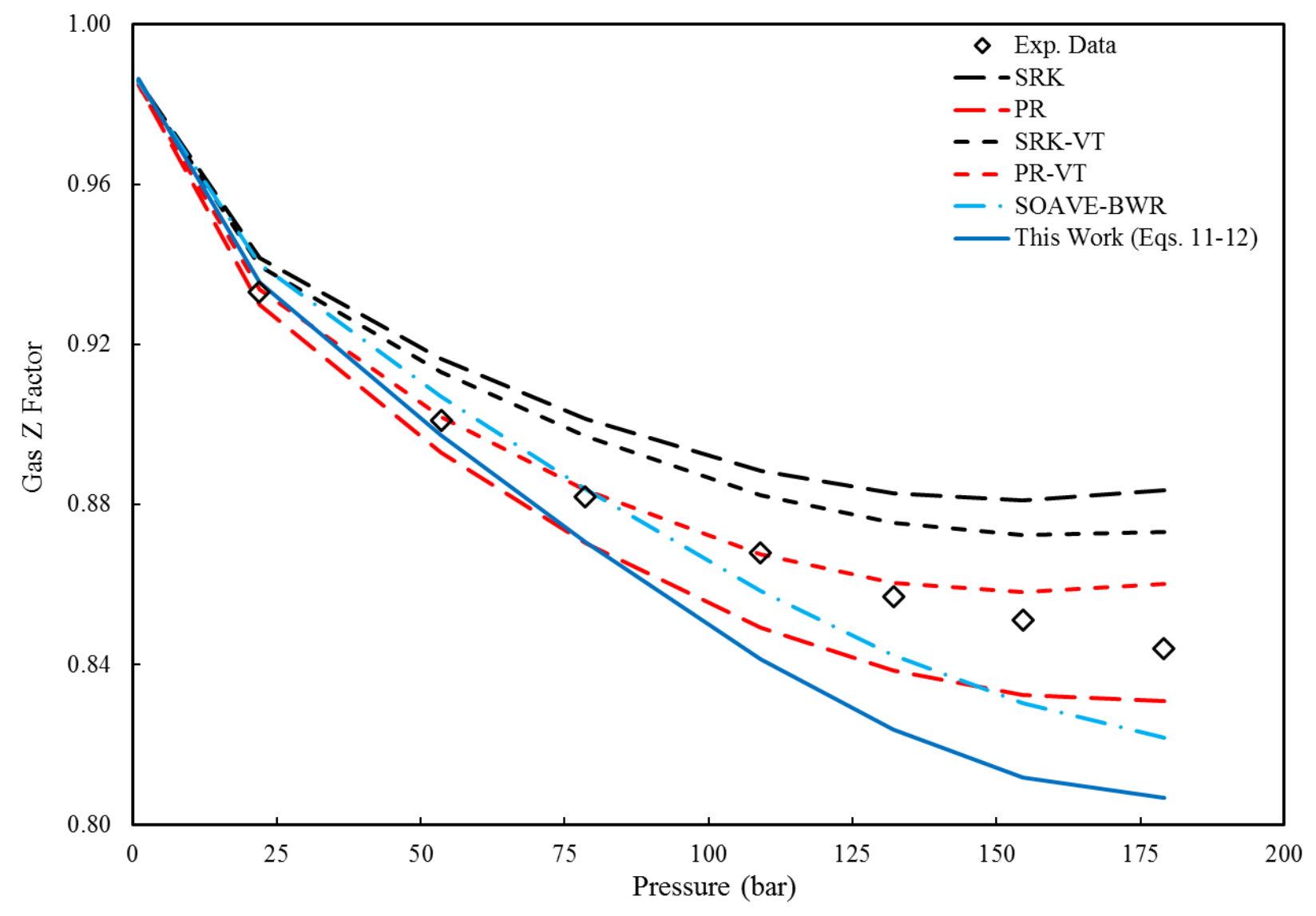

Fig. 8. Gas compressibility factor vs. pressure for the oil mixture from [44] 


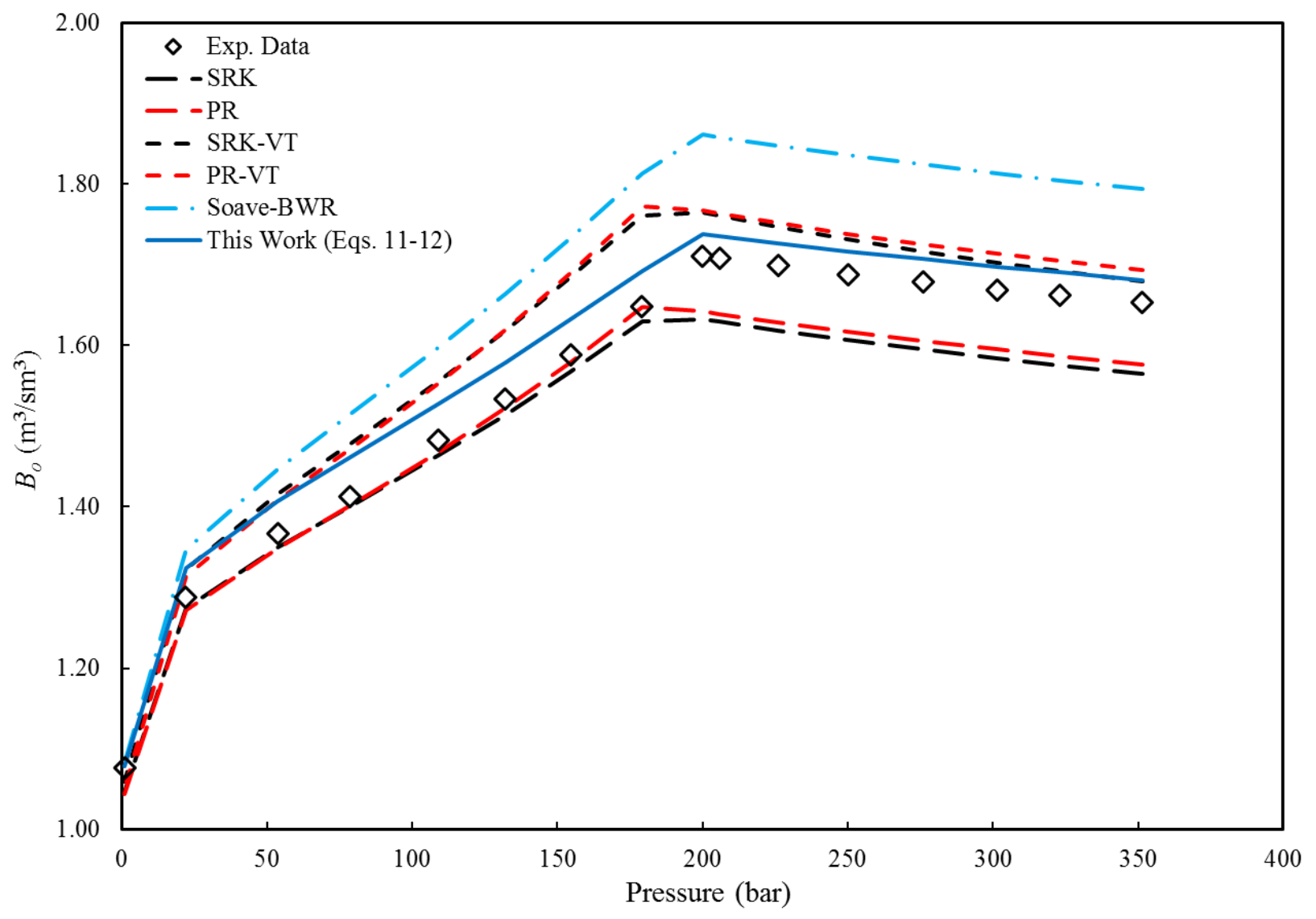

Fig. 9. Oil formation volume factor vs. pressure for the oil mixture from [44] 


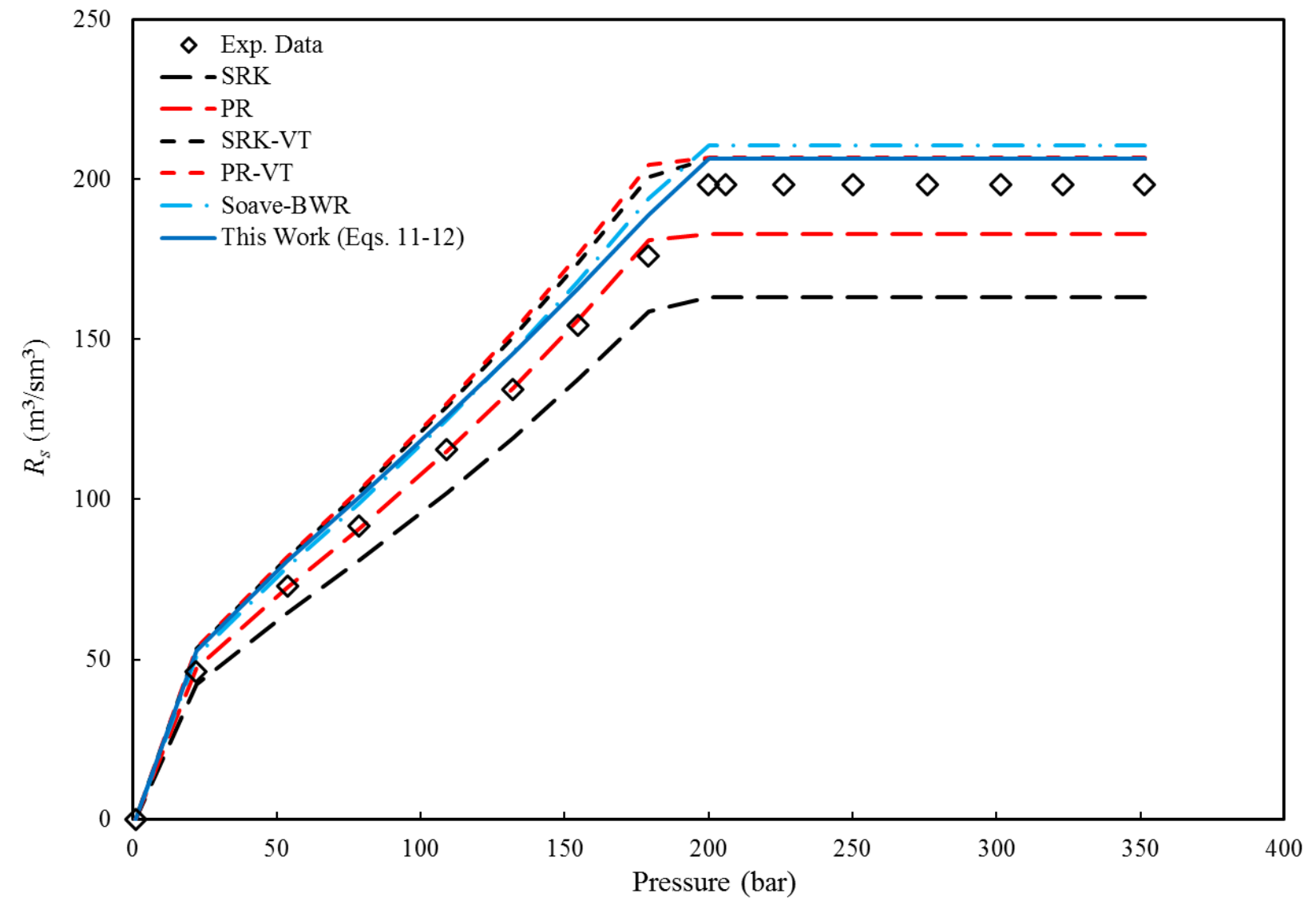

Fig. 10. Solution gas-oil ratio vs. pressure for the oil mixture from [44] 


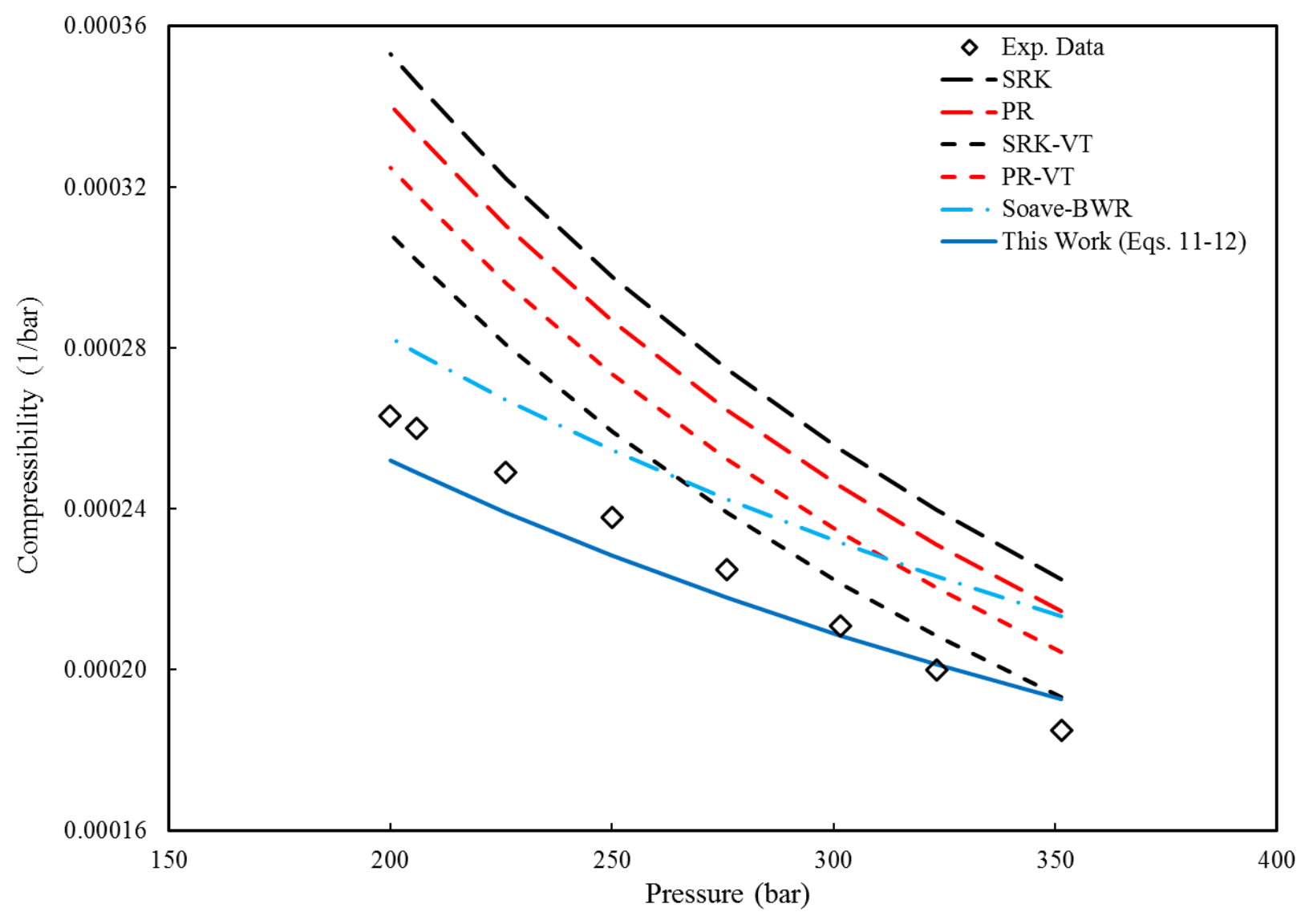

Fig. 11. Oil compressibility vs. pressure for the oil mixture from [44] 


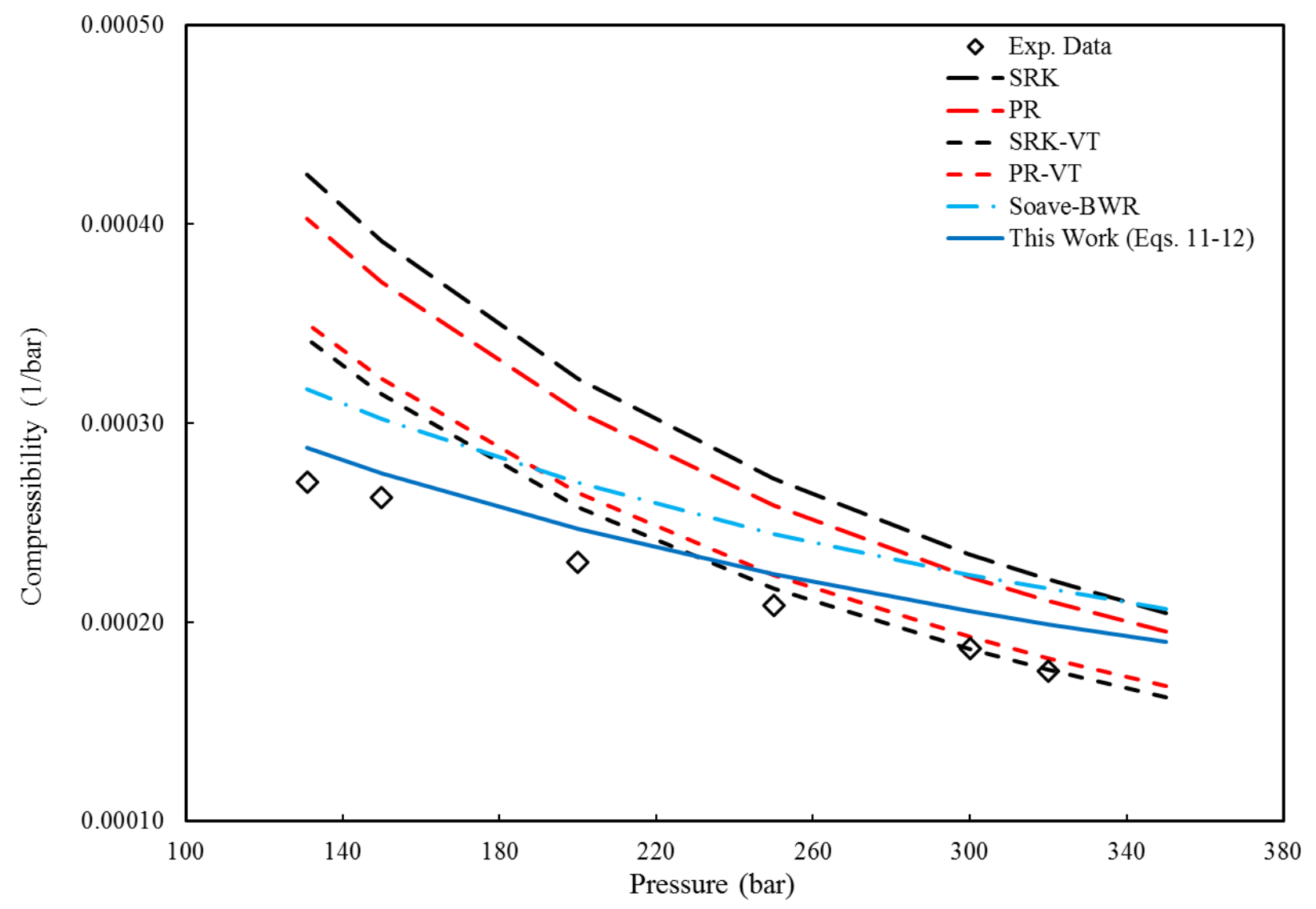

Fig. 12. Oil compressibility vs. pressure for fluid 73 from the database 


\section{Supplementary Information}

Table A1. An overview of the reservoir fluid systems tested

\begin{tabular}{|c|c|c|c|c|c|c|c|c|c|}
\hline Fluid no. & $\% \mathrm{~N}_{2}$ & $\% \mathrm{CO}_{2}$ & $\% \mathrm{C}_{1}$ & $\% \mathrm{C}_{7+}$ & $M W_{7+}$ & $S G_{7+}$ & Type & $T(\mathrm{~K})$ & $P^{s a t}$ (bar) \\
\hline Fluid 1 & 0.34 & 0.84 & 49.23 & 31.45 & 230.34 & 0.8656 & OIL & 366.45 & 274.50 \\
\hline Fluid 2 & 0.00 & 1.81 & 49.83 & 30.53 & 227.66 & 0.8755 & OIL & 337.25 & 289.70 \\
\hline Fluid 3 & 0.08 & 0.27 & 49.71 & 40.22 & 251.22 & 0.8853 & OIL & 337.85 & 270.40 \\
\hline Fluid 4 & 0.00 & 1.43 & 49.97 & 44.04 & 270.86 & 0.8998 & OIL & 337.25 & 282.30 \\
\hline Fluid 5 & 0.01 & 1.38 & 32.10 & 48.21 & 212.22 & 0.8655 & OIL & 346.15 & 133.60 \\
\hline Fluid 6 & 0.02 & 0.96 & 32.03 & 61.38 & 283.46 & 0.9174 & OIL & 333.15 & 137.80 \\
\hline Fluid 7 & 0.18 & 0.82 & 22.92 & 44.00 & 257.71 & 0.8742 & OIL & 374.85 & 96.90 \\
\hline Fluid 8 & 0.00 & 0.20 & 23.64 & 45.80 & 254.44 & 0.8734 & OIL & 372.05 & 117.70 \\
\hline Fluid 9 & 0.00 & 0.45 & 45.85 & 29.02 & 216.04 & 0.8527 & OIL & 387.35 & 255.60 \\
\hline Fluid 10 & 0.00 & 0.35 & 54.26 & 21.27 & 200.91 & 0.8328 & OIL & 388.15 & 320.20 \\
\hline Fluid 11 & 0.38 & 0.45 & 26.58 & 42.72 & 245.43 & 0.8864 & OIL & 394.25 & 145.80 \\
\hline Fluid 12 & 0.00 & 0.00 & 36.20 & 34.40 & 219.98 & 0.8568 & OIL & 383.15 & 172.90 \\
\hline Fluid 13 & 0.00 & 0.00 & 31.28 & 36.78 & 201.48 & 0.8354 & OIL & 393.15 & 153.90 \\
\hline Fluid 14 & 0.00 & 0.08 & 32.16 & 35.47 & 208.07 & 0.8354 & OIL & 393.15 & 153.00 \\
\hline Fluid 15 & 0.00 & 2.25 & 44.66 & 50.45 & 290.30 & 0.9185 & OIL & 322.65 & 232.20 \\
\hline Fluid 16 & 0.13 & 0.09 & 41.32 & 53.81 & 291.72 & 0.9226 & OIL & & 198.70 \\
\hline Fluid 17 & 0.81 & 0.08 & 42.14 & 54.64 & 299.54 & 0.9268 & OIL & 346.05 & 208.70 \\
\hline Fluid 18 & 0.16 & 0.23 & 39.45 & 51.13 & 248.24 & 0.9170 & OIL & 346.15 & 202.30 \\
\hline Fluid 19 & 0.05 & 2.25 & 23.21 & 72.97 & 236.22 & 0.9226 & OIL & 329.75 & 105.10 \\
\hline Fluid 20 & 0.00 & 2.65 & 41.99 & 53.54 & 288.86 & 0.9214 & OIL & 319.55 & 207.10 \\
\hline Fluid 21 & 0.07 & 3.59 & 35.53 & 53.76 & 268.57 & 0.9185 & OIL & 339.85 & 174.80 \\
\hline Fluid 22 & 0.99 & 1.41 & 34.66 & 33.74 & 182.36 & 0.8238 & OIL & 427.60 & 186.23 \\
\hline Fluid 23 & 0.67 & 1.31 & 39.55 & 30.58 & 194.70 & 0.8326 & OIL & 418.10 & 224.30 \\
\hline Fluid 24 & 2.18 & 3.15 & 74.71 & 6.39 & 150.96 & 0.7932 & $\mathrm{GC}$ & $323.15-469.15$ & $375.20-336.70$ \\
\hline Fluid 25 & 0.70 & 2.47 & 63.68 & 12.47 & 162.04 & 0.8036 & $\mathrm{GC}$ & $423.15-455.15$ & $322.31-313.86$ \\
\hline Fluid 26 & 0.81 & 2.42 & 63.45 & 11.13 & 167.74 & 0.8070 & $\mathrm{GC}$ & $423.15-460.15$ & $311.27-303.99$ \\
\hline Fluid 27 & 2.66 & 2.48 & 63.43 & 11.46 & 166.80 & 0.7986 & $\mathrm{GC}$ & $323.15-460.15$ & $299.40-310.60$ \\
\hline Fluid 28 & 1.13 & 0.03 & 27.86 & 68.15 & 343.11 & 0.9400 & OIL & 345.93 & 107.85 \\
\hline Fluid 29 & 0.00 & 4.70 & 38.64 & 53.59 & 276.63 & 0.9268 & OIL & 318.15 & 185.20 \\
\hline Fluid 30 & 0.50 & 0.04 & 21.50 & 56.52 & 317.15 & 0.9195 & OIL & 331.15 & 76.70 \\
\hline Fluid 31 & 0.15 & 0.82 & 32.81 & 65.83 & 350.86 & 0.9747 & OIL & 329.15 & 141.20 \\
\hline Fluid 32 & 2.32 & 0.25 & 47.64 & 25.12 & 212.74 & 0.8298 & OIL & $303.25-417.85$ & $219.20-276.60$ \\
\hline
\end{tabular}




\begin{tabular}{|c|c|c|c|c|c|c|c|c|c|}
\hline Fluid 33 & 0.36 & 0.40 & 47.24 & 27.18 & 214.21 & 0.8451 & OIL & 394.25 & 245.70 \\
\hline Fluid 34 & 0.00 & 0.67 & 46.63 & 28.94 & 217.29 & 0.8568 & OIL & 373.75 & 245.70 \\
\hline Fluid 35 & 1.49 & 0.32 & 45.29 & 25.92 & 222.70 & 0.8590 & OIL & $299.85-394.25$ & $212.40-275.00$ \\
\hline Fluid 36 & 0.08 & 0.27 & 49.71 & 40.23 & 250.15 & 0.8813 & OIL & 337.85 & 270.40 \\
\hline Fluid 37 & 0.24 & 2.10 & 26.13 & 71.43 & 260.97 & 0.8923 & OIL & 318.35 & 90.40 \\
\hline Fluid 38 & 0.09 & 2.28 & 30.08 & 67.33 & 279.08 & 0.9096 & OIL & 318.15 & 108.60 \\
\hline Fluid 39 & 0.12 & 2.08 & 28.46 & 69.09 & 273.23 & 0.9020 & OIL & 317.95 & 94.20 \\
\hline Fluid 40 & 0.10 & 3.84 & 46.77 & 39.98 & 256.08 & 0.8915 & OIL & 331.15 & 259.80 \\
\hline Fluid 41 & 0.07 & 3.85 & 45.46 & 41.67 & 258.79 & 0.8900 & OIL & 331.55 & 239.90 \\
\hline Fluid 42 & 0.38 & 0.14 & 18.79 & 50.59 & 246.49 & 0.8521 & OIL & 362.25 & 72.30 \\
\hline Fluid 43 & 1.64 & 1.95 & 44.40 & 24.50 & 209.50 & 0.8528 & OIL & 377.95 & 276.20 \\
\hline Fluid 44 & 0.01 & 1.37 & 32.09 & 48.21 & 210.39 & 0.8725 & OIL & 346.15 & 133.60 \\
\hline Fluid 45 & 0.01 & 3.87 & 33.36 & 55.95 & 267.64 & 0.9087 & OIL & 339.85 & 155.40 \\
\hline Fluid 46 & 0.23 & 0.05 & 37.62 & 53.43 & 257.79 & 0.9034 & OIL & 342.15 & 156.90 \\
\hline Fluid 47 & 0.00 & 0.18 & 36.35 & 60.22 & 273.53 & 0.9094 & OIL & 335.15 & 142.60 \\
\hline Fluid 48 & 0.00 & 0.14 & 50.21 & 34.33 & 221.50 & 0.8575 & OIL & 344.35 & 267.50 \\
\hline Fluid 49 & 0.17 & 0.08 & 44.72 & 38.18 & 235.17 & 0.8749 & OIL & 335.25 & 219.20 \\
\hline Fluid 50 & 0.23 & 0.16 & 35.13 & 52.20 & 299.31 & 0.8659 & OIL & 318.75 & 119.50 \\
\hline Fluid 51 & 0.10 & 0.09 & 46.95 & 38.08 & 249.18 & 0.8815 & OIL & 338.35 & 260.60 \\
\hline Fluid 52 & 0.32 & 0.97 & 30.18 & 68.14 & 314.82 & 0.9641 & OIL & 329.15 & 143.80 \\
\hline Fluid 53 & 0.00 & 1.81 & 49.83 & 30.53 & 226.51 & 0.8616 & OIL & 337.25 & 289.70 \\
\hline Fluid 54 & 0.00 & 1.43 & 49.97 & 44.05 & 270.11 & 0.9004 & OIL & 337.85 & 282.30 \\
\hline Fluid 55 & 0.07 & 3.81 & 40.24 & 52.58 & 280.56 & 0.9094 & OIL & 331.15 & 210.40 \\
\hline Fluid 56 & 0.24 & 2.54 & 40.82 & 49.53 & 284.34 & 0.9029 & OIL & 323.35 & 235.80 \\
\hline Fluid 57 & 3.57 & 20.78 & 21.99 & 36.53 & 232.93 & 0.8816 & OIL & 401.05 & 233.30 \\
\hline Fluid 58 & 3.82 & 21.24 & 22.99 & 35.00 & 239.23 & 0.8804 & OIL & 401.05 & 251.30 \\
\hline Fluid 59 & 0.00 & 0.20 & 36.34 & 42.31 & 203.78 & 0.8550 & OIL & 347.15 & 149.60 \\
\hline Fluid 60 & 0.00 & 0.45 & 48.76 & 30.15 & 196.37 & 0.8478 & OIL & 358.15 & 264.10 \\
\hline Fluid 61 & 5.50 & 33.53 & 18.58 & 30.73 & 200.38 & 0.8416 & OIL & 409.15 & 276.90 \\
\hline Fluid 62 & 0.43 & 0.06 & 25.25 & 52.97 & 202.39 & 0.8249 & OIL & 395.15 & 103.77 \\
\hline Fluid 63 & 0.04 & 0.06 & 39.89 & 42.76 & 221.79 & 0.8428 & OIL & 323.15 & 150.42 \\
\hline Fluid 64 & 0.10 & 0.56 & 30.65 & 57.97 & 183.89 & 0.8680 & OIL & 334.80 & 123.40 \\
\hline Fluid 65 & 0.55 & 0.15 & 61.24 & 13.04 & 175.74 & 0.8156 & OIL & 347.04 & 338.86 \\
\hline Fluid 66 & 0.25 & 0.01 & 22.56 & 38.31 & 238.00 & 0.9040 & OIL & 341.48 & 96.44 \\
\hline Fluid 67 & 0.19 & 0.00 & 23.10 & 44.43 & 207.00 & 0.8829 & OIL & 341.48 & 96.78 \\
\hline Fluid 68 & 0.07 & 0.02 & 33.27 & 54.95 & 204.06 & 0.8498 & OIL & 323.15 & 113.76 \\
\hline Fluid 69 & 0.24 & 0.02 & 36.88 & 51.77 & 211.46 & 0.8368 & OIL & 325.15 & 116.52 \\
\hline Fluid 70 & 0.65 & 0.14 & 40.77 & 28.01 & 203.82 & 0.8446 & OIL & 335.15 & 182.37 \\
\hline Fluid 71 & 0.02 & 0.05 & 34.21 & 57.61 & 208.21 & 0.8372 & OIL & 321.15 & 122.02 \\
\hline Fluid 72 & 1.22 & 0.01 & 38.36 & 26.42 & 200.00 & 0.8170 & OIL & 344.26 & 181.93 \\
\hline Fluid 73 & 1.11 & 0.08 & 28.50 & 41.06 & 189.39 & 0.8053 & OIL & 384.85 & 131.00 \\
\hline Fluid 74 & 1.17 & 0.05 & 28.65 & 40.86 & 188.76 & 0.8048 & OIL & 384.85 & 132.00 \\
\hline Fluid 75 & 0.97 & 1.46 & 29.78 & 40.79 & 190.80 & 0.8215 & OIL & 378.15 & 148.35 \\
\hline
\end{tabular}




\begin{tabular}{|c|c|c|c|c|c|c|c|c|c|}
\hline Fluid 76 & 0.96 & 0.18 & 27.56 & 41.10 & 187.77 & 0.8218 & OIL & 382.04 & 134.08 \\
\hline Fluid 77 & 0.00 & 2.35 & 47.22 & 38.15 & 216.82 & 0.8381 & OIL & 355.37 & 247.29 \\
\hline Fluid 78 & 0.00 & 0.00 & 28.07 & 60.69 & 192.00 & 0.8400 & OIL & 319.26 & 103.40 \\
\hline Fluid 79 & 0.26 & 8.95 & 43.32 & 26.93 & 224.49 & 0.8448 & OIL & 359.26 & 268.39 \\
\hline Fluid 80 & 0.15 & 2.04 & 44.59 & 39.17 & 206.00 & 0.8410 & OIL & 353.15 & 218.82 \\
\hline Fluid 81 & 0.11 & 3.35 & 43.44 & 34.55 & 191.00 & 0.8380 & OIL & 349.82 & 214.82 \\
\hline Fluid 82 & 0.14 & 0.00 & 35.85 & 62.51 & 226.98 & 0.8719 & OIL & 328.15 & 141.87 \\
\hline Fluid 83 & 0.29 & 1.70 & 45.39 & 40.04 & 211.00 & 0.8400 & OIL & 352.04 & 223.78 \\
\hline Fluid 84 & 0.19 & 1.82 & 42.39 & 44.01 & 205.00 & 0.8365 & OIL & 350.93 & 209.30 \\
\hline Fluid 85 & 0.21 & 1.88 & 44.80 & 42.28 & 208.00 & 0.8430 & OIL & 350.93 & 216.41 \\
\hline Fluid 86 & 0.10 & 5.58 & 42.64 & 31.63 & 178.00 & 0.8290 & OIL & 347.59 & 242.74 \\
\hline Fluid 87 & 0.13 & 5.13 & 42.47 & 33.69 & 186.00 & 0.8330 & OIL & 347.59 & 232.68 \\
\hline Fluid 88 & 0.62 & 0.16 & 26.67 & 51.15 & 195.67 & 0.8295 & OIL & 398.15 & 116.57 \\
\hline Fluid 89 & 0.21 & 5.01 & 45.97 & 25.89 & 182.56 & 0.8202 & OIL & 357.04 & 273.77 \\
\hline Fluid 90 & 0.20 & 6.51 & 44.14 & 27.38 & 220.00 & 0.8429 & OIL & 359.15 & 257.08 \\
\hline Fluid 91 & 4.94 & 0.82 & 42.41 & 37.63 & 228.41 & 0.8589 & OIL & 389.82 & 296.82 \\
\hline Fluid 92 & 4.14 & 0.12 & 42.81 & 31.23 & 226.24 & 0.8665 & OIL & 381.48 & 274.83 \\
\hline Fluid 93 & 3.64 & 1.17 & 38.42 & 32.74 & 201.20 & 0.8496 & OIL & 403.15 & 251.11 \\
\hline Fluid 94 & 3.06 & 0.23 & 36.02 & 32.39 & 181.76 & 0.8220 & OIL & 377.59 & 194.36 \\
\hline Fluid 95 & 1.42 & 0.07 & 9.59 & 41.89 & 156.99 & 0.7840 & OIL & 364.82 & 49.16 \\
\hline Fluid 96 & 1.94 & 1.11 & 10.95 & 44.76 & 154.00 & 0.7970 & OIL & 394.26 & 80.92 \\
\hline Fluid 97 & 1.69 & 0.03 & 7.50 & 75.15 & 229.43 & 0.8299 & OIL & 359.26 & 34.11 \\
\hline Fluid 98 & 7.18 & 0.68 & 40.28 & 27.00 & 169.45 & 0.8145 & OIL & 398.71 & 266.83 \\
\hline Fluid 99 & 1.89 & 2.26 & 35.79 & 25.20 & 168.00 & 0.7916 & OIL & 439.26 & 198.20 \\
\hline Fluid 100 & 7.37 & 2.51 & 51.58 & 15.05 & 164.97 & 0.8108 & OIL & 382.04 & 379.21 \\
\hline Fluid 101 & 5.82 & 0.47 & 42.24 & 30.52 & 195.89 & 0.8366 & OIL & 402.04 & 293.72 \\
\hline Fluid 102 & 0.26 & 0.01 & 2.26 & 44.19 & 168.40 & 0.7916 & OIL & 372.59 & 15.10 \\
\hline Fluid 103 & 6.16 & 0.83 & 28.88 & 39.94 & 184.63 & 0.8247 & OIL & 399.82 & 196.82 \\
\hline Fluid 104 & 4.94 & 0.31 & 35.60 & 27.99 & 179.80 & 0.8376 & OIL & 386.48 & 215.19 \\
\hline Fluid 105 & 2.10 & 0.03 & 20.18 & 36.43 & 139.91 & 0.7859 & OIL & 369.82 & 101.35 \\
\hline Fluid 106 & 2.54 & 0.57 & 38.96 & 32.71 & 206.00 & 0.8540 & OIL & 395.93 & 230.26 \\
\hline Fluid 107 & 3.72 & 2.94 & 48.69 & 17.95 & 169.50 & 0.8220 & OIL & 402.59 & 296.20 \\
\hline Fluid 108 & 3.22 & 0.95 & 39.02 & 28.11 & 195.26 & 0.8509 & OIL & 383.15 & 244.05 \\
\hline Fluid 109 & 2.39 & 0.13 & 43.63 & 17.54 & 145.76 & 0.7949 & OIL & 377.59 & 232.15 \\
\hline Fluid 110 & 4.89 & 0.26 & 32.40 & 34.52 & 185.74 & 0.8307 & OIL & 390.37 & 210.61 \\
\hline Fluid 111 & 6.88 & 0.13 & 40.06 & 27.97 & 179.26 & 0.8217 & OIL & 409.82 & 284.75 \\
\hline Fluid 112 & 3.50 & 0.46 & 49.96 & 20.19 & 188.15 & 0.8082 & OIL & 407.59 & 326.12 \\
\hline Fluid 113 & 2.00 & 0.08 & 10.81 & 58.57 & 198.30 & 0.8430 & OIL & 382.04 & 63.29 \\
\hline Fluid 114 & 3.35 & 0.32 & 42.55 & 23.66 & 195.75 & 0.8364 & OIL & 405.37 & 257.17 \\
\hline Fluid 115 & 8.46 & 7.19 & 36.77 & 13.24 & 126.06 & 0.7845 & OIL & 413.15 & 201.86 \\
\hline Fluid 116 & 3.44 & 0.04 & 37.89 & 20.96 & 133.49 & 0.7792 & OIL & 379.82 & 182.02 \\
\hline Fluid 117 & 7.71 & 0.97 & 37.93 & 16.16 & 178.67 & 0.8149 & OIL & 392.04 & 230.68 \\
\hline Fluid 118 & 1.64 & 0.54 & 23.24 & 38.18 & 190.96 & 0.8327 & OIL & 385.93 & 123.42 \\
\hline
\end{tabular}




\begin{tabular}{|c|c|c|c|c|c|c|c|c|c|}
\hline Fluid 119 & 4.86 & 0.54 & 44.64 & 21.65 & 176.31 & 0.8205 & OIL & 414.26 & 272.94 \\
\hline Fluid 120 & 7.26 & 0.48 & 34.38 & 29.21 & 166.40 & 0.8007 & OIL & 402.04 & 191.40 \\
\hline Fluid 121 & 3.16 & 0.21 & 22.75 & 26.91 & 160.30 & 0.7899 & OIL & 377.59 & 119.42 \\
\hline Fluid 122 & 5.82 & 0.46 & 41.55 & 31.39 & 204.00 & 0.8545 & OIL & 393.15 & 284.18 \\
\hline Fluid 123 & 6.60 & 0.09 & 16.61 & 59.73 & 233.07 & 0.8433 & OIL & 360.93 & 128.91 \\
\hline Fluid 124 & 2.55 & 0.02 & 13.50 & 32.32 & 157.60 & 0.7850 & OIL & 372.04 & 76.12 \\
\hline Fluid 125 & 0.28 & 0.06 & 33.29 & 41.32 & 208.00 & 0.8349 & OIL & 316.48 & 119.88 \\
\hline Fluid 126 & 3.85 & 2.67 & 46.45 & 26.34 & 196.83 & 0.8365 & OIL & 397.04 & 294.87 \\
\hline Fluid 127 & 9.06 & 0.61 & 42.73 & 29.12 & 153.93 & 0.7993 & OIL & 395.37 & 248.21 \\
\hline Fluid 128 & 4.42 & 0.04 & 44.15 & 14.23 & 154.10 & 0.7866 & OIL & 379.82 & 222.63 \\
\hline Fluid 129 & 4.25 & 0.00 & 37.92 & 25.28 & 126.95 & 0.7692 & OIL & 390.37 & 195.47 \\
\hline Fluid 130 & 0.83 & 0.02 & 18.16 & 55.79 & 256.00 & 0.8801 & OIL & 309.82 & 63.69 \\
\hline Fluid 131 & 3.11 & 0.04 & 17.11 & 29.53 & 156.50 & 0.7842 & OIL & 372.04 & 88.46 \\
\hline Fluid 132 & 4.61 & 0.70 & 22.69 & 38.22 & 165.64 & 0.8022 & OIL & 399.82 & 133.39 \\
\hline Fluid 133 & 2.15 & 0.22 & 24.77 & 45.17 & 196.02 & 0.8381 & OIL & 409.26 & 132.98 \\
\hline Fluid 134 & 4.95 & 0.52 & 43.21 & 21.31 & 165.75 & 0.8128 & OIL & 400.93 & 246.47 \\
\hline Fluid 135 & 3.73 & 0.00 & 41.47 & 28.00 & 213.81 & 0.8490 & OIL & 401.48 & 263.72 \\
\hline Fluid 136 & 4.66 & 2.10 & 29.26 & 31.67 & 149.98 & 0.7967 & OIL & 394.26 & 189.61 \\
\hline Fluid 137 & 8.28 & 1.02 & 48.69 & 18.57 & 175.09 & 0.8150 & OIL & 397.04 & 296.34 \\
\hline Fluid 138 & 3.19 & 7.13 & 51.17 & 14.54 & 157.07 & 0.8065 & OIL & 401.48 & 305.07 \\
\hline Fluid 139 & 5.53 & 3.50 & 30.92 & 34.38 & 181.70 & 0.8239 & OIL & 417.59 & 205.93 \\
\hline Fluid 140 & 3.60 & 0.92 & 45.33 & 21.18 & 179.92 & 0.8269 & OIL & 395.37 & 292.34 \\
\hline Fluid 141 & 4.88 & 1.86 & 40.34 & 27.79 & 199.25 & 0.8361 & OIL & 404.26 & 298.66 \\
\hline Fluid 142 & 5.31 & 0.85 & 45.91 & 18.94 & 170.00 & 0.8090 & OIL & 400.37 & 247.50 \\
\hline Fluid 143 & 0.30 & 0.67 & 24.44 & 46.59 & 240.00 & 0.8703 & OIL & 300.93 & 80.23 \\
\hline Fluid 144 & 2.75 & 0.10 & 32.00 & 30.91 & 128.29 & 0.7724 & OIL & 382.04 & 156.51 \\
\hline Fluid 145 & 4.38 & 0.24 & 39.08 & 30.21 & 183.20 & 0.8411 & OIL & 397.59 & 257.59 \\
\hline Fluid 146 & 4.51 & 0.74 & 50.88 & 16.32 & 172.50 & 0.8264 & OIL & 395.93 & 316.75 \\
\hline Fluid 147 & 4.31 & 0.13 & 19.61 & 59.33 & 227.12 & 0.8369 & OIL & 342.59 & 109.81 \\
\hline Fluid 148 & 0.69 & 2.75 & 35.24 & 26.33 & 182.78 & 0.8300 & OIL & 384.00 & 200.64 \\
\hline Fluid 149 & 3.37 & 3.73 & 54.29 & 14.78 & 145.93 & 0.7926 & OIL & 397.59 & 299.92 \\
\hline Fluid 150 & 14.89 & 0.18 & 34.99 & 27.79 & 200.80 & 0.8567 & OIL & 378.15 & 427.96 \\
\hline Fluid 151 & 4.55 & 0.00 & 16.31 & 45.31 & 213.00 & 0.8711 & OIL & 375.37 & 114.11 \\
\hline Fluid 152 & 8.22 & 0.71 & 15.43 & 46.64 & 199.00 & 0.8540 & OIL & 398.71 & 164.01 \\
\hline Fluid 153 & 7.11 & 0.63 & 45.99 & 16.79 & 143.00 & 0.7920 & OIL & 391.48 & 239.57 \\
\hline Fluid 154 & 3.61 & 1.04 & 39.27 & 23.14 & 203.78 & 0.8501 & OIL & 388.00 & 244.97 \\
\hline Fluid 155 & 3.59 & 1.63 & 49.97 & 22.57 & 196.79 & 0.8259 & OIL & 388.71 & 304.06 \\
\hline Fluid 156 & 5.84 & 0.43 & 12.03 & 53.74 & 198.87 & 0.8324 & OIL & 405.37 & 120.98 \\
\hline Fluid 157 & 5.05 & 0.28 & 36.83 & 25.92 & 126.91 & 0.7704 & OIL & 406.00 & 210.98 \\
\hline Fluid 158 & 4.79 & 1.09 & 46.91 & 24.66 & 161.78 & 0.8068 & OIL & 395.00 & 269.59 \\
\hline Fluid 159 & 5.03 & 0.33 & 38.11 & 33.94 & 195.00 & 0.8520 & OIL & 400.93 & 260.46 \\
\hline Fluid 160 & 5.25 & 0.17 & 41.63 & 33.99 & 218.87 & 0.8579 & OIL & 391.48 & 298.18 \\
\hline Fluid 161 & 2.47 & 0.22 & 22.93 & 49.67 & 122.76 & 0.7597 & OIL & 405.37 & 115.47 \\
\hline
\end{tabular}




\begin{tabular}{|c|c|c|c|c|c|c|c|c|c|}
\hline Fluid 162 & 0.23 & 0.63 & 36.24 & 52.77 & 300.00 & 0.9243 & OIL & 344.82 & 160.56 \\
\hline Fluid 163 & 0.77 & 0.11 & 47.34 & 33.64 & 214.89 & 0.8442 & OIL & 345.95 & 243.00 \\
\hline Fluid 164 & 0.69 & 0.12 & 47.06 & 33.86 & 213.64 & 0.8436 & OIL & 345.95 & 238.00 \\
\hline Fluid 165 & 0.16 & 0.91 & 36.47 & 33.29 & 218.00 & 0.8515 & OIL & 377.60 & 181.70 \\
\hline Fluid 166 & 0.60 & 0.14 & 39.21 & 35.73 & 247.40 & 0.8900 & OIL & 335.93 & 188.57 \\
\hline Fluid 167 & 0.36 & 0.17 & 27.23 & 42.38 & 271.00 & 0.8790 & OIL & 327.59 & 94.11 \\
\hline Fluid 168 & 0.29 & 0.48 & 28.36 & 42.31 & 252.00 & 0.8800 & OIL & 329.26 & 112.52 \\
\hline Fluid 169 & 0.33 & 0.22 & 25.56 & 46.01 & 222.00 & 0.8780 & OIL & 329.26 & 109.97 \\
\hline Fluid 170 & 0.35 & 0.47 & 26.52 & 46.57 & 253.00 & 0.8920 & OIL & 330.37 & 103.42 \\
\hline Fluid 171 & 0.12 & 0.51 & 28.81 & 47.70 & 250.00 & 0.8760 & OIL & 329.82 & 111.35 \\
\hline Fluid 172 & 0.16 & 0.30 & 24.66 & 49.61 & 239.00 & 0.8750 & OIL & 329.82 & 96.53 \\
\hline Fluid 173 & 0.21 & 0.15 & 27.77 & 49.94 & 228.00 & 0.8630 & OIL & 329.82 & 109.63 \\
\hline Fluid 174 & 0.11 & 0.28 & 27.53 & 48.90 & 245.00 & 0.8790 & OIL & 330.37 & 106.18 \\
\hline Fluid 175 & 0.79 & 0.10 & 24.79 & 47.85 & 227.00 & 0.8840 & OIL & 329.82 & 96.46 \\
\hline Fluid 176 & 0.04 & 0.17 & 31.22 & 50.44 & 264.00 & 0.8890 & OIL & 330.37 & 116.52 \\
\hline Fluid 177 & 0.00 & 0.17 & 28.56 & 44.68 & 249.00 & 0.8620 & OIL & 329.82 & 106.73 \\
\hline Fluid 178 & 0.45 & 0.08 & 29.35 & 39.62 & 227.00 & 0.8630 & OIL & 329.82 & 117.56 \\
\hline Fluid 179 & 0.56 & 0.07 & 29.90 & 43.10 & 242.00 & 0.8770 & OIL & 329.26 & 113.97 \\
\hline Fluid 180 & 0.03 & 0.30 & 27.80 & 44.88 & 254.00 & 0.8800 & OIL & 329.82 & 113.42 \\
\hline Fluid 181 & 0.06 & 0.81 & 31.34 & 47.60 & 270.00 & 0.8920 & OIL & 328.71 & 120.73 \\
\hline Fluid 182 & 0.00 & 0.15 & 19.50 & 51.22 & 225.00 & 0.8490 & OIL & 328.71 & 70.67 \\
\hline Fluid 183 & 0.15 & 0.19 & 31.15 & 40.32 & 221.00 & 0.8480 & OIL & 330.37 & 113.76 \\
\hline Fluid 184 & 0.50 & 0.87 & 29.72 & 45.99 & 271.00 & 0.8820 & OIL & 329.82 & 112.66 \\
\hline Fluid 185 & 0.68 & 1.02 & 25.49 & 46.03 & 264.00 & 0.9020 & OIL & 329.82 & 105.70 \\
\hline Fluid 186 & 0.22 & 1.37 & 27.92 & 52.13 & 255.00 & 0.8930 & OIL & 330.37 & 106.73 \\
\hline Fluid 187 & 0.20 & 1.23 & 26.54 & 49.22 & 290.00 & 0.9100 & OIL & 328.71 & 110.11 \\
\hline Fluid 188 & 0.44 & 0.83 & 27.75 & 45.72 & 272.00 & 0.9020 & OIL & 329.26 & 107.90 \\
\hline Fluid 189 & 0.14 & 0.54 & 29.44 & 44.68 & 290.00 & 0.9010 & OIL & 329.82 & 108.94 \\
\hline Fluid 190 & 0.26 & 1.26 & 28.27 & 47.50 & 274.00 & 0.9080 & OIL & 329.82 & 115.83 \\
\hline Fluid 191 & 0.20 & 0.80 & 31.42 & 44.91 & 251.00 & 0.8890 & OIL & 328.71 & 119.83 \\
\hline Fluid 192 & 0.54 & 0.50 & 27.79 & 46.70 & 214.00 & 0.8870 & OIL & 329.26 & 114.11 \\
\hline Fluid 193 & 0.41 & 0.65 & 30.21 & 40.47 & 247.00 & 0.8750 & OIL & 330.37 & 129.62 \\
\hline Fluid 194 & 0.20 & 1.19 & 32.26 & 42.16 & 134.00 & 0.8790 & OIL & 329.26 & 123.28 \\
\hline Fluid 195 & 0.10 & 1.16 & 32.93 & 41.62 & 279.00 & 0.8790 & OIL & 329.26 & 124.45 \\
\hline Fluid 196 & 0.15 & 0.65 & 30.48 & 49.54 & 239.00 & 0.8660 & OIL & 327.59 & 115.14 \\
\hline Fluid 197 & 0.45 & 0.51 & 30.56 & 41.10 & 268.00 & 0.8920 & OIL & 330.37 & 119.62 \\
\hline Fluid 198 & 0.23 & 1.06 & 24.75 & 46.12 & 256.00 & 0.9050 & OIL & 329.82 & 105.49 \\
\hline Fluid 199 & 0.19 & 0.12 & 28.62 & 44.78 & 274.00 & 0.9250 & OIL & 330.37 & 121.76 \\
\hline Fluid 200 & 0.08 & 1.37 & 35.97 & 39.71 & 274.00 & 0.8980 & OIL & 348.71 & 172.71 \\
\hline Fluid 201 & 0.13 & 1.45 & 36.02 & 37.30 & 230.10 & 0.8960 & OIL & 347.59 & 198.09 \\
\hline Fluid 202 & 0.00 & 1.12 & 26.95 & 40.81 & 249.00 & 0.8760 & OIL & 370.93 & 129.41 \\
\hline Fluid 203 & 0.00 & 1.25 & 33.35 & 43.29 & 252.00 & 0.8510 & OIL & 383.15 & 145.48 \\
\hline Fluid 204 & 0.05 & 0.85 & 41.05 & 29.01 & 198.00 & 0.8480 & OIL & 389.26 & 229.94 \\
\hline
\end{tabular}




\begin{tabular}{|c|c|c|c|c|c|c|c|c|c|}
\hline Fluid 205 & 0.06 & 0.94 & 44.44 & 28.38 & 195.00 & 0.8460 & OIL & 388.71 & 250.28 \\
\hline Fluid 206 & 0.04 & 0.78 & 40.91 & 31.34 & 202.00 & 0.8450 & OIL & 389.26 & 215.12 \\
\hline Fluid 207 & 0.06 & 0.85 & 40.70 & 31.36 & 195.00 & 0.8470 & OIL & 390.37 & 219.25 \\
\hline Fluid 208 & 0.03 & 0.97 & 41.64 & 29.08 & 208.00 & 0.8500 & OIL & 389.26 & 211.60 \\
\hline Fluid 209 & 0.03 & 1.04 & 41.88 & 29.07 & 200.00 & 0.8480 & OIL & 385.93 & 222.98 \\
\hline Fluid 210 & 0.02 & 0.99 & 38.78 & 33.37 & 210.00 & 0.8490 & OIL & 388.71 & 208.15 \\
\hline Fluid 211 & 0.24 & 0.39 & 5.82 & 83.21 & 304.00 & 0.9420 & OIL & 344.26 & 21.58 \\
\hline Fluid 212 & 0.06 & 5.01 & 23.03 & 38.82 & 254.00 & 0.8770 & OIL & 365.37 & 139.35 \\
\hline Fluid 213 & 0.10 & 1.32 & 8.86 & 68.67 & 243.00 & 0.9340 & OIL & 354.26 & 46.68 \\
\hline Fluid 214 & 0.11 & 2.35 & 35.21 & 34.97 & 213.00 & 0.8410 & OIL & 394.26 & 175.61 \\
\hline Fluid 215 & 0.30 & 0.90 & 53.47 & 16.92 & 173.00 & 0.8360 & OIL & 353.15 & 307.51 \\
\hline Fluid 216 & 0.45 & 0.44 & 35.05 & 48.24 & 225.00 & 0.9000 & OIL & 355.37 & 173.75 \\
\hline Fluid 217 & 0.55 & 1.02 & 36.25 & 30.25 & 200.00 & 0.8370 & OIL & 385.37 & 189.33 \\
\hline Fluid 218 & 1.64 & 0.08 & 28.40 & 35.97 & 252.00 & 0.8430 & OIL & 328.15 & 116.80 \\
\hline Fluid 219 & 0.00 & 0.00 & 52.00 & 36.84 & 199.00 & 0.8410 & OIL & 366.48 & 264.69 \\
\hline Fluid 220 & 0.25 & 0.24 & 40.91 & 28.58 & 182.00 & 0.8000 & OIL & 422.04 & 209.81 \\
\hline Fluid 221 & 1.67 & 2.18 & 60.51 & 16.29 & 181.00 & 0.7890 & OIL & 392.04 & 332.53 \\
\hline Fluid 222 & 0.16 & 0.91 & 36.47 & 33.29 & 218.00 & 0.8520 & OIL & 377.59 & 180.64 \\
\hline Fluid 223 & 0.00 & 0.00 & 57.52 & 19.11 & 203.00 & 0.8100 & OIL & 373.15 & 349.22 \\
\hline Fluid 224 & 0.56 & 3.55 & 45.33 & 36.11 & 253.00 & 0.8360 & OIL & 365.93 & 267.86 \\
\hline Fluid 225 & 1.64 & 0.08 & 28.40 & 35.97 & 252.00 & 0.8430 & OIL & 328.15 & 117.76 \\
\hline Fluid 226 & 0.40 & 1.00 & 45.40 & 45.08 & 250.00 & 0.8880 & OIL & 344.26 & 238.97 \\
\hline Fluid 227 & 0.67 & 2.11 & 34.93 & 35.15 & 230.00 & 0.8550 & OIL & 387.59 & 187.81 \\
\hline Fluid 228 & 0.34 & 0.84 & 49.23 & 31.45 & 230.00 & 0.8650 & OIL & 366.48 & 274.48 \\
\hline Fluid 229 & 0.44 & 0.38 & 49.10 & 28.00 & 231.00 & 0.8360 & OIL & 365.93 & 257.79 \\
\hline Fluid 230 & 0.90 & 0.16 & 47.12 & 33.00 & 217.00 & 0.8500 & OIL & 347.59 & 234.01 \\
\hline Fluid 231 & 0.36 & 1.06 & 50.50 & 39.00 & 291.00 & 0.9010 & OIL & 342.04 & 254.42 \\
\hline Fluid 232 & 0.33 & 0.19 & 35.42 & 57.73 & 255.00 & 0.9170 & OIL & 343.71 & 159.06 \\
\hline Fluid 233 & 0.41 & 0.44 & 40.23 & 31.23 & 210.00 & 0.8450 & OIL & 370.93 & 198.98 \\
\hline Fluid 234 & 0.25 & 2.19 & 16.33 & 52.27 & 249.00 & 0.8800 & OIL & 374.82 & 86.94 \\
\hline Fluid 235 & 0.32 & 3.69 & 21.55 & 43.41 & 243.00 & 0.8690 & OIL & 388.15 & 109.70 \\
\hline Fluid 236 & 0.21 & 0.75 & 6.05 & 64.81 & 231.00 & 0.8570 & OIL & 337.59 & 24.27 \\
\hline Fluid 237 & 0.88 & 1.34 & 5.63 & 67.03 & 224.00 & 0.8550 & OIL & 326.48 & 25.92 \\
\hline Fluid 238 & 0.30 & 0.01 & 7.14 & 67.15 & 233.00 & 0.8600 & OIL & 333.15 & 25.79 \\
\hline Fluid 239 & 0.31 & 0.28 & 6.80 & 66.76 & 237.00 & 0.8580 & OIL & 335.37 & 25.79 \\
\hline Fluid 240 & 0.33 & 0.35 & 6.72 & 71.06 & 225.00 & 0.8580 & OIL & 332.04 & 24.82 \\
\hline Fluid 241 & 0.41 & 0.26 & 6.14 & 69.51 & 225.00 & 0.8600 & OIL & 329.82 & 23.86 \\
\hline Fluid 242 & 0.53 & 0.12 & 22.80 & 46.04 & 242.00 & 0.8640 & OIL & 342.04 & 91.36 \\
\hline Fluid 243 & 0.78 & 0.10 & 20.64 & 47.67 & 237.00 & 0.8570 & OIL & 342.59 & 83.36 \\
\hline Fluid 244 & 0.60 & 0.12 & 23.71 & 44.81 & 238.00 & 0.8680 & OIL & 342.04 & 95.56 \\
\hline Fluid 245 & 1.13 & 0.13 & 25.45 & 41.02 & 237.00 & 0.8510 & OIL & 342.59 & 99.70 \\
\hline Fluid 246 & 0.54 & 0.18 & 21.62 & 47.54 & 236.00 & 0.8630 & OIL & 342.04 & 86.67 \\
\hline Fluid 247 & 1.39 & 0.28 & 21.32 & 47.03 & 257.00 & 0.8700 & OIL & 342.04 & 84.12 \\
\hline
\end{tabular}




\begin{tabular}{cccccccccc} 
Fluid 248 & 0.68 & 0.16 & 22.84 & 47.90 & 226.00 & 0.8640 & OIL & 342.04 & 97.01 \\
Fluid 249 & 0.39 & 0.14 & 21.40 & 50.39 & 245.00 & 0.8420 & OIL & 338.15 & 77.50 \\
Fluid 250 & 1.02 & 0.12 & 19.76 & 54.66 & 247.00 & 0.8500 & OIL & 344.54 & 79.43 \\
Fluid 251 & 1.67 & 1.38 & 26.68 & 40.41 & 217.00 & 0.8550 & OIL & 372.04 & 134.72 \\
Fluid 252 & 0.65 & 0.02 & 45.02 & 22.44 & 184.00 & 0.8100 & OIL & 333.15 & 206.98 \\
Fluid 253 & 0.00 & 0.00 & 46.79 & 26.41 & 158.00 & 0.7660 & OIL & 373.15 & 202.77 \\
Fluid 254 & 0.00 & 0.00 & 36.15 & 27.79 & 191.00 & 0.7720 & OIL & 373.15 & 154.30 \\
Fluid 255 & 0.00 & 0.00 & 74.18 & 10.72 & 159.00 & 0.7660 & GC & 373.15 & 327.71 \\
Fluid 256 & 0.00 & 0.00 & 73.48 & 11.20 & 161.00 & 0.7670 & GC & 373.15 & 326.95 \\
Fluid 257 & 0.33 & 3.03 & 41.33 & 33.69 & 200.00 & 0.8480 & OIL & 366.48 & 220.63 \\
Fluid 258 & 0.31 & 0.69 & 47.69 & 34.64 & 234.00 & 0.8690 & OIL & 384.26 & 262.00 \\
Fluid 259 & 0.03 & 8.39 & 47.43 & 18.61 & 180.00 & 0.8300 & OIL & 419.26 & 275.79 \\
Fluid 260 & 0.38 & 7.03 & 48.73 & 20.26 & 181.00 & 0.8050 & OIL & 427.04 & 286.55 \\
\hline Min & 0.00 & 0.00 & 2.26 & 6.39 & 122.76 & 0.7597 & - & 299.85 & 15.10 \\
Max & 14.89 & 33.53 & 74.71 & 83.21 & 350.86 & 0.9747 & - & 469.15 & 427.96 \\
\hline
\end{tabular}


Table A2. Summary of AAD\% in predicted saturation pressures, reservoir fluid densities and stock tank oil densities (PC-SAFT Yan et al. [24])

\begin{tabular}{|c|c|c|c|c|c|c|c|c|c|c|c|c|}
\hline \multirow[b]{2}{*}{ Fluid no. } & \multicolumn{4}{|c|}{ Saturation Pressure } & \multicolumn{4}{|c|}{ Density } & \multicolumn{4}{|c|}{ Stock Tank Oil Density } \\
\hline & SRK & PR & PC-SAFT & SBWR & SRK & PR & PC-SAFT & SBWR & SRK & PR & PC-SAFT & SBWR \\
\hline Fluid 1 & 3.47 & 5.88 & 6.15 & 8.59 & 13.03 & 3.00 & 2.56 & 2.54 & 18.55 & 8.89 & 0.36 & 5.66 \\
\hline Fluid 2 & 7.54 & 10.42 & 0.11 & 7.15 & 13.26 & 3.14 & 1.14 & 3.31 & - & - & - & - \\
\hline Fluid 3 & 5.13 & 8.28 & 0.54 & 6.25 & 13.96 & 3.94 & 1.65 & 4.58 & - & - & - & - \\
\hline Fluid 4 & 4.02 & 7.80 & 2.08 & 8.57 & 13.75 & 3.76 & 1.39 & 6.35 & - & - & - & - \\
\hline Fluid 5 & 3.21 & 1.31 & 0.14 & 1.93 & 13.16 & 2.73 & 1.41 & 4.26 & - & - & - & - \\
\hline Fluid 6 & 4.09 & 0.14 & 3.14 & 11.90 & 11.88 & 1.58 & 2.44 & 11.06 & - & - & - & - \\
\hline Fluid 7 & 0.49 & 2.18 & 6.03 & 5.53 & 18.97 & 9.58 & 3.18 & 3.43 & 20.11 & 10.70 & 0.78 & 4.24 \\
\hline Fluid 8 & 14.84 & 16.25 & 1.88 & 10.48 & 16.52 & 6.85 & 0.37 & 0.57 & - & - & - & - \\
\hline Fluid 9 & 10.02 & 11.87 & 11.67 & 0.45 & 13.63 & 4.05 & 3.50 & 3.25 & 20.18 & 10.71 & 0.48 & 2.60 \\
\hline Fluid 10 & 7.89 & 10.30 & 17.84 & 14.30 & 10.68 & 1.16 & 7.21 & 2.68 & 20.98 & 11.55 & 0.31 & 0.73 \\
\hline Fluid 11 & 5.09 & 6.40 & 9.45 & 0.42 & 12.37 & 2.28 & 1.92 & 2.13 & 15.22 & 5.17 & 2.64 & 9.92 \\
\hline Fluid 12 & 0.66 & 0.60 & 8.66 & 6.77 & 15.11 & 5.38 & 0.87 & 3.04 & 18.64 & 8.95 & 0.60 & 4.19 \\
\hline Fluid 13 & 10.79 & 11.46 & 0.58 & 5.89 & - & - & - & - & 21.71 & 12.36 & 1.81 & 1.25 \\
\hline Fluid 14 & 7.14 & 7.88 & 5.72 & 1.44 & - & - & - & - & 20.41 & 10.91 & 0.21 & 0.88 \\
\hline Fluid 15 & 0.65 & 5.33 & 10.30 & 19.22 & 11.43 & 1.16 & 4.08 & 11.45 & 12.44 & 2.17 & 4.85 & 18.25 \\
\hline Fluid 16 & 4.99 & 0.79 & 5.17 & 7.27 & 10.45 & 0.20 & 2.93 & 12.01 & 11.66 & 1.29 & 4.46 & 19.06 \\
\hline Fluid 17 & 9.42 & 4.73 & 10.47 & 3.61 & 9.84 & 0.58 & 3.53 & 13.44 & 11.74 & 1.39 & 4.28 & 19.66 \\
\hline Fluid 18 & 1.41 & 2.24 & 3.26 & 8.62 & 7.49 & 3.40 & 4.35 & 12.28 & 8.87 & 1.93 & 5.74 & 18.13 \\
\hline Fluid 19 & 0.13 & 3.73 & 6.39 & 11.07 & 7.41 & 3.64 & 6.31 & 14.57 & 8.42 & 2.46 & 7.41 & 17.94 \\
\hline Fluid 20 & 1.60 & 3.28 & 12.28 & 19.82 & 10.96 & 0.64 & 4.30 & 11.61 & 11.89 & 1.55 & 5.01 & 18.83 \\
\hline Fluid 21 & 4.53 & 0.58 & 4.85 & 7.98 & 9.34 & 1.24 & 3.75 & 12.21 & 10.64 & 0.10 & 5.02 & 18.32 \\
\hline Fluid 22 & 4.88 & 5.16 & 0.90 & 1.94 & 12.17 & 2.21 & 2.83 & 1.73 & 18.65 & 8.83 & 0.59 & 0.75 \\
\hline Fluid 23 & 6.24 & 7.03 & 0.37 & 1.89 & 11.46 & 1.54 & 3.97 & 1.05 & 19.65 & 10.01 & 0.07 & 1.03 \\
\hline Fluid 24 & 8.50 & 2.48 & 17.62 & 11.79 & - & - & - & - & 18.11 & 8.16 & 1.88 & 0.15 \\
\hline Fluid 25 & 6.88 & 1.39 & 20.20 & 10.11 & - & - & - & - & 18.28 & 8.37 & 1.87 & 0.08 \\
\hline Fluid 26 & 9.94 & 4.09 & 22.05 & 13.42 & - & - & - & - & 18.01 & 8.09 & 2.72 & 0.87 \\
\hline Fluid 27 & 11.35 & 5.81 & 27.36 & 18.81 & 8.95 & 0.83 & 4.51 & 20.77 & - & - & - & - \\
\hline Fluid 28 & 21.84 & 16.66 & 18.18 & 1.56 & - & - & - & - & - & - & - & - \\
\hline Fluid 29 & 7.03 & 1.66 & 16.07 & 16.03 & 8.51 & 2.09 & 5.29 & 14.15 & 9.00 & 1.71 & 6.54 & 21.13 \\
\hline Fluid 30 & 16.48 & 12.36 & 28.73 & 0.78 & 12.74 & 2.50 & 3.32 & 12.17 & 13.99 & 3.93 & 4.25 & 17.45 \\
\hline Fluid 31 & 19.66 & 12.23 & 24.32 & 8.78 & 1.92 & 9.39 & 8.61 & 26.20 & - & - & - & - \\
\hline Fluid 32 & 8.45 & 10.44 & 22.61 & 7.23 & 18.28 & 9.31 & 2.01 & 8.40 & 24.54 & 15.58 & 0.74 & 2.88 \\
\hline Fluid 33 & 0.38 & 2.16 & 21.68 & 9.48 & 13.71 & 4.20 & 4.99 & 2.90 & 19.66 & 10.10 & 1.31 & 2.87 \\
\hline Fluid 34 & 4.87 & 6.93 & 14.29 & 2.48 & 12.81 & 3.03 & 3.50 & 2.09 & 16.96 & 7.09 & 3.31 & 6.24 \\
\hline Fluid 35 & 4.87 & 7.37 & 25.47 & 12.20 & 15.24 & 5.73 & 1.99 & 4.18 & 18.11 & 8.38 & 1.44 & 5.37 \\
\hline Fluid 36 & 8.09 & 10.96 & 1.40 & 8.06 & 15.53 & 5.70 & 0.92 & 2.47 & 16.91 & 7.09 & 2.39 & 9.33 \\
\hline Fluid 37 & 7.78 & 4.27 & 8.52 & 5.11 & 14.39 & 4.42 & 4.13 & 7.96 & - & - & - & - \\
\hline Fluid 38 & 11.34 & 7.05 & 14.17 & 6.78 & 12.15 & 1.96 & 5.20 & 10.98 & - & - & - & - \\
\hline Fluid 39 & 16.05 & 11.89 & 18.13 & 0.75 & 13.33 & 3.25 & 4.75 & 9.51 & - & - & - & - \\
\hline
\end{tabular}




\begin{tabular}{|c|c|c|c|c|c|c|c|c|c|c|c|c|}
\hline Fluid 40 & 6.25 & 9.50 & 1.94 & 11.31 & 13.21 & 3.16 & 1.87 & 2.94 & - & - & - & - \\
\hline Fluid 41 & 4.91 & 8.02 & 2.84 & 10.65 & 13.85 & 3.87 & 1.87 & 2.79 & - & - & - & - \\
\hline Fluid 42 & 1.65 & 2.93 & 2.05 & 1.25 & 21.06 & 11.81 & 1.07 & 4.29 & - & - & - & - \\
\hline Fluid 43 & 8.05 & 9.63 & 1.35 & 4.83 & 15.54 & 5.67 & 0.72 & 3.03 & 16.77 & 6.81 & 2.26 & 5.32 \\
\hline Fluid 44 & 5.66 & 3.59 & 1.87 & 0.32 & 11.95 & 1.38 & 2.18 & 5.42 & 12.76 & 2.33 & 4.17 & 10.18 \\
\hline Fluid 45 & 2.61 & 0.83 & 2.78 & 8.85 & - & - & - & - & 13.43 & 3.23 & 3.32 & 14.90 \\
\hline Fluid 46 & 11.57 & 7.94 & 10.18 & 1.09 & 10.92 & 0.45 & 3.21 & 9.92 & 12.77 & 2.47 & 3.89 & 14.73 \\
\hline Fluid 47 & 13.45 & 9.43 & 11.67 & 2.42 & 11.64 & 1.36 & 3.53 & 9.07 & 12.94 & 2.69 & 4.83 & 16.33 \\
\hline Fluid 48 & 11.12 & 13.12 & 5.22 & 9.04 & 16.12 & 6.30 & 0.75 & 2.22 & 18.11 & 8.37 & 1.80 & 5.33 \\
\hline Fluid 49 & 4.27 & 6.83 & 2.05 & 6.60 & 13.90 & 3.88 & 1.32 & 0.59 & - & - & - & - \\
\hline Fluid 50 & 5.93 & 8.09 & 10.19 & 17.13 & 25.60 & 16.94 & 0.91 & 3.40 & 27.11 & 18.61 & 0.72 & 0.26 \\
\hline Fluid 51 & 12.66 & 15.25 & 5.37 & 12.73 & - & - & - & - & 16.29 & 6.39 & 2.73 & 9.76 \\
\hline Fluid 52 & 5.90 & 0.36 & 7.72 & 17.19 & 4.70 & 6.40 & 4.86 & 7.21 & 5.35 & 5.73 & 6.22 & 7.86 \\
\hline Fluid 53 & 15.57 & 17.76 & 6.04 & 13.23 & 17.77 & 8.19 & 1.43 & 3.82 & 18.51 & 8.83 & 1.12 & 5.16 \\
\hline Fluid 54 & 4.21 & 7.94 & 2.09 & 8.14 & 13.71 & 3.72 & 1.81 & 6.33 & 15.03 & 5.03 & 3.02 & 13.40 \\
\hline Fluid 55 & 2.90 & 6.53 & 1.39 & 16.39 & 12.32 & 2.07 & 3.88 & 10.14 & 13.57 & 3.41 & 5.05 & 16.21 \\
\hline Fluid 56 & 19.31 & 22.36 & 10.29 & 31.27 & 14.85 & 4.94 & 1.92 & 6.84 & 16.42 & 6.61 & 2.44 & 12.68 \\
\hline Fluid 57 & 8.73 & 9.85 & 7.69 & 0.53 & 11.87 & 1.48 & 2.49 & 4.12 & 13.91 & 3.67 & 3.56 & 10.75 \\
\hline Fluid 58 & 11.31 & 12.52 & 10.16 & 0.66 & 12.06 & 2.04 & 2.95 & 0.55 & 15.11 & 5.03 & 3.07 & 10.01 \\
\hline Fluid 59 & 1.89 & 0.26 & 1.35 & 1.60 & 13.91 & 3.78 & 0.72 & 0.63 & 16.27 & 6.24 & 1.55 & 5.41 \\
\hline Fluid 60 & 10.58 & 12.08 & 7.05 & 12.62 & 13.21 & 3.26 & 0.23 & 3.16 & 16.09 & 6.02 & 1.93 & 5.06 \\
\hline Fluid 61 & 9.90 & 10.60 & 7.47 & 5.29 & 16.18 & 6.22 & 1.58 & 1.98 & 18.34 & 8.56 & 1.63 & 3.28 \\
\hline Fluid 62 & 6.90 & 7.28 & 5.03 & 0.57 & 20.54 & 11.31 & 0.78 & 6.16 & 24.36 & 15.35 & 1.34 & 3.69 \\
\hline Fluid 63 & 4.29 & 5.90 & 1.49 & 8.98 & 18.16 & 8.49 & 1.80 & 1.89 & 21.18 & 11.81 & 1.30 & 1.91 \\
\hline Fluid 64 & 7.25 & 5.05 & 0.85 & 2.67 & 9.96 & 0.88 & 3.43 & 5.32 & 10.78 & 0.02 & 5.07 & 9.64 \\
\hline Fluid 65 & 8.31 & 11.16 & 7.39 & 3.80 & 15.27 & 5.91 & 1.80 & 3.03 & 18.81 & 9.02 & 1.65 & 1.07 \\
\hline Fluid 66 & 1.43 & 0.90 & 1.93 & 4.74 & 7.28 & 3.93 & 4.66 & 10.52 & 9.01 & 1.86 & 5.61 & 14.79 \\
\hline Fluid 67 & 2.22 & 0.20 & 3.34 & 4.59 & 7.44 & 3.81 & 4.93 & 9.09 & 9.17 & 1.74 & 5.85 & 12.87 \\
\hline Fluid 68 & 1.73 & 0.38 & 3.48 & 6.63 & 16.16 & 6.23 & 0.88 & 1.06 & 18.26 & 8.49 & 0.61 & 3.50 \\
\hline Fluid 69 & 14.37 & 12.40 & 14.22 & 5.54 & 15.95 & 6.05 & 2.08 & 1.48 & 18.52 & 8.80 & 1.44 & 4.33 \\
\hline Fluid 70 & 1.69 & 3.14 & 6.52 & 4.90 & 12.07 & 1.99 & 4.18 & 1.45 & 17.57 & 7.70 & 2.30 & 4.22 \\
\hline Fluid 71 & 8.58 & 10.30 & 5.77 & 15.67 & 21.03 & 11.71 & 1.51 & 3.88 & 22.66 & 13.46 & 1.17 & 0.71 \\
\hline Fluid 72 & 11.60 & 12.31 & 6.57 & 13.48 & 16.40 & 6.36 & 0.61 & 2.81 & 19.73 & 10.09 & 0.67 & 1.25 \\
\hline Fluid 73 & 12.16 & 12.48 & 6.74 & 7.03 & 20.78 & 11.46 & 0.84 & 7.75 & 24.49 & 15.46 & 0.96 & 4.87 \\
\hline Fluid 74 & 12.20 & 12.54 & 6.46 & 7.03 & 20.86 & 11.56 & 0.87 & 7.88 & 24.80 & 15.80 & 1.29 & 5.27 \\
\hline Fluid 75 & 14.27 & 14.88 & 9.71 & 11.13 & 18.54 & 8.74 & 0.29 & 3.61 & 21.31 & 11.88 & 0.04 & 1.24 \\
\hline Fluid 76 & 13.63 & 14.18 & 9.91 & 10.80 & 18.25 & 8.37 & 0.47 & 3.58 & 20.84 & 11.34 & 0.38 & 1.29 \\
\hline Fluid 77 & 13.54 & 14.61 & 7.38 & 6.99 & 20.23 & 10.83 & 0.83 & 3.85 & 23.49 & 14.41 & 0.65 & 0.60 \\
\hline Fluid 78 & 9.30 & 11.18 & 12.82 & 18.01 & 13.67 & 3.28 & 2.48 & 4.16 & 14.83 & 4.60 & 2.92 & 6.45 \\
\hline Fluid 79 & 11.52 & 12.84 & 0.28 & 3.64 & 17.41 & 7.87 & 1.32 & 3.83 & 21.61 & 12.30 & 1.85 & 2.01 \\
\hline Fluid 80 & 0.73 & 2.19 & 0.33 & 0.64 & 13.54 & 3.22 & 3.06 & 3.33 & 17.22 & 7.34 & 2.12 & 5.80 \\
\hline Fluid 81 & 0.02 & 1.30 & 0.85 & 4.64 & 12.69 & 2.24 & 2.22 & 2.56 & 15.30 & 5.13 & 2.62 & 6.05 \\
\hline Fluid 82 & 2.80 & 0.39 & 0.91 & 6.83 & 14.52 & 4.40 & 3.23 & 4.99 & 16.95 & 7.09 & 2.82 & 7.57 \\
\hline
\end{tabular}




\begin{tabular}{|c|c|c|c|c|c|c|c|c|c|c|c|c|}
\hline Fluid 83 & 3.94 & 5.35 & 2.84 & 3.06 & 15.67 & 5.66 & 1.11 & 2.07 & 17.95 & 8.17 & 1.88 & 5.32 \\
\hline Fluid 84 & 8.19 & 9.38 & 8.63 & 8.92 & 15.17 & 5.07 & 1.65 & 1.99 & 18.18 & 8.41 & 1.46 & 4.55 \\
\hline Fluid 85 & 0.89 & 2.43 & 0.92 & 1.40 & 14.01 & 3.79 & 2.49 & 2.75 & 16.63 & 6.68 & 2.81 & 6.74 \\
\hline Fluid 86 & 12.44 & 13.41 & 11.08 & 19.40 & 12.86 & 2.44 & 1.27 & 2.64 & 15.31 & 5.09 & 1.96 & 4.59 \\
\hline Fluid 87 & 9.22 & 10.33 & 7.79 & 14.56 & 11.71 & 1.16 & 3.33 & 3.14 & 15.45 & 5.27 & 2.42 & 5.42 \\
\hline Fluid 88 & 3.47 & 3.74 & 4.61 & 1.14 & 16.95 & 6.82 & 1.21 & 1.44 & 19.98 & 10.39 & 0.88 & 0.77 \\
\hline Fluid 89 & 18.06 & 18.82 & 12.55 & 21.52 & 21.66 & 12.29 & 5.84 & 9.78 & 20.61 & 11.05 & 0.54 & 1.25 \\
\hline Fluid 90 & 6.93 & 8.42 & 3.46 & 1.25 & 16.03 & 6.11 & 1.14 & 2.72 & 18.52 & 8.82 & 1.77 & 5.24 \\
\hline Fluid 91 & 4.44 & 6.27 & 1.85 & 7.84 & 12.51 & 2.62 & 2.16 & 0.40 & 16.60 & 6.69 & 2.68 & 8.22 \\
\hline Fluid 92 & 3.33 & 1.24 & 7.87 & 12.28 & 10.23 & 1.21 & 4.02 & 3.78 & 15.30 & 5.20 & 2.54 & 8.64 \\
\hline Fluid 93 & 2.74 & 3.78 & 0.41 & 0.53 & 11.20 & 1.21 & 2.39 & 2.14 & 15.17 & 4.99 & 2.24 & 6.49 \\
\hline Fluid 94 & 0.84 & 1.48 & 3.00 & 1.28 & 14.78 & 4.75 & 0.53 & 3.51 & 15.66 & 5.49 & 3.55 & 4.56 \\
\hline Fluid 95 & 5.14 & 5.00 & 5.99 & 4.60 & 12.97 & 2.33 & 1.54 & 0.84 & 16.13 & 5.82 & 0.23 & 0.37 \\
\hline Fluid 96 & 18.05 & 17.60 & 3.52 & 16.84 & - & - & - & - & 16.94 & 6.74 & 1.64 & 1.43 \\
\hline Fluid 97 & 1.70 & 2.73 & 2.37 & 3.95 & 21.17 & 11.85 & 1.25 & 1.39 & 22.30 & 13.09 & 0.11 & 1.14 \\
\hline Fluid 98 & 0.30 & 0.69 & 4.26 & 4.29 & 7.05 & 3.12 & 5.35 & 0.38 & 16.47 & 6.33 & 0.60 & 1.99 \\
\hline Fluid 99 & 6.59 & 7.01 & 0.25 & 5.03 & - & - & - & - & 19.66 & 9.88 & 1.54 & 1.95 \\
\hline Fluid 100 & 7.19 & 9.50 & 0.08 & 17.01 & - & - & - & - & 16.02 & 5.80 & 1.00 & 2.22 \\
\hline Fluid 101 & 2.16 & 3.58 & 1.74 & 0.95 & 6.65 & 3.70 & 7.25 & 2.80 & 16.47 & 6.45 & 1.91 & 5.02 \\
\hline Fluid 102 & 7.41 & 7.00 & 6.24 & 11.32 & 13.98 & 3.43 & 1.23 & 1.61 & 17.95 & 7.87 & 1.78 & 2.38 \\
\hline Fluid 103 & 9.13 & 9.37 & 8.22 & 7.72 & 12.55 & 2.22 & 1.69 & 1.69 & 16.60 & 6.51 & 1.03 & 2.84 \\
\hline Fluid 104 & 1.37 & 0.78 & 3.38 & 2.85 & 10.28 & 0.58 & 2.42 & 2.06 & 13.54 & 3.04 & 2.46 & 5.30 \\
\hline Fluid 105 & 10.43 & 10.08 & 12.34 & 13.85 & 10.08 & 0.76 & 1.78 & 1.25 & 13.64 & 2.94 & 0.73 & 0.62 \\
\hline Fluid 106 & 2.98 & 1.80 & 5.25 & 5.75 & 10.56 & 0.24 & 3.14 & 2.20 & 15.06 & 4.89 & 2.42 & 7.17 \\
\hline Fluid 107 & 1.26 & 0.45 & 13.00 & 6.51 & 5.72 & 4.86 & 9.39 & 4.08 & 15.52 & 5.23 & 0.74 & 2.65 \\
\hline Fluid 108 & 1.70 & 2.82 & 1.71 & 3.91 & 9.26 & 1.00 & 2.58 & 0.45 & 14.76 & 4.50 & 1.81 & 6.09 \\
\hline Fluid 109 & 13.69 & 13.87 & 10.98 & 21.23 & 9.79 & 3.73 & 3.06 & 4.22 & 15.74 & 5.34 & 1.02 & 0.71 \\
\hline Fluid 110 & 4.23 & 4.79 & 1.97 & 4.41 & 9.66 & 0.63 & 3.54 & 0.13 & 16.27 & 6.18 & 1.34 & 3.89 \\
\hline Fluid 111 & 8.32 & 9.21 & 4.54 & 9.85 & - & - & - & - & 16.85 & 6.79 & 0.57 & 2.31 \\
\hline Fluid 112 & 15.76 & 17.02 & 8.24 & 15.45 & 11.62 & 2.26 & 1.07 & 4.88 & 19.81 & 10.12 & 0.55 & 0.34 \\
\hline Fluid 113 & 4.69 & 5.16 & 7.59 & 3.05 & 11.41 & 0.68 & 3.54 & 4.82 & 15.23 & 5.03 & 2.09 & 5.34 \\
\hline Fluid 114 & 0.48 & 1.60 & 6.55 & 0.27 & - & - & - & - & 15.74 & 5.57 & 2.11 & 4.80 \\
\hline Fluid 115 & 5.68 & 4.03 & 26.63 & 0.17 & 5.76 & 4.00 & 5.04 & 1.83 & 13.18 & 2.35 & 0.07 & 0.02 \\
\hline Fluid 116 & 2.62 & 2.58 & 0.78 & 10.26 & - & - & - & - & 14.86 & 4.31 & 0.57 & 0.90 \\
\hline Fluid 117 & 8.72 & 7.47 & 26.07 & 3.51 & 7.12 & 2.73 & 5.31 & 1.50 & 17.83 & 7.85 & 0.27 & 0.75 \\
\hline Fluid 118 & 0.97 & 1.19 & 2.80 & 0.34 & 9.87 & 1.97 & 4.83 & 2.96 & 17.05 & 7.04 & 0.37 & 2.77 \\
\hline Fluid 119 & 3.80 & 2.25 & 11.53 & 0.02 & 8.14 & 1.49 & 3.40 & 2.08 & 16.42 & 6.30 & 1.12 & 2.89 \\
\hline Fluid 120 & 4.17 & 4.03 & 6.79 & 2.11 & 11.48 & 1.55 & 1.05 & 3.46 & 16.80 & 6.63 & 0.02 & 0.20 \\
\hline Fluid 121 & 3.30 & 2.98 & 1.01 & 5.12 & 11.95 & 1.27 & 2.18 & 2.20 & 16.12 & 5.83 & 0.59 & 0.26 \\
\hline Fluid 122 & 4.11 & 2.31 & 6.93 & 7.52 & 9.59 & 0.98 & 4.02 & 3.42 & 14.25 & 3.97 & 3.16 & 8.05 \\
\hline Fluid 123 & 14.46 & 15.60 & 10.72 & 13.88 & 17.51 & 7.96 & 0.79 & 0.37 & 19.90 & 10.39 & 0.99 & 3.94 \\
\hline Fluid 124 & 6.05 & 4.81 & 4.03 & 5.34 & 12.89 & 2.19 & 1.36 & 2.70 & 16.62 & 6.36 & 0.41 & 0.95 \\
\hline Fluid 125 & 0.63 & 2.30 & 1.92 & 7.99 & 16.65 & 6.73 & 0.26 & 1.87 & 17.97 & 8.16 & 1.73 & 4.29 \\
\hline
\end{tabular}




\begin{tabular}{|c|c|c|c|c|c|c|c|c|c|c|c|c|}
\hline Fluid 126 & 3.00 & 1.24 & 12.40 & 5.83 & 6.69 & 3.45 & 7.66 & 2.21 & 16.68 & 6.68 & 1.79 & 4.85 \\
\hline Fluid 127 & 16.55 & 15.31 & 18.13 & 7.31 & 6.22 & 4.00 & 6.09 & 0.82 & 15.79 & 5.51 & 0.82 & 1.38 \\
\hline Fluid 128 & 2.20 & 2.84 & 4.63 & 9.64 & 14.95 & 5.34 & 3.19 & 8.19 & 18.34 & 8.31 & 2.12 & 2.38 \\
\hline Fluid 129 & 6.05 & 6.07 & 5.12 & 13.26 & 8.41 & 1.60 & 1.87 & 2.45 & 15.47 & 4.97 & 1.42 & 2.07 \\
\hline Fluid 130 & 0.33 & 2.87 & 5.97 & 11.64 & 14.11 & 3.91 & 2.80 & 7.84 & 16.33 & 6.43 & 1.81 & 9.36 \\
\hline Fluid 131 & 1.37 & 0.97 & 0.14 & 2.68 & 12.09 & 1.41 & 1.59 & 2.41 & 14.77 & 4.28 & 1.72 & 1.18 \\
\hline Fluid 132 & 4.31 & 3.96 & 3.02 & 4.33 & 13.72 & 3.38 & 0.45 & 2.90 & 15.88 & 5.62 & 1.11 & 1.43 \\
\hline Fluid 133 & 1.31 & 1.18 & 0.05 & 4.77 & 10.65 & 0.37 & 3.39 & 1.41 & 15.43 & 5.27 & 2.65 & 5.73 \\
\hline Fluid 134 & 5.14 & 4.06 & 11.29 & 1.66 & 8.16 & 1.62 & 3.05 & 2.21 & 15.97 & 5.74 & 0.72 & 1.99 \\
\hline Fluid 135 & 1.66 & 2.99 & 4.40 & 4.00 & 12.41 & 2.68 & 0.76 & 2.90 & 17.27 & 7.37 & 1.02 & 4.96 \\
\hline Fluid 136 & 7.35 & 7.29 & 15.00 & 11.53 & 7.76 & 2.69 & 5.59 & 0.23 & 15.92 & 5.62 & 0.03 & 0.32 \\
\hline Fluid 137 & 13.80 & 11.38 & 22.31 & 6.79 & 6.62 & 3.02 & 6.15 & 2.07 & 17.28 & 7.25 & 0.36 & 1.61 \\
\hline Fluid 138 & 0.59 & 1.65 & 27.56 & 9.24 & 9.77 & 0.87 & 5.02 & 5.30 & 15.33 & 4.98 & 1.13 & 2.17 \\
\hline Fluid 139 & 2.79 & 3.07 & 9.66 & 1.68 & 12.41 & 2.59 & 0.79 & 3.54 & 15.44 & 5.21 & 2.35 & 4.20 \\
\hline Fluid 140 & 7.66 & 8.78 & 1.65 & 12.14 & 9.77 & 1.68 & 3.78 & 3.11 & 16.52 & 6.40 & 0.39 & 2.47 \\
\hline Fluid 141 & 9.91 & 11.09 & 2.45 & 6.77 & 11.08 & 1.30 & 1.85 & 2.54 & 17.26 & 7.33 & 1.42 & 4.36 \\
\hline Fluid 142 & 12.11 & 10.54 & 20.96 & 5.53 & 7.23 & 2.41 & 6.14 & 2.34 & 14.50 & 4.11 & 3.55 & 4.44 \\
\hline Fluid 143 & 2.21 & 5.15 & 3.43 & 15.17 & 14.38 & 4.17 & 2.39 & 5.65 & 16.63 & 6.72 & 1.36 & 7.50 \\
\hline Fluid 144 & 11.15 & 10.74 & 12.40 & 16.76 & 8.55 & 1.99 & 2.17 & 1.69 & 15.88 & 5.41 & 2.47 & 2.99 \\
\hline Fluid 145 & 4.42 & 5.26 & 3.13 & 7.09 & 11.61 & 1.88 & 1.12 & 2.54 & 14.27 & 3.90 & 2.00 & 5.34 \\
\hline Fluid 146 & 2.44 & 4.18 & 3.98 & 10.83 & 13.45 & 4.98 & 3.19 & 7.08 & 14.87 & 4.50 & 1.18 & 3.28 \\
\hline Fluid 147 & 10.73 & 12.11 & 7.08 & 13.43 & 18.25 & 8.72 & 0.75 & 0.25 & 20.82 & 11.40 & 0.34 & 2.53 \\
\hline Fluid 148 & 8.88 & 9.23 & 13.40 & 11.35 & 9.78 & 0.61 & 4.06 & 1.16 & 15.54 & 5.31 & 1.47 & 3.79 \\
\hline Fluid 149 & 3.32 & 5.19 & 14.12 & 13.79 & - & - & - & - & 15.65 & 5.29 & 0.08 & 0.33 \\
\hline Fluid 150 & 10.89 & 13.26 & 6.33 & 4.82 & - & - & - & - & 14.39 & 4.10 & 2.16 & 6.98 \\
\hline Fluid 151 & 2.94 & 1.88 & 2.48 & 3.59 & 8.29 & 2.80 & 4.92 & 7.81 & 11.37 & 0.74 & 4.76 & 10.79 \\
\hline Fluid 152 & 8.96 & 9.37 & 7.51 & 5.97 & 10.54 & 1.92 & 4.30 & 6.03 & 12.84 & 2.35 & 3.86 & 8.34 \\
\hline Fluid 153 & 6.77 & 5.76 & 10.39 & 3.95 & 3.86 & 6.06 & 6.22 & 0.65 & 15.72 & 5.31 & 1.03 & 0.80 \\
\hline Fluid 154 & 3.03 & 4.05 & 3.83 & 3.92 & 9.28 & 0.84 & 2.57 & 0.81 & 15.68 & 5.51 & 1.12 & 4.79 \\
\hline Fluid 155 & 0.67 & 1.19 & 14.67 & 4.13 & 11.50 & 2.16 & 5.09 & 1.67 & 18.51 & 8.73 & 0.95 & 2.85 \\
\hline Fluid 156 & 13.92 & 13.89 & 12.05 & 8.67 & 13.55 & 3.50 & 1.46 & 0.15 & 17.81 & 7.95 & 0.86 & 3.24 \\
\hline Fluid 157 & 11.46 & 11.60 & 10.28 & 17.02 & 8.45 & 1.40 & 1.12 & 3.07 & 15.29 & 4.78 & 1.27 & 1.90 \\
\hline Fluid 158 & 4.23 & 3.02 & 7.77 & 3.59 & - & - & - & - & 15.40 & 5.11 & 1.76 & 2.73 \\
\hline Fluid 159 & 10.24 & 11.02 & 7.46 & 6.77 & - & - & - & - & 18.33 & 8.52 & 0.33 & 2.65 \\
\hline Fluid 160 & 4.74 & 6.46 & 1.68 & 3.32 & 11.34 & 1.40 & 2.09 & 0.29 & 15.62 & 5.55 & 2.79 & 8.14 \\
\hline Fluid 161 & 7.62 & 6.87 & 9.02 & 10.70 & - & - & - & - & 15.30 & 4.80 & 0.97 & 2.11 \\
\hline Fluid 162 & 11.38 & 7.18 & 11.97 & 2.45 & 7.95 & 2.81 & 5.26 & 16.05 & 11.04 & 0.60 & 4.65 & 20.22 \\
\hline Fluid 163 & 9.26 & 11.01 & 0.65 & 5.58 & - & - & - & - & 20.11 & 10.61 & 1.31 & 2.81 \\
\hline Fluid 164 & 8.82 & 10.54 & 0.37 & 5.52 & 17.55 & 7.87 & 1.00 & 2.44 & 20.89 & 11.48 & 0.28 & 1.67 \\
\hline Fluid 165 & 2.03 & 2.73 & 0.12 & 2.02 & 14.61 & 4.50 & 2.31 & 2.01 & 17.53 & 7.67 & 3.81 & 5.29 \\
\hline Fluid 166 & 3.38 & 0.53 & 8.32 & 1.36 & 11.44 & 0.92 & 2.93 & 8.34 & 13.46 & 3.19 & 3.26 & 12.28 \\
\hline Fluid 167 & 12.39 & 9.66 & 19.03 & 4.31 & - & - & - & - & 17.18 & 7.40 & 2.36 & 9.87 \\
\hline Fluid 168 & 2.06 & 0.36 & 4.95 & 5.01 & - & - & - & - & 16.04 & 6.08 & 1.80 & 9.35 \\
\hline
\end{tabular}




\begin{tabular}{|c|c|c|c|c|c|c|c|c|c|c|c|c|}
\hline Fluid 169 & 5.39 & 7.60 & 7.61 & 12.93 & - & - & - & - & 12.71 & 2.28 & 3.45 & 10.53 \\
\hline Fluid 170 & 7.61 & 4.69 & 8.51 & 1.69 & - & - & - & - & 13.69 & 3.46 & 2.97 & 12.21 \\
\hline Fluid 171 & 2.76 & 0.31 & 4.99 & 5.31 & - & - & - & - & 15.48 & 5.47 & 3.30 & 10.74 \\
\hline Fluid 172 & 0.68 & 3.02 & 0.92 & 8.37 & - & - & - & - & 14.79 & 4.67 & 3.08 & 10.32 \\
\hline Fluid 173 & 1.12 & 3.20 & 1.24 & 8.19 & - & - & - & - & 15.67 & 5.64 & 2.96 & 8.85 \\
\hline Fluid 174 & 2.33 & 0.17 & 2.70 & 6.16 & - & - & - & - & 14.72 & 4.61 & 3.19 & 10.94 \\
\hline Fluid 175 & 11.51 & 8.68 & 9.66 & 2.24 & - & - & - & - & 12.39 & 1.94 & 3.63 & 11.53 \\
\hline Fluid 176 & 9.05 & 5.98 & 11.61 & 2.20 & - & - & - & - & 14.92 & 4.88 & 3.16 & 12.64 \\
\hline Fluid 177 & 0.84 & 2.82 & 2.19 & 6.57 & - & - & - & - & 18.68 & 9.05 & 1.39 & 6.62 \\
\hline Fluid 178 & 0.47 & 2.34 & 0.59 & 6.10 & - & - & - & - & 16.33 & 6.34 & 1.51 & 6.77 \\
\hline Fluid 179 & 10.28 & 7.67 & 12.94 & 2.33 & - & - & - & - & 15.05 & 4.97 & 2.76 & 10.20 \\
\hline Fluid 180 & 4.26 & 6.55 & 2.38 & 11.33 & - & - & - & - & 16.17 & 6.23 & 1.85 & 9.46 \\
\hline Fluid 181 & 8.07 & 4.94 & 12.79 & 3.05 & - & - & - & - & 14.72 & 4.67 & 3.31 & 13.31 \\
\hline Fluid 182 & 4.41 & 6.15 & 5.01 & 9.46 & - & - & - & - & 18.62 & 8.93 & 0.86 & 4.67 \\
\hline Fluid 183 & 5.25 & 3.58 & 6.91 & 0.54 & - & - & - & - & 18.26 & 8.51 & 0.90 & 4.64 \\
\hline Fluid 184 & 7.59 & 4.85 & 13.33 & 1.27 & - & - & - & - & 17.09 & 7.31 & 2.04 & 10.13 \\
\hline Fluid 185 & 5.47 & 2.33 & 8.31 & 4.59 & - & - & - & - & 12.97 & 2.67 & 3.18 & 13.66 \\
\hline Fluid 186 & 11.53 & 8.28 & 12.57 & 0.20 & - & - & - & - & 12.88 & 2.58 & 4.31 & 14.38 \\
\hline Fluid 187 & 0.50 & 2.83 & 4.70 & 11.94 & - & - & - & - & 13.50 & 3.32 & 3.11 & 15.55 \\
\hline Fluid 188 & 11.70 & 8.29 & 15.90 & 0.43 & - & - & - & - & 13.34 & 3.10 & 3.41 & 14.43 \\
\hline Fluid 189 & 11.33 & 7.99 & 17.69 & 0.16 & - & - & - & - & 15.32 & 5.35 & 2.34 & 13.23 \\
\hline Fluid 190 & 5.42 & 2.04 & 8.04 & 6.40 & - & - & - & - & 11.95 & 1.55 & 4.21 & 15.96 \\
\hline Fluid 191 & 14.31 & 11.09 & 17.70 & 3.74 & - & - & - & - & 13.64 & 3.42 & 3.65 & 13.16 \\
\hline Fluid 192 & 9.65 & 6.81 & 5.82 & 0.84 & - & - & - & - & 11.11 & 0.47 & 3.90 & 11.84 \\
\hline Fluid 193 & 5.27 & 7.35 & 2.38 & 11.08 & - & - & - & - & 16.54 & 6.63 & 1.45 & 8.14 \\
\hline Fluid 194 & 19.93 & 18.07 & 7.78 & 2.07 & - & - & - & - & 7.34 & 4.09 & 4.75 & 5.73 \\
\hline Fluid 195 & 5.18 & 2.60 & 13.64 & 2.05 & - & - & - & - & 18.75 & 9.19 & 1.21 & 8.59 \\
\hline Fluid 196 & 3.52 & 1.18 & 5.46 & 4.87 & - & - & - & - & 16.62 & 6.74 & 2.48 & 8.78 \\
\hline Fluid 197 & 8.81 & 5.88 & 14.27 & 0.58 & - & - & - & - & 15.09 & 5.05 & 2.49 & 11.66 \\
\hline Fluid 198 & 0.37 & 2.66 & 0.41 & 9.47 & - & - & - & - & 12.04 & 1.61 & 3.38 & 14.05 \\
\hline Fluid 199 & 10.52 & 6.42 & 12.32 & 2.68 & - & - & - & - & 9.62 & 1.05 & 4.78 & 18.75 \\
\hline Fluid 200 & 4.15 & 1.42 & 17.31 & 2.91 & - & - & - & - & 14.21 & 4.10 & 3.24 & 13.97 \\
\hline Fluid 201 & 2.89 & 5.31 & 4.58 & 7.51 & - & - & - & - & 10.79 & 0.16 & 4.51 & 14.01 \\
\hline Fluid 202 & 1.44 & 0.08 & 4.37 & 4.56 & - & - & - & - & 16.22 & 6.29 & 2.09 & 9.28 \\
\hline Fluid 203 & 5.21 & 4.22 & 6.30 & 14.81 & - & - & - & - & 21.12 & 11.81 & 0.89 & 4.68 \\
\hline Fluid 204 & 3.77 & 4.66 & 1.30 & 4.08 & - & - & - & - & 15.33 & 5.15 & 1.81 & 5.89 \\
\hline Fluid 205 & 1.94 & 3.06 & 0.60 & 2.75 & - & - & - & - & 15.07 & 4.86 & 2.17 & 6.16 \\
\hline Fluid 206 & 0.71 & 0.22 & 3.08 & 2.50 & - & - & - & - & 16.10 & 6.04 & 1.92 & 5.76 \\
\hline Fluid 207 & 0.41 & 1.29 & 0.61 & 0.97 & - & - & - & - & 14.97 & 4.74 & 2.12 & 6.17 \\
\hline Fluid 208 & 6.96 & 5.80 & 11.39 & 9.79 & - & - & - & - & 16.08 & 6.02 & 1.92 & 6.23 \\
\hline Fluid 209 & 0.83 & 0.19 & 3.93 & 0.92 & - & - & - & - & 15.52 & 5.37 & 1.89 & 5.95 \\
\hline Fluid 210 & 3.17 & 4.03 & 1.14 & 0.06 & - & - & - & - & 16.53 & 6.55 & 1.72 & 5.92 \\
\hline Fluid 211 & 12.35 & 7.68 & 4.61 & 6.87 & - & - & - & - & 7.96 & 2.86 & 5.82 & 23.52 \\
\hline
\end{tabular}




\begin{tabular}{|c|c|c|c|c|c|c|c|c|c|c|c|c|}
\hline Fluid 212 & 16.86 & 17.91 & 20.08 & 14.22 & - & - & - & - & 16.88 & 7.02 & 1.36 & 8.37 \\
\hline Fluid 213 & 3.86 & 7.02 & 0.92 & 9.07 & - & - & - & - & 6.36 & 4.77 & 6.65 & 19.61 \\
\hline Fluid 214 & 2.56 & 3.07 & 0.75 & 1.61 & - & - & - & - & 18.59 & 8.84 & 0.35 & 3.28 \\
\hline Fluid 215 & 3.68 & 5.72 & 0.23 & 12.38 & - & - & - & - & 13.47 & 2.98 & 2.61 & 5.79 \\
\hline Fluid 216 & 5.74 & 3.12 & 1.06 & 0.59 & - & - & - & - & 9.73 & 1.04 & 5.04 & 14.61 \\
\hline Fluid 217 & 3.34 & 3.90 & 0.18 & 2.41 & - & - & - & - & 17.56 & 7.65 & 0.65 & 3.42 \\
\hline Fluid 218 & 5.76 & 7.34 & 3.01 & 7.90 & - & - & - & - & 23.24 & 14.16 & 1.10 & 0.90 \\
\hline Fluid 219 & 0.88 & 0.71 & 1.08 & 1.72 & - & - & - & - & 15.91 & 5.84 & 2.67 & 6.40 \\
\hline Fluid 220 & 5.14 & 5.63 & 0.38 & 1.95 & - & - & - & - & 20.52 & 10.95 & 0.39 & 0.59 \\
\hline Fluid 221 & 0.47 & 2.32 & 12.30 & 4.33 & - & - & - & - & 21.75 & 12.35 & 0.01 & 1.00 \\
\hline Fluid 222 & 0.01 & 0.93 & 2.06 & 2.98 & - & - & - & - & 17.08 & 7.16 & 1.32 & 5.58 \\
\hline Fluid 223 & 14.89 & 16.65 & 3.62 & 3.98 & - & - & - & - & 22.09 & 12.78 & 0.02 & 0.01 \\
\hline Fluid 224 & 20.16 & 21.29 & 13.12 & 7.41 & - & - & - & - & 24.29 & 15.38 & 0.01 & 1.49 \\
\hline Fluid 225 & 6.53 & 8.09 & 2.17 & 8.65 & - & - & - & - & 23.24 & 14.16 & 1.10 & 0.90 \\
\hline Fluid 226 & 1.63 & 1.51 & 3.31 & 1.60 & - & - & - & - & 13.06 & 2.79 & 4.69 & 14.42 \\
\hline Fluid 227 & 4.06 & 4.93 & 0.92 & 1.65 & - & - & - & - & 18.06 & 8.30 & 1.15 & 5.61 \\
\hline Fluid 228 & 0.44 & 1.73 & 4.57 & 9.11 & - & - & - & - & 15.78 & 5.77 & 2.75 & 8.88 \\
\hline Fluid 229 & 5.57 & 7.06 & 3.50 & 7.04 & - & - & - & - & 21.49 & 12.18 & 0.36 & 2.58 \\
\hline Fluid 230 & 1.93 & 0.06 & 6.01 & 3.09 & - & - & - & - & 17.01 & 7.11 & 2.00 & 6.36 \\
\hline Fluid 231 & 12.60 & 8.19 & 24.59 & 16.28 & - & - & - & - & 14.62 & 4.60 & 3.64 & 15.49 \\
\hline Fluid 232 & 15.26 & 10.97 & 9.92 & 1.55 & - & - & - & - & 8.10 & 2.76 & 6.99 & 20.67 \\
\hline Fluid 233 & 0.98 & 1.97 & 1.76 & 0.11 & - & - & - & - & 17.38 & 7.49 & 1.12 & 4.75 \\
\hline Fluid 234 & 8.59 & 9.79 & 9.71 & 7.46 & - & - & - & - & 15.67 & 5.66 & 2.01 & 9.53 \\
\hline Fluid 235 & 4.12 & 3.28 & 13.69 & 9.76 & - & - & - & - & 17.18 & 7.34 & 1.30 & 7.38 \\
\hline Fluid 236 & 3.53 & 5.39 & 25.01 & 5.79 & - & - & - & - & 18.32 & 8.58 & 0.14 & 4.48 \\
\hline Fluid 237 & 2.10 & 0.18 & 4.11 & 1.47 & - & - & - & - & 18.55 & 8.83 & 0.45 & 3.79 \\
\hline Fluid 238 & 3.83 & 5.96 & 6.42 & 8.39 & - & - & - & - & 18.01 & 8.24 & 0.26 & 4.96 \\
\hline Fluid 239 & 5.43 & 7.40 & 6.86 & 9.33 & - & - & - & - & 18.77 & 9.10 & 0.07 & 4.45 \\
\hline Fluid 240 & 0.41 & 2.65 & 3.05 & 4.47 & - & - & - & - & 17.05 & 7.16 & 1.27 & 6.05 \\
\hline Fluid 241 & 0.93 & 3.24 & 2.68 & 4.86 & - & - & - & - & 16.85 & 6.93 & 1.12 & 6.03 \\
\hline Fluid 242 & 0.92 & 2.65 & 0.68 & 4.42 & - & - & - & - & 18.06 & 8.32 & 0.77 & 6.05 \\
\hline Fluid 243 & 2.50 & 4.07 & 2.44 & 5.50 & - & - & - & - & 18.94 & 9.29 & 0.08 & 4.37 \\
\hline Fluid 244 & 2.86 & 1.00 & 2.93 & 0.98 & - & - & - & - & 16.82 & 6.93 & 1.34 & 7.28 \\
\hline Fluid 245 & 5.60 & 4.06 & 8.90 & 3.94 & - & - & - & - & 19.74 & 10.20 & 0.32 & 4.00 \\
\hline Fluid 246 & 0.82 & 2.54 & 1.39 & 4.56 & - & - & - & - & 17.27 & 7.43 & 1.28 & 6.56 \\
\hline Fluid 247 & 9.22 & 7.11 & 12.11 & 5.12 & - & - & - & - & 18.61 & 8.97 & 0.58 & 6.44 \\
\hline Fluid 248 & 2.28 & 4.00 & 3.72 & 6.40 & - & - & - & - & 15.73 & 5.67 & 2.12 & 7.69 \\
\hline Fluid 249 & 3.47 & 4.90 & 2.10 & 6.91 & - & - & - & - & 22.22 & 13.01 & 0.19 & 2.01 \\
\hline Fluid 250 & 3.03 & 4.56 & 2.12 & 6.48 & - & - & - & - & 20.99 & 11.64 & 0.38 & 3.83 \\
\hline Fluid 251 & 6.85 & 5.81 & 8.28 & 8.83 & - & - & - & - & 16.21 & 6.21 & 2.22 & 7.12 \\
\hline Fluid 252 & 6.11 & 7.01 & 0.38 & 12.60 & - & - & - & - & 19.26 & 9.53 & 0.29 & 0.95 \\
\hline Fluid 253 & 5.78 & 6.03 & 3.49 & 9.80 & - & - & - & - & 20.87 & 11.25 & 1.62 & 3.01 \\
\hline Fluid 254 & 8.80 & 9.02 & 4.33 & 5.06 & - & - & - & - & 25.49 & 16.56 & 2.82 & 5.35 \\
\hline
\end{tabular}




\begin{tabular}{|c|c|c|c|c|c|c|c|c|c|c|c|c|}
\hline Fluid 255 & 10.86 & 6.69 & 16.80 & 0.94 & - & - & - & - & 20.83 & 11.25 & 0.52 & 1.94 \\
\hline Fluid 256 & 10.44 & 6.42 & 17.11 & 1.82 & - & - & - & - & 21.11 & 11.56 & 0.68 & 2.14 \\
\hline Fluid 257 & 1.18 & 0.16 & 3.22 & 0.20 & - & - & - & - & 14.85 & 4.65 & 3.14 & 7.57 \\
\hline Fluid 258 & 4.74 & 2.66 & 6.38 & 16.33 & - & - & - & - & 15.43 & 5.39 & 3.05 & 9.95 \\
\hline Fluid 259 & 8.45 & 6.35 & 20.36 & 4.55 & - & - & - & - & 15.49 & 5.27 & 1.70 & 4.28 \\
\hline Fluid 260 & 3.17 & 4.92 & 8.07 & 2.22 & - & - & - & - & 19.50 & 9.79 & 0.16 & 0.43 \\
\hline Average & 6.35 & 6.26 & 7.36 & 6.72 & 12.62 & 3.95 & 2.82 & 4.46 & 16.49 & 6.76 & 2.03 & 6.45 \\
\hline
\end{tabular}


Table A3. Summary of AAD\% in predicted saturation pressures, reservoir fluid densities and stock tank oil densities (PC-SAFT with new general characterization Eqs. (12-13))

\begin{tabular}{|c|c|c|c|c|c|c|c|c|c|}
\hline \multirow[b]{2}{*}{ Fluid no. } & \multicolumn{3}{|c|}{ Saturation Pressure } & \multicolumn{3}{|c|}{ Density } & \multicolumn{3}{|c|}{ Stock Tank Oil Density } \\
\hline & SRK-VT & PR-VT & PC-SAFT & SRK-VT & PR-VT & PC-SAFT & SRK-VT & PR-VT & PC-SAFT \\
\hline Fluid 1 & 3.47 & 5.88 & 0.98 & 1.68 & 1.55 & 1.10 & 0.77 & 0.97 & 2.05 \\
\hline Fluid 2 & 7.54 & 10.42 & 5.91 & 1.57 & 1.97 & 1.21 & - & - & - \\
\hline Fluid 3 & 5.13 & 8.28 & 6.12 & 0.96 & 1.26 & 0.84 & - & - & - \\
\hline Fluid 4 & 4.02 & 7.80 & 5.86 & 0.92 & 1.20 & 1.30 & - & - & - \\
\hline Fluid 5 & 3.21 & 1.31 & 4.17 & 0.84 & 0.90 & 0.58 & - & - & - \\
\hline Fluid 6 & 4.09 & 0.14 & 4.84 & 0.41 & 0.52 & 0.80 & - & - & - \\
\hline Fluid 7 & 0.49 & 2.18 & 2.04 & 2.43 & 2.59 & 4.48 & 0.21 & 0.53 & 2.27 \\
\hline Fluid 8 & 14.84 & 16.25 & 5.60 & 0.77 & 0.59 & 1.65 & - & - & - \\
\hline Fluid 9 & 10.02 & 11.87 & 7.20 & 1.10 & 0.71 & 2.32 & 0.76 & 0.55 & 0.58 \\
\hline Fluid 10 & 7.89 & 10.30 & 13.60 & 1.93 & 1.25 & 6.03 & 0.48 & 0.63 & 0.42 \\
\hline Fluid 11 & 5.09 & 6.40 & 4.77 & 0.73 & 0.30 & 0.20 & 0.17 & 0.12 & 0.58 \\
\hline Fluid 12 & 0.66 & 0.60 & 4.69 & 1.25 & 1.37 & 0.97 & 0.07 & 0.21 & 0.70 \\
\hline Fluid 13 & 10.79 & 11.46 & 2.07 & - & - & - & 1.24 & 1.55 & 2.55 \\
\hline Fluid 14 & 7.14 & 7.88 & 2.92 & - & - & - & 0.15 & 0.46 & 0.59 \\
\hline Fluid 15 & 0.65 & 5.33 & 0.26 & 0.67 & 0.87 & 0.64 & 0.03 & 0.12 & 1.46 \\
\hline Fluid 16 & 4.99 & 0.79 & 3.50 & 0.43 & 0.47 & 0.67 & 0.01 & 0.11 & 0.79 \\
\hline Fluid 17 & 9.42 & 4.73 & 0.79 & 0.86 & 0.76 & 0.38 & 0.39 & 0.49 & 0.47 \\
\hline Fluid 18 & 1.41 & 2.24 & 9.76 & 0.83 & 0.73 & 0.51 & 0.13 & 0.12 & 1.45 \\
\hline Fluid 19 & 0.13 & 3.73 & 12.96 & 0.23 & 0.31 & 1.67 & 0.72 & 0.79 & 2.61 \\
\hline Fluid 20 & 1.60 & 3.28 & 1.38 & 0.66 & 0.83 & 0.57 & 0.26 & 0.34 & 1.40 \\
\hline Fluid 21 & 4.53 & 0.58 & 3.00 & 0.50 & 0.56 & 0.21 & 0.19 & 0.34 & 1.15 \\
\hline Fluid 22 & 4.88 & 5.16 & 3.53 & 2.33 & 2.00 & 2.22 & 0.08 & 0.39 & 0.11 \\
\hline Fluid 23 & 6.24 & 7.03 & 3.38 & 3.22 & 2.85 & 3.21 & 0.76 & 1.01 & 0.74 \\
\hline Fluid 24 & 8.50 & 2.48 & 12.91 & - & - & - & 0.80 & 0.69 & 1.52 \\
\hline Fluid 25 & 6.88 & 1.39 & 15.95 & - & - & - & 0.58 & 0.35 & 1.42 \\
\hline Fluid 26 & 9.94 & 4.09 & 17.73 & - & - & - & 1.32 & 1.07 & 2.27 \\
\hline Fluid 27 & 11.35 & 5.81 & 24.08 & 2.12 & 1.09 & 3.15 & - & - & - \\
\hline Fluid 28 & 21.84 & 16.66 & 7.83 & - & - & - & - & - & - \\
\hline Fluid 29 & 7.03 & 1.66 & 5.26 & 0.88 & 0.93 & 1.01 & 0.61 & 0.48 & 2.22 \\
\hline Fluid 30 & 16.48 & 12.36 & 20.22 & 0.94 & 0.93 & 0.49 & 0.45 & 0.29 & 1.28 \\
\hline Fluid 31 & 19.66 & 12.23 & 8.95 & 2.64 & 2.45 & 1.95 & - & - & - \\
\hline Fluid 32 & 8.45 & 10.44 & 18.65 & 2.61 & 3.17 & 1.47 & 1.07 & 1.24 & 1.20 \\
\hline Fluid 33 & 0.38 & 2.16 & 17.34 & 0.12 & 0.12 & 3.74 & 1.03 & 0.79 & 0.39 \\
\hline Fluid 34 & 4.87 & 6.93 & 9.32 & 0.37 & 0.68 & 2.21 & 0.91 & 0.69 & 2.07 \\
\hline Fluid 35 & 4.87 & 7.37 & 19.29 & 2.50 & 3.09 & 1.41 & 0.80 & 0.56 & 0.14 \\
\hline Fluid 36 & 8.09 & 10.96 & 7.67 & 1.39 & 1.66 & 1.07 & 0.46 & 0.62 & 0.48 \\
\hline Fluid 37 & 7.78 & 4.27 & 1.57 & 0.03 & 0.16 & 1.93 & - & - & - \\
\hline Fluid 38 & 11.34 & 7.05 & 5.38 & 0.39 & 0.23 & 2.31 & - & - & - \\
\hline
\end{tabular}




\begin{tabular}{|c|c|c|c|c|c|c|c|c|c|}
\hline Fluid 39 & 16.05 & 11.89 & 9.72 & 0.28 & 0.29 & 2.21 & - & - & - \\
\hline Fluid 40 & 6.25 & 9.50 & 5.15 & 0.73 & 1.18 & 0.09 & - & - & - \\
\hline Fluid 41 & 4.91 & 8.02 & 4.14 & 0.72 & 1.13 & 0.07 & - & - & - \\
\hline Fluid 42 & 1.65 & 2.93 & 0.92 & 1.14 & 1.14 & 1.84 & - & - & - \\
\hline Fluid 43 & 8.05 & 9.63 & 2.68 & 2.84 & 2.71 & 1.80 & 0.25 & 0.07 & 0.98 \\
\hline Fluid 44 & 5.66 & 3.59 & 2.65 & 0.63 & 0.82 & 0.46 & 0.57 & 0.31 & 1.88 \\
\hline Fluid 45 & 2.61 & 0.83 & 4.34 & - & - & - & 1.15 & 1.29 & 0.16 \\
\hline Fluid 46 & 11.57 & 7.94 & 2.89 & 0.77 & 0.77 & 0.21 & 0.26 & 0.44 & 0.83 \\
\hline Fluid 47 & 13.45 & 9.43 & 3.41 & 0.36 & 0.29 & 0.52 & 0.10 & 0.19 & 1.73 \\
\hline Fluid 48 & 11.12 & 13.12 & 9.73 & 1.22 & 1.48 & 0.90 & 0.10 & 0.33 & 0.50 \\
\hline Fluid 49 & 4.27 & 6.83 & 3.68 & 1.02 & 1.42 & 0.26 & - & - & - \\
\hline Fluid 50 & 5.93 & 8.09 & 4.92 & 0.95 & 0.96 & 1.82 & 0.73 & 0.78 & 1.54 \\
\hline Fluid 51 & 12.66 & 15.25 & 11.15 & - & - & - & 0.03 & 0.17 & 0.78 \\
\hline Fluid 52 & 5.90 & 0.36 & 3.90 & 0.36 & 0.32 & 1.59 & 0.44 & 0.54 & 0.41 \\
\hline Fluid 53 & 15.57 & 17.76 & 10.88 & 3.49 & 3.78 & 2.84 & 0.84 & 1.06 & 0.27 \\
\hline Fluid 54 & 4.21 & 7.94 & 5.80 & 0.93 & 1.21 & 0.89 & 0.53 & 0.65 & 0.40 \\
\hline Fluid 55 & 2.90 & 6.53 & 6.78 & 0.59 & 0.73 & 0.95 & 0.15 & 0.22 & 2.11 \\
\hline Fluid 56 & 19.31 & 22.36 & 17.47 & 0.85 & 1.03 & 0.47 & 1.26 & 1.36 & 0.04 \\
\hline Fluid 57 & 8.73 & 9.85 & 2.65 & 0.75 & 0.91 & 0.91 & 0.33 & 0.06 & 1.31 \\
\hline Fluid 58 & 11.31 & 12.52 & 4.94 & 0.27 & 0.10 & 0.77 & 0.20 & 0.05 & 1.02 \\
\hline Fluid 59 & 1.89 & 0.26 & 2.59 & 1.27 & 1.43 & 0.61 & 0.64 & 0.94 & 0.03 \\
\hline Fluid 60 & 10.58 & 12.08 & 10.74 & 1.86 & 2.27 & 0.74 & 0.03 & 0.34 & 0.56 \\
\hline Fluid 61 & 9.90 & 10.60 & 3.32 & 1.66 & 1.17 & 1.32 & 0.21 & 0.39 & 0.65 \\
\hline Fluid 62 & 6.90 & 7.28 & 7.20 & 1.38 & 0.78 & 1.19 & 1.39 & 1.58 & 1.77 \\
\hline Fluid 63 & 4.29 & 5.90 & 2.35 & 0.59 & 0.55 & 1.00 & 0.10 & 0.08 & 0.55 \\
\hline Fluid 64 & 7.25 & 5.05 & 5.17 & 0.46 & 0.50 & 0.72 & 0.56 & 0.34 & 2.16 \\
\hline Fluid 65 & 8.31 & 11.16 & 3.42 & 4.17 & 4.87 & 1.03 & 0.84 & 0.64 & 1.06 \\
\hline Fluid 66 & 1.43 & 0.90 & 5.43 & 1.87 & 1.65 & 1.37 & 0.99 & 0.43 & 1.84 \\
\hline Fluid 67 & 2.22 & 0.20 & 6.66 & 2.14 & 2.08 & 1.97 & 1.37 & 0.92 & 2.53 \\
\hline Fluid 68 & 1.73 & 0.38 & 0.27 & 0.77 & 1.08 & 1.04 & 1.15 & 1.39 & 1.47 \\
\hline Fluid 69 & 14.37 & 12.40 & 10.31 & 1.19 & 0.84 & 1.09 & 0.05 & 0.18 & 0.27 \\
\hline Fluid 70 & 1.69 & 3.14 & 3.12 & 2.47 & 2.03 & 2.84 & 0.68 & 0.41 & 0.51 \\
\hline Fluid 71 & 8.58 & 10.30 & 9.24 & 2.37 & 2.53 & 2.24 & 2.34 & 2.47 & 1.92 \\
\hline Fluid 72 & 11.60 & 12.31 & 8.62 & 1.29 & 1.34 & 0.47 & 0.04 & 0.29 & 0.05 \\
\hline Fluid 73 & 12.16 & 12.48 & 8.29 & 2.03 & 1.45 & 1.15 & 0.83 & 1.07 & 1.20 \\
\hline Fluid 74 & 12.20 & 12.54 & 8.01 & 1.94 & 1.48 & 1.19 & 1.10 & 1.33 & 1.53 \\
\hline Fluid 75 & 14.27 & 14.88 & 11.86 & 1.23 & 1.15 & 0.60 & 0.36 & 0.66 & 0.58 \\
\hline Fluid 76 & 13.63 & 14.18 & 11.99 & 1.72 & 1.36 & 0.94 & 0.71 & 1.07 & 0.96 \\
\hline Fluid 77 & 13.54 & 14.61 & 10.62 & 1.01 & 1.23 & 0.44 & 0.12 & 0.17 & 0.10 \\
\hline Fluid 78 & 9.30 & 11.18 & 15.88 & 1.09 & 1.00 & 1.07 & 0.71 & 0.44 & 1.35 \\
\hline Fluid 79 & 11.52 & 12.84 & 3.54 & 1.57 & 1.40 & 0.95 & 0.14 & 0.25 & 1.14 \\
\hline Fluid 80 & 0.73 & 2.19 & 3.42 & 1.73 & 2.01 & 1.53 & 0.04 & 0.10 & 0.68 \\
\hline Fluid 81 & 0.02 & 1.30 & 2.69 & 0.88 & 1.15 & 0.66 & 0.38 & 0.16 & 1.08 \\
\hline
\end{tabular}




\begin{tabular}{|c|c|c|c|c|c|c|c|c|c|}
\hline Fluid 82 & 2.80 & 0.39 & 6.43 & 0.38 & 0.40 & 1.47 & 1.28 & 1.33 & 1.08 \\
\hline Fluid 83 & 3.94 & 5.35 & 6.39 & 0.91 & 1.10 & 0.53 & 0.17 & 0.00 & 0.55 \\
\hline Fluid 84 & 8.19 & 9.38 & 11.82 & 0.87 & 1.07 & 0.52 & 0.35 & 0.50 & 0.18 \\
\hline Fluid 85 & 0.89 & 2.43 & 4.76 & 1.20 & 1.44 & 0.91 & 0.69 & 0.54 & 1.31 \\
\hline Fluid 86 & 12.44 & 13.41 & 13.95 & 1.35 & 1.45 & 1.04 & 0.12 & 0.35 & 0.54 \\
\hline Fluid 87 & 9.22 & 10.33 & 10.90 & 1.83 & 2.08 & 1.85 & 0.37 & 0.15 & 0.99 \\
\hline Fluid 88 & 3.47 & 3.74 & 7.09 & 0.80 & 1.45 & 0.42 & 0.16 & 0.41 & 0.19 \\
\hline Fluid 89 & 18.06 & 18.82 & 15.17 & 7.70 & 7.42 & 6.54 & 1.84 & 2.04 & 1.10 \\
\hline Fluid 90 & 6.93 & 8.42 & 0.40 & 1.65 & 1.87 & 0.52 & 0.12 & 0.06 & 0.47 \\
\hline Fluid 91 & 4.44 & 6.27 & 5.96 & 0.70 & 0.38 & 0.77 & 0.24 & 0.06 & 0.87 \\
\hline Fluid 92 & 3.33 & 1.24 & 3.28 & 2.24 & 1.88 & 2.38 & 0.36 & 0.65 & 0.42 \\
\hline Fluid 93 & 2.74 & 3.78 & 3.81 & 0.97 & 1.00 & 0.80 & 0.33 & 0.65 & 0.46 \\
\hline Fluid 94 & 0.84 & 1.48 & 0.27 & 1.35 & 1.38 & 0.79 & 2.67 & 2.35 & 2.63 \\
\hline Fluid 95 & 5.14 & 5.00 & 7.04 & 1.97 & 1.84 & 1.18 & 0.61 & 0.13 & 0.15 \\
\hline Fluid 96 & 18.05 & 17.60 & 1.84 & - & - & - & 1.99 & 2.60 & 2.32 \\
\hline Fluid 97 & 1.70 & 2.73 & 4.81 & 0.36 & 0.17 & 2.02 & 0.43 & 0.69 & 0.88 \\
\hline Fluid 98 & 0.30 & 0.69 & 1.43 & 3.69 & 3.16 & 4.49 & 0.64 & 0.97 & 0.43 \\
\hline Fluid 99 & 6.59 & 7.01 & 1.65 & - & - & - & 1.50 & 1.93 & 1.99 \\
\hline Fluid 100 & 7.19 & 9.50 & 2.82 & - & - & - & 0.26 & 0.56 & 0.01 \\
\hline Fluid 101 & 2.16 & 3.58 & 1.65 & 5.41 & 5.03 & 6.16 & 0.05 & 0.30 & 0.53 \\
\hline Fluid 102 & 7.41 & 7.00 & 5.32 & 2.20 & 1.81 & 1.03 & 1.45 & 2.31 & 2.15 \\
\hline Fluid 103 & 9.13 & 9.37 & 10.62 & 1.21 & 1.26 & 0.75 & 0.29 & 0.70 & 0.06 \\
\hline Fluid 104 & 1.37 & 0.78 & 0.52 & 0.98 & 0.97 & 0.93 & 0.31 & 0.21 & 0.89 \\
\hline Fluid 105 & 10.43 & 10.08 & 13.64 & 1.12 & 0.92 & 1.26 & 0.73 & 0.00 & 0.12 \\
\hline Fluid 106 & 2.98 & 1.80 & 1.50 & 0.93 & 1.10 & 1.42 & 0.32 & 0.61 & 0.53 \\
\hline Fluid 107 & 1.26 & 0.45 & 9.88 & 4.32 & 4.45 & 7.73 & 0.85 & 1.26 & 0.49 \\
\hline Fluid 108 & 1.70 & 2.82 & 1.68 & 0.59 & 0.26 & 1.29 & 0.98 & 1.31 & 0.11 \\
\hline Fluid 109 & 13.69 & 13.87 & 12.65 & 3.53 & 2.92 & 3.10 & 1.54 & 2.12 & 1.78 \\
\hline Fluid 110 & 4.23 & 4.79 & 4.78 & 2.35 & 1.92 & 2.58 & 0.47 & 0.76 & 0.03 \\
\hline Fluid 111 & 8.32 & 9.21 & 7.21 & - & - & - & 0.81 & 1.18 & 0.51 \\
\hline Fluid 112 & 15.76 & 17.02 & 10.47 & 0.73 & 0.77 & 0.68 & 0.80 & 1.26 & 1.14 \\
\hline Fluid 113 & 4.69 & 5.16 & 10.18 & 2.88 & 3.21 & 2.06 & 0.12 & 0.32 & 0.60 \\
\hline Fluid 114 & 0.48 & 1.60 & 3.34 & - & - & - & 0.41 & 0.04 & 0.81 \\
\hline Fluid 115 & 5.68 & 4.03 & 23.84 & 1.90 & 1.57 & 4.38 & 0.55 & 1.03 & 0.85 \\
\hline Fluid 116 & 2.62 & 2.58 & 2.45 & - & - & - & 0.64 & 1.19 & 1.18 \\
\hline Fluid 117 & 8.72 & 7.47 & 22.87 & 2.49 & 1.44 & 4.52 & 1.24 & 1.69 & 1.14 \\
\hline Fluid 118 & 0.97 & 1.19 & 0.33 & 3.48 & 3.51 & 3.76 & 1.24 & 1.65 & 0.86 \\
\hline Fluid 119 & 3.80 & 2.25 & 8.31 & 1.47 & 0.66 & 2.58 & 0.43 & 0.72 & 0.00 \\
\hline Fluid 120 & 4.17 & 4.03 & 4.70 & 0.75 & 0.36 & 0.53 & 0.26 & 0.89 & 0.63 \\
\hline Fluid 121 & 3.30 & 2.98 & 2.28 & 1.55 & 1.30 & 1.71 & 0.72 & 0.04 & 0.13 \\
\hline Fluid 122 & 4.11 & 2.31 & 2.90 & 1.95 & 1.99 & 2.14 & 0.30 & 0.02 & 1.18 \\
\hline Fluid 123 & 14.46 & 15.60 & 13.61 & 1.27 & 0.80 & 0.28 & 0.04 & 0.25 & 0.13 \\
\hline Fluid 124 & 6.05 & 4.81 & 5.07 & 2.08 & 1.54 & 1.14 & 0.07 & 0.84 & 0.79 \\
\hline
\end{tabular}




\begin{tabular}{|c|c|c|c|c|c|c|c|c|c|}
\hline Fluid 125 & 0.63 & 2.30 & 1.18 & 1.13 & 1.47 & 0.78 & 0.29 & 0.02 & 0.57 \\
\hline Fluid 126 & 3.00 & 1.24 & 8.62 & 4.85 & 4.24 & 6.39 & 0.15 & 0.40 & 0.42 \\
\hline Fluid 127 & 16.55 & 15.31 & 15.03 & 4.47 & 4.05 & 5.21 & 0.05 & 0.32 & 0.03 \\
\hline Fluid 128 & 2.20 & 2.84 & 2.73 & 6.25 & 6.17 & 3.63 & 2.10 & 2.65 & 2.60 \\
\hline Fluid 129 & 6.05 & 6.07 & 6.78 & 0.76 & 0.41 & 1.48 & 1.15 & 1.62 & 1.94 \\
\hline Fluid 130 & 0.33 & 2.87 & 1.29 & 0.79 & 0.53 & 0.61 & 0.82 & 1.11 & 0.44 \\
\hline Fluid 131 & 1.37 & 0.97 & 0.96 & 1.60 & 1.20 & 1.22 & 2.08 & 1.31 & 1.33 \\
\hline Fluid 132 & 4.31 & 3.96 & 4.82 & 1.52 & 0.82 & 0.69 & 0.65 & 0.14 & 0.43 \\
\hline Fluid 133 & 1.31 & 1.18 & 2.82 & 2.71 & 2.51 & 2.23 & 0.68 & 0.37 & 1.23 \\
\hline Fluid 134 & 5.14 & 4.06 & 8.40 & 1.00 & 0.42 & 2.29 & 0.54 & 0.89 & 0.30 \\
\hline Fluid 135 & 1.66 & 2.99 & 0.79 & 1.09 & 1.44 & 0.42 & 0.96 & 1.30 & 0.52 \\
\hline Fluid 136 & 7.35 & 7.29 & 12.56 & 2.81 & 2.68 & 4.83 & 0.82 & 1.17 & 0.84 \\
\hline Fluid 137 & 13.80 & 11.38 & 18.78 & 3.06 & 2.12 & 5.00 & 0.83 & 1.18 & 0.58 \\
\hline Fluid 138 & 0.59 & 1.65 & 24.05 & 2.61 & 3.59 & 4.36 & 0.14 & 0.42 & 0.11 \\
\hline Fluid 139 & 2.79 & 3.07 & 6.76 & 0.97 & 0.96 & 0.31 & 0.86 & 0.50 & 1.22 \\
\hline Fluid 140 & 7.66 & 8.78 & 4.45 & 2.13 & 2.16 & 2.48 & 1.27 & 1.69 & 0.82 \\
\hline Fluid 141 & 9.91 & 11.09 & 5.62 & 0.62 & 0.18 & 0.97 & 0.41 & 0.65 & 0.09 \\
\hline Fluid 142 & 12.11 & 10.54 & 17.79 & 2.33 & 1.74 & 5.04 & 2.57 & 2.19 & 2.68 \\
\hline Fluid 143 & 2.21 & 5.15 & 0.66 & 0.27 & 0.35 & 0.48 & 1.12 & 1.46 & 0.64 \\
\hline Fluid 144 & 11.15 & 10.74 & 13.72 & 1.71 & 1.15 & 1.75 & 2.16 & 2.83 & 2.98 \\
\hline Fluid 145 & 4.42 & 5.26 & 6.10 & 2.11 & 1.93 & 1.57 & 0.41 & 0.81 & 0.30 \\
\hline Fluid 146 & 2.44 & 4.18 & 1.13 & 5.62 & 5.74 & 3.67 & 0.51 & 1.00 & 0.11 \\
\hline Fluid 147 & 10.73 & 12.11 & 9.90 & 0.81 & 0.38 & 0.29 & 0.56 & 0.82 & 0.65 \\
\hline Fluid 148 & 8.88 & 9.23 & 10.55 & 0.93 & 0.54 & 3.03 & 0.24 & 0.67 & 0.20 \\
\hline Fluid 149 & 3.32 & 5.19 & 11.17 & - & - & - & 0.62 & 0.97 & 0.70 \\
\hline Fluid 150 & 10.89 & 13.26 & 9.96 & - & - & - & 0.79 & 1.16 & 0.11 \\
\hline Fluid 151 & 2.94 & 1.88 & 1.03 & 3.18 & 3.34 & 2.65 & 1.48 & 0.99 & 2.28 \\
\hline Fluid 152 & 8.96 & 9.37 & 10.57 & 2.87 & 3.56 & 2.61 & 1.12 & 0.70 & 1.88 \\
\hline Fluid 153 & 6.77 & 5.76 & 8.02 & 4.23 & 3.21 & 5.43 & 1.49 & 2.04 & 1.78 \\
\hline Fluid 154 & 3.03 & 4.05 & 0.58 & 0.93 & 0.28 & 1.48 & 1.05 & 1.57 & 0.52 \\
\hline Fluid 155 & 0.67 & 1.19 & 11.09 & 2.01 & 2.06 & 3.86 & 0.34 & 0.57 & 0.06 \\
\hline Fluid 156 & 13.92 & 13.89 & 14.44 & 1.67 & 1.47 & 0.43 & 0.64 & 0.94 & 0.31 \\
\hline Fluid 157 & 11.46 & 11.60 & 11.96 & 1.05 & 0.61 & 0.73 & 1.07 & 1.52 & 1.82 \\
\hline Fluid 158 & 4.23 & 3.02 & 4.89 & - & - & - & 0.66 & 0.39 & 0.82 \\
\hline Fluid 159 & 10.24 & 11.02 & 10.21 & - & - & - & 1.19 & 1.49 & 0.80 \\
\hline Fluid 160 & 4.74 & 6.46 & 5.62 & 0.83 & 0.17 & 0.73 & 0.18 & 0.04 & 0.88 \\
\hline Fluid 161 & 7.62 & 6.87 & 10.43 & - & - & - & 0.49 & 0.79 & 1.40 \\
\hline Fluid 162 & 11.38 & 7.18 & 3.47 & 2.81 & 2.77 & 1.09 & 0.16 & 0.00 & 0.46 \\
\hline Fluid 163 & 9.26 & 11.01 & 4.71 & - & - & - & 0.04 & 0.22 & 0.38 \\
\hline Fluid 164 & 8.82 & 10.54 & 4.41 & 1.09 & 1.34 & 0.30 & 1.09 & 1.27 & 0.64 \\
\hline Fluid 165 & 2.03 & 2.73 & 3.54 & 0.72 & 0.84 & 1.31 & 1.21 & 0.93 & 2.81 \\
\hline Fluid 166 & 3.38 & 0.53 & 2.53 & 0.50 & 0.55 & 0.27 & 0.50 & 0.80 & 0.33 \\
\hline Fluid 167 & 12.39 & 9.66 & 13.88 & - & - & - & 0.34 & 0.09 & 0.32 \\
\hline
\end{tabular}




\begin{tabular}{|c|c|c|c|c|c|c|c|c|c|}
\hline Fluid 168 & 2.06 & 0.36 & 0.46 & - & - & - & 0.90 & 1.22 & 0.49 \\
\hline Fluid 169 & 5.39 & 7.60 & 11.22 & - & - & - & 0.18 & 0.56 & 0.76 \\
\hline Fluid 170 & 7.61 & 4.69 & 3.39 & - & - & - & 0.54 & 0.86 & 0.07 \\
\hline Fluid 171 & 2.76 & 0.31 & 0.30 & - & - & - & 0.50 & 0.27 & 1.08 \\
\hline Fluid 172 & 0.68 & 3.02 & 4.99 & - & - & - & 0.11 & 0.17 & 0.76 \\
\hline Fluid 173 & 1.12 & 3.20 & 5.14 & - & - & - & 0.28 & 0.05 & 0.98 \\
\hline Fluid 174 & 2.33 & 0.17 & 1.85 & - & - & - & 0.08 & 0.18 & 0.78 \\
\hline Fluid 175 & 11.51 & 8.68 & 5.03 & - & - & - & 0.35 & 0.69 & 0.68 \\
\hline Fluid 176 & 9.05 & 5.98 & 5.62 & - & - & - & 0.02 & 0.19 & 0.51 \\
\hline Fluid 177 & 0.84 & 2.82 & 1.61 & - & - & - & 0.37 & 0.62 & 0.21 \\
\hline Fluid 178 & 0.47 & 2.34 & 2.95 & - & - & - & 0.97 & 1.33 & 0.37 \\
\hline Fluid 179 & 10.28 & 7.67 & 8.00 & - & - & - & 0.27 & 0.54 & 0.40 \\
\hline Fluid 180 & 4.26 & 6.55 & 6.60 & - & - & - & 0.79 & 1.09 & 0.43 \\
\hline Fluid 181 & 8.07 & 4.94 & 6.56 & - & - & - & 0.29 & 0.08 & 0.59 \\
\hline Fluid 182 & 4.41 & 6.15 & 7.84 & - & - & - & 0.91 & 1.18 & 0.54 \\
\hline Fluid 183 & 5.25 & 3.58 & 3.49 & - & - & - & 0.86 & 1.17 & 0.50 \\
\hline Fluid 184 & 7.59 & 4.85 & 7.87 & - & - & - & 0.17 & 0.41 & 0.12 \\
\hline Fluid 185 & 5.47 & 2.33 & 2.87 & - & - & - & 0.70 & 1.03 & 0.07 \\
\hline Fluid 186 & 11.53 & 8.28 & 6.60 & - & - & - & 0.52 & 0.30 & 1.27 \\
\hline Fluid 187 & 0.50 & 2.83 & 1.48 & - & - & - & 0.38 & 0.63 & 0.23 \\
\hline Fluid 188 & 11.70 & 8.29 & 9.61 & - & - & - & 0.23 & 0.50 & 0.23 \\
\hline Fluid 189 & 11.33 & 7.99 & 11.11 & - & - & - & 0.44 & 0.71 & 0.47 \\
\hline Fluid 190 & 5.42 & 2.04 & 1.93 & - & - & - & 0.26 & 0.05 & 0.73 \\
\hline Fluid 191 & 14.31 & 11.09 & 11.57 & - & - & - & 0.02 & 0.18 & 0.76 \\
\hline Fluid 192 & 9.65 & 6.81 & 1.30 & - & - & - & 0.68 & 1.02 & 0.47 \\
\hline Fluid 193 & 5.27 & 7.35 & 6.37 & - & - & - & 1.14 & 1.48 & 0.66 \\
\hline Fluid 194 & 19.93 & 18.07 & 6.44 & - & - & - & 1.26 & 1.68 & 0.75 \\
\hline Fluid 195 & 5.18 & 2.60 & 8.18 & - & - & - & 0.52 & 0.76 & 0.71 \\
\hline Fluid 196 & 3.52 & 1.18 & 0.93 & - & - & - & 0.07 & 0.14 & 0.54 \\
\hline Fluid 197 & 8.81 & 5.88 & 8.58 & - & - & - & 0.61 & 0.91 & 0.18 \\
\hline Fluid 198 & 0.37 & 2.66 & 4.46 & - & - & - & 0.96 & 1.31 & 0.18 \\
\hline Fluid 199 & 10.52 & 6.42 & 5.46 & - & - & - & 0.50 & 0.81 & 0.17 \\
\hline Fluid 200 & 4.15 & 1.42 & 10.74 & - & - & - & 0.08 & 0.31 & 0.28 \\
\hline Fluid 201 & 2.89 & 5.31 & 0.39 & - & - & - & 0.27 & 0.57 & 0.85 \\
\hline Fluid 202 & 1.44 & 0.08 & 0.34 & - & - & - & 0.62 & 0.89 & 0.10 \\
\hline Fluid 203 & 5.21 & 4.22 & 2.88 & - & - & - & 0.02 & 0.16 & 0.31 \\
\hline Fluid 204 & 3.77 & 4.66 & 4.53 & - & - & - & 0.70 & 1.02 & 0.06 \\
\hline Fluid 205 & 1.94 & 3.06 & 2.78 & - & - & - & 0.37 & 0.66 & 0.43 \\
\hline Fluid 206 & 0.71 & 0.22 & 0.33 & - & - & - & 0.38 & 0.65 & 0.33 \\
\hline Fluid 207 & 0.41 & 1.29 & 2.69 & - & - & - & 0.46 & 0.77 & 0.35 \\
\hline Fluid 208 & 6.96 & 5.80 & 7.53 & - & - & - & 0.48 & 0.76 & 0.22 \\
\hline Fluid 209 & 0.83 & 0.19 & 0.45 & - & - & - & 0.61 & 0.92 & 0.17 \\
\hline Fluid 210 & 3.17 & 4.03 & 4.44 & - & - & - & 0.48 & 0.76 & 0.11 \\
\hline
\end{tabular}




\begin{tabular}{|c|c|c|c|c|c|c|c|c|c|}
\hline Fluid 211 & 12.35 & 7.68 & 2.81 & - & - & - & 0.18 & 0.05 & 0.51 \\
\hline Fluid 212 & 16.86 & 17.91 & 15.87 & - & - & - & 1.06 & 1.38 & 0.76 \\
\hline Fluid 213 & 3.86 & 7.02 & 5.99 & - & - & - & 0.51 & 0.85 & 0.58 \\
\hline Fluid 214 & 2.56 & 3.07 & 3.57 & - & - & - & 1.13 & 1.47 & 0.89 \\
\hline Fluid 215 & 3.68 & 5.72 & 2.44 & - & - & - & 0.04 & 0.32 & 0.83 \\
\hline Fluid 216 & 5.74 & 3.12 & 5.97 & - & - & - & 0.22 & 0.55 & 1.03 \\
\hline Fluid 217 & 3.34 & 3.90 & 3.01 & - & - & - & 1.10 & 1.44 & 0.63 \\
\hline Fluid 218 & 5.76 & 7.34 & 0.18 & - & - & - & 1.44 & 1.71 & 2.02 \\
\hline Fluid 219 & 0.88 & 0.71 & 4.79 & - & - & - & 0.46 & 0.26 & 1.13 \\
\hline Fluid 220 & 5.14 & 5.63 & 1.65 & - & - & - & 0.62 & 0.85 & 0.91 \\
\hline Fluid 221 & 0.47 & 2.32 & 9.75 & - & - & - & 0.24 & 0.15 & 0.36 \\
\hline Fluid 222 & 0.01 & 0.93 & 1.30 & - & - & - & 0.73 & 1.06 & 0.27 \\
\hline Fluid 223 & 14.89 & 16.65 & 6.25 & - & - & - & 0.22 & 0.38 & 0.58 \\
\hline Fluid 224 & 20.16 & 21.29 & 15.78 & - & - & - & 0.14 & 0.03 & 0.76 \\
\hline Fluid 225 & 6.53 & 8.09 & 0.63 & - & - & - & 1.44 & 1.71 & 2.02 \\
\hline Fluid 226 & 1.63 & 1.51 & 3.02 & - & - & - & 0.84 & 0.69 & 1.77 \\
\hline Fluid 227 & 4.06 & 4.93 & 4.27 & - & - & - & 0.81 & 1.10 & 0.40 \\
\hline Fluid 228 & 0.44 & 1.73 & 0.16 & - & - & - & 0.01 & 0.22 & 0.73 \\
\hline Fluid 229 & 5.57 & 7.06 & 0.08 & - & - & - & 0.31 & 0.50 & 0.58 \\
\hline Fluid 230 & 1.93 & 0.06 & 1.72 & - & - & - & 0.12 & 0.36 & 0.41 \\
\hline Fluid 231 & 12.60 & 8.19 & 15.24 & - & - & - & 0.71 & 0.57 & 0.72 \\
\hline Fluid 232 & 15.26 & 10.97 & 2.39 & - & - & - & 1.08 & 0.94 & 2.24 \\
\hline Fluid 233 & 0.98 & 1.97 & 1.54 & - & - & - & 0.79 & 1.09 & 0.33 \\
\hline Fluid 234 & 8.59 & 9.79 & 5.72 & - & - & - & 0.91 & 1.22 & 0.34 \\
\hline Fluid 235 & 4.12 & 3.28 & 9.85 & - & - & - & 1.06 & 1.36 & 0.63 \\
\hline Fluid 236 & 3.53 & 5.39 & 21.34 & - & - & - & 1.66 & 2.03 & 1.40 \\
\hline Fluid 237 & 2.10 & 0.18 & 0.70 & - & - & - & 2.42 & 2.77 & 2.02 \\
\hline Fluid 238 & 3.83 & 5.96 & 9.54 & - & - & - & 1.61 & 1.99 & 1.37 \\
\hline Fluid 239 & 5.43 & 7.40 & 9.84 & - & - & - & 1.61 & 1.98 & 1.44 \\
\hline Fluid 240 & 0.41 & 2.65 & 6.36 & - & - & - & 0.98 & 1.30 & 0.44 \\
\hline Fluid 241 & 0.93 & 3.24 & 6.02 & - & - & - & 1.22 & 1.56 & 0.65 \\
\hline Fluid 242 & 0.92 & 2.65 & 4.04 & - & - & - & 1.24 & 1.57 & 0.94 \\
\hline Fluid 243 & 2.50 & 4.07 & 5.47 & - & - & - & 1.58 & 1.94 & 1.41 \\
\hline Fluid 244 & 2.86 & 1.00 & 0.73 & - & - & - & 1.09 & 1.40 & 0.61 \\
\hline Fluid 245 & 5.60 & 4.06 & 5.62 & - & - & - & 1.07 & 1.35 & 1.00 \\
\hline Fluid 246 & 0.82 & 2.54 & 4.70 & - & - & - & 0.87 & 1.19 & 0.48 \\
\hline Fluid 247 & 9.22 & 7.11 & 8.00 & - & - & - & 1.27 & 1.59 & 1.18 \\
\hline Fluid 248 & 2.28 & 4.00 & 7.08 & - & - & - & 0.53 & 0.86 & 0.15 \\
\hline Fluid 249 & 3.47 & 4.90 & 4.70 & - & - & - & 0.81 & 1.06 & 1.15 \\
\hline Fluid 250 & 3.03 & 4.56 & 5.13 & - & - & - & 0.68 & 0.91 & 0.82 \\
\hline Fluid 251 & 6.85 & 5.81 & 4.66 & - & - & - & 0.28 & 0.50 & 0.42 \\
\hline Fluid 252 & 6.11 & 7.01 & 2.14 & - & - & - & 0.45 & 0.68 & 0.44 \\
\hline Fluid 253 & 5.78 & 6.03 & 4.50 & - & - & - & 0.67 & 0.95 & 1.79 \\
\hline
\end{tabular}




\begin{tabular}{lccccccccc} 
Fluid 254 & 8.80 & 9.02 & 4.76 & - & - & - & 1.41 & 1.71 & 2.91 \\
Fluid 255 & 10.86 & 6.69 & 14.68 & - & - & - & 0.41 & 0.28 & 0.69 \\
Fluid 256 & 10.44 & 6.42 & 14.98 & - & - & - & 0.26 & 0.12 & 0.85 \\
Fluid 257 & 1.18 & 0.16 & 0.60 & - & - & - & 0.39 & 0.21 & 1.32 \\
Fluid 258 & 4.74 & 2.66 & 1.59 & - & - & - & 0.23 & 0.04 & 0.87 \\
Fluid 259 & 8.45 & 6.35 & 16.70 & - & - & - & 0.35 & 0.64 & 0.32 \\
Fluid 260 & 3.17 & 4.92 & 5.19 & - & - & - & 0.40 & 0.64 & 0.48 \\
\hline Average & $\mathbf{6 . 3 5}$ & $\mathbf{6 . 2 6}$ & $\mathbf{6 . 5 1}$ & $\mathbf{1 . 6 3}$ & $\mathbf{1 . 5 5}$ & $\mathbf{1 . 7 3}$ & $\mathbf{0 . 6 6}$ & $\mathbf{0 . 8 0}$ & $\mathbf{0 . 8 6}$ \\
\hline
\end{tabular}

